University of Puerto Rico

Mayaguez, Puerto Rico

\title{
DEVELOPMENT AND ANALYSIS OF A LINEARLY SEGMENTED CPC COLLECTOR FOR INDUSTRIAL STEAM GENERATION
}

by

$$
A C 0.5-760 \times 00033
$$

\section{José Alberto Atienza Figueroa}

A thes is submitted in Partial Fulfillment of the Requirements for the Degree of

\section{MASTER OF SCIENCE}

in

MECHANICAL ENGINEERING

June 1980

Approved by:

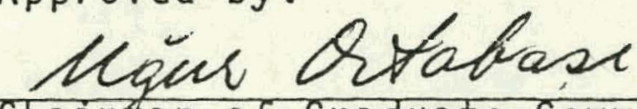

Chaighan of Graduate Committee

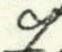

Member of Gradyate Committee
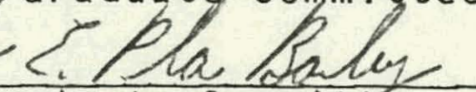

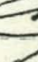

Member of Graguate Committee

Director of the Department

Freme A. Sesolto

Representatiye Graduate School

Tenaldo aboú

Director of Graduate School

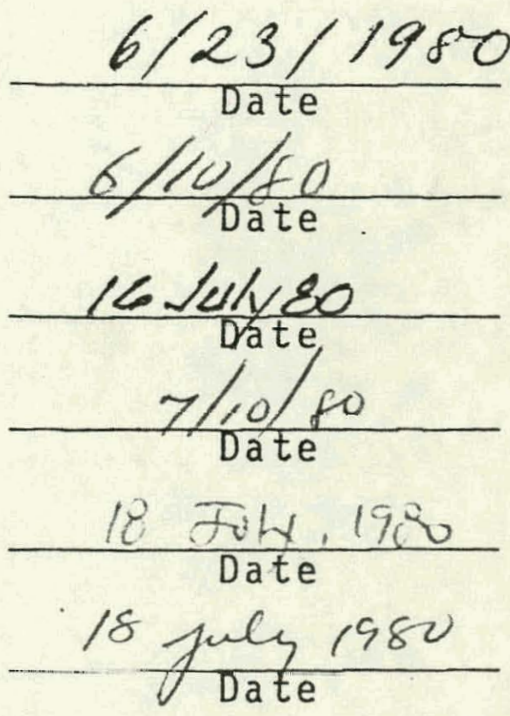

(n)

48 DISTRBDUTON OF THIS DOCLMENT IS UNLMTTED 


\section{DISCLAIMER}

This report was prepared as an account of work sponsored by an agency of the United States Government. Neither the United States Government nor any agency Thereof, nor any of their employees, makes any warranty, express or implied, or assumes any legal liability or responsibility for the accuracy, completeness, or usefulness of any information, apparatus, product, or process disclosed, or represents that its use would not infringe privately owned rights. Reference herein to any specific commercial product, process, or service by trade name, trademark, manufacturer, or otherwise does not necessarily constitute or imply its endorsement, recommendation, or favoring by the United States Government or any agency thereof. The views and opinions of authors expressed herein do not necessarily state or reflect those of the United States Government or any agency thereof. 


\section{DISCLAIMER}

Portions of this document may be illegible in electronic image products. Images are produced from the best available original document. 
To my wife, my mother and in memory of my son. 


\section{ABSTRACT}

This study involves the design, analysis and construction of a modular, non-imaging, trough, concentrating solar collector for generation of process steam in a tropical climate. The most innovative feature of this concentrator is that the mirror surface consists of long and narrow planar segments placed inside sealed low-cost glass tubes. The absorber is a cylindrical fin inside an evacuated glass tube.

As an extension of the same study, the optical efficiency of the segmented concentrator. has been simulated by means of a Monte-Carlo Ray-Tracing program. Laser Ray-Tracing techniques were also used to evaluate the possibilities of this new concept.

A preliminary evaluation of the experimental concentrator was done using a relatively simple method that combines results from two experimental measurements: overall heat loss coefficient and optical efficiency. A transient behaviour test was used to measure the overall heat loss coefficient throughout a wide range of temperatures. 


\section{ACKNOWLEDGEMENTS}

I would like to express my deep gratitude to Dr. Ugur Ortabasi and Dr. Angel M. López Berrios for their guidance and support.

Thanks are due to the Center for Energy and Environment Research (CEER), especially to the Solar Energy Division for their support in funding this project.

I also want to acknowledge Oak Ridge Associated Universities for their financial assistance under the Laboratory Graduate Participation Program :

Special thanks to the graduate committee members, Dr. Kenneth G. Soderstrom, Dr. Fernando E. Pla and Dr. Jerome Hemmye; and to all those who in some way supported me during my graduate studies. 
TABLE OF CONTENTS

Page

I. INTRODUCTION . . . . . . . . . . 1

II . LITERATURE REVIEW . . . . . . . . . . . 3

III. REVIEW OF SOLAR ENERGY THERMAL COLLECTORS . . 6

A. Concentrating Collectors . . . . . 8

B. Compound Parabolic Concentrators . . . 12

C. Absorbers for Concentrating Collectors.. 15

IV. CONCEPTUAL DESIGN OF THE FACETTED COLLECTOR • 19

A. Characteristics of the Facetted CPC . . 19

B. Principles of Absorber Design .. . . . 23

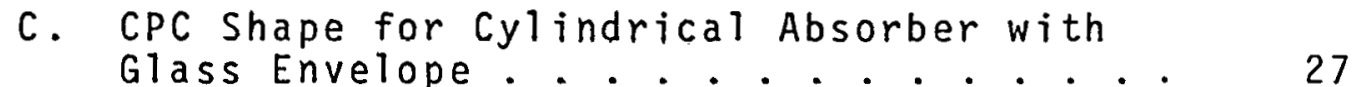

D. Computer Simulation of Optical Perform-

E. Collector Orientation Study . . . ... 38

V. LASER EXPERIMENTS WITH A SIMULATION MODEL . . 46

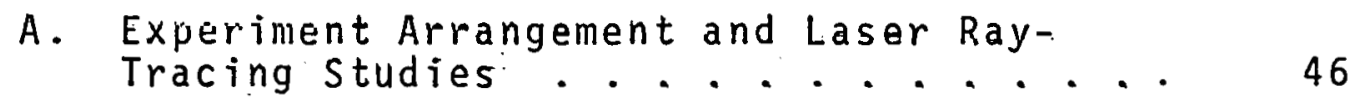

B. Discussion of Results . . . . . . . 49

VI. DESIGN AND CONSTRUCTION OF A PROTOTYPE . . . 59

A. Manufacturing of Mirror Units . . . . 59

B. Collector. Frame .......... 67

C. Final Collector Assembly and Adjustment . 72

VII. PRELIMINARY EFFICIENCY TEST , . . . . . 77

A. Time Constant Mcasurements : ...... 79

B. Optical Efficiency Measurements. “. . .. 81 
C. Transient $U_{L}$ Measurement . . . . . . . . 87

D. Discussion of Results . . . . . . . 89

VIII. CONCLUSIONS . . . . . . . . . . . . . . . . 93

IX. REFERENCES . . . . . . . . . . . . . . . . 95

X. APPENDICES.................... . . 98

A. Solar Data deasünements. . . . . . . 98

B. Detailed Derivation of Analytical Expressions for the CPC Shape...:.... 101

C. Calculations for Seasonal Solar Elevation Variations..................... 109

D. Computer Program for CPC Shape...... . 120

E. Test Data Obtained by Transient $U_{L}$-Method 123

F. Calculations for Efficiency Curve . . . . 127

G. Nomenclature . . . . . . . . . 128 
4.1 Physical and Economical Parameters of the CPC with Encapsulation tubes........ . 24

4.2 Angle Averaged Light Thruputs . . . . . . . . 36

4.3 Tilt Adjustment during the Year . . . . . . . 44

7:1 Time Constant Measurement vs Flow Rate . . . 82

7.2 Test Data for Optical Efficiency of Absorber Tube.................... 85

7.3 Test Data for Optical Efficiency of the Collector ............. 86

A.1 Typlcal Insolation and $K_{D}$ Values for Different Locations in Puerto Rico...... 98

A.2 Monthly Average Total Daily Insolation . . . 99

C.1 Tilt Adjustment during the Year at $\theta_{C}=9^{\circ}$. . 115

C.2 Tilt Adjustment during the Year at $\dot{\theta}_{C}=8^{\circ}$. . 116

C.3 Tilt Adjustment during the Year at $\theta_{C}=7^{\circ}$. . 118

F.1 Calculated Results for the Efficiency Curve. . 127 


\section{LIST OF FIGURES}

Figure

Description

Page

3.1 Parabolic Concentrator with Cylindrical

Absorber . . . . . . . . . . . . .

3.2 Original Design for a Compound Parabolic Concentrator . . . . . . . . . . . . .

3.3 Ideal Cylindrical Concentrator with Arbitrary Absorber Shape ... . . . . . . .

3.4 CPC Concentrator with Various Absorber Shapes

3.5 Cross Section of Various Types of Evacuated Tubular Collectors............. . . 18

4.1 Principal Design Features of. Facetted CPC . . 20

4.2 Effect of Truncation on Concentration Ratio . 22

4.3 Schematic of the Evacuated Absorber Tube Design... . . . . . . . . . . . . . . .

4.4 Definition of Some Important Parameters for a CPC with Cylindrical Absorber Inside a. Glass Envelope...................

4.5 Reflector Shape for CPC with Evacuated Absorber Tube . . . . . . . . . . . .

4.6. Variation of Reflector. Length with Concentration Ratio . . . . . . . . . 32

4.7 Flow Chart for Computer Simulation . . . . . 34

4.8 Thruput Intercepted by Absorber for Various Wall Thickness?............. . 37

4.9 Fraction Thruput vs Incidence Angle . . . . . 39

4.10. Fraction of the Radiation Incidence on the Aperture of a. CPC at Angle $\theta_{i}$ Which Reach the Absorber

4.11 Projected Solar Elevation . . . . . . . . 4 42

4.12 Schematic for Orientation of the Concentrator 45 
Figure

Description

Page

5.1 Experimental Model Mounted on Indexing Rotary Table... . . . . . . . . . . .

5.2 Experimental Model Camera Stand and Stiding Table .................

5.3 Multiple Exposure Photograph of Laser Light Incident at $0^{\circ}$ with no Encapsulation Tubes.

5.4 Multiple Exposure Photograph of Laser Light Incident at $9^{\circ}$ with no Encapsulation Tubes.

5.5 Multiple Exposure Photograph of Laser Light Incident at $171^{\circ}$ with no Encapsulation Tubes

5.6 Mirror Segments of Experimental Model with and without Encapsulation Tubes . . . . . .

5.7 Multiple Exposure Photograph of Laser Light Incident at $0^{\circ}$ with Encapsulation Tubes . .

5.8 Multiple Exposure Photograph of Laser Light Incident at $9^{\circ}$ with Encapsulation Tubes. .

5.9 Multiple Exposure Photograph of Laser Light Incident at $11^{\circ}$ with Encapsulation Tubes.

6.7 Evacuated Tubular Receiver . . . . . . . . 60

6.2 Encapsulated Mirror Segments . . . . . . . 61

6.3 Collector Frame . . . . . . . . . . 62

6.4 Schematic for Mirror Tube Design . . . . . 63

6.5 Mirror Assembly . . . . . . . . . . . 65

6.6 Schematic of the Method for Measuring Twist
of the Mirror Assembly............ 66

6.7 Dual Axis Tracking Frame. . . . . . . . 68

$\begin{array}{lll}6.8 & \text { Support Structure for Mirror and Absorber } & \\ \text { Tubes ........................................ } & 69\end{array}$

6.9 Construction Plan for the supporting.

Structure................. 
6.10 Attachment of Mirror Tubes to Supporting Structure..................

6.11 Schematic of the Method for Adjustment of the Mirror Tubes ............. . 75

6.12 Segmented CPC Prototype . . . . . . . . 76

$7.7 \Delta T$ vs Time During a Typical Time Constant

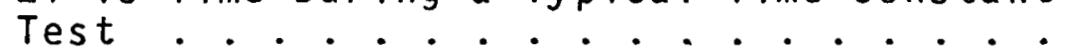

7.2 Set-up for the Optical Efficiency Measurement for Absorber Tube Alone.......

7.3 Thermal Analys is Diagram for Evacuated Tubular Collector.............

$7.4 \quad U_{L}$ as a Function of Absorber Temperature for the Three Different Absorber Tubes of the CEER Design................

7.5 Thermal Performance Curve of the Prototype

A.1 Locations for Solar Data Collection ..... 100

B.1 CPC with Evacuated Cylindrical Absorber : 102

C.1 Solar Geometry ..............

C.2 Projected Solar Elevation for Latitude $0^{\circ}$. 


\section{CHAPTER I}

INTRODUCTION

Presently, Puerto Rico depends nearly $100 \%$ on foreign oil for its energy needs. Increasing oil prices due to the exponential growth in the consumption and the world wide depletion of fossil fuel resources are already affecting the island's economy significantly.

Although there does not exist a study of the amount of industrial process heat used by puerto Rican industry, it is known that several, of its leading industries such as food processing, chemical and pharmaceutical industries are large users of industrial steam. If the percentage of energy used in this sector is assumed to be the same as in the United States, the production of industrial process heat might represent one of the largest single use of energy, with some estimates ranging up to $20 \%$ of the total energy consumption ${ }^{1}$. The generation of a significant portion of this heat is an attractive potential application of solar energy.

Since a considerable portion (27\%) of the process heat generated in the United States ${ }^{2}$ is between $150^{\circ} \mathrm{F}$ to $550^{\circ} \mathrm{F}$, utilization of existing. solar thermal conversion technology appears to be a practical alternative solution with a short term impact on crude $0 . i 1$ needs.

The objective of the present work is the development and analysis of a potential low cost, long life and high efficiency concentrating solar collector capable of reaching temperatures 
high enough to generate industrial process heat. A Segmented Compound Parabolic Concentrator ( $C P C)$ was chosen for this purpose because it offers three major advantages with respect to the present work. First, it has a high collection efficiency for a minimum of tracking adjustment. Second, for a given concentration ratio it makes use of more diffuse solar radiation than other concentrator types. This is an important feature, because in tropical regions the diffuse component fraction is a considerable portion of the total radiation. Third, it is less sensitive to shape or contour error which result from the segmenting (facetting) of the mirror surface. The study included the detailed design of a segmented Compound Parabolic Concentrator ( $C P C)$, the construction of a prototype and a preliminary evaluation of its performance. 
CHAPTER II

\section{LITERATURE REVIEW}

The Compound Parabolic Concentrator (CPC) emerged in the mid 1960's in at least three different locations and in widely different context. At the University of Chicago, the CPC was developed as a light collector for Cerenkov Counters by Hinterburger and Winston in 1966. Almost simultaneously, Baranov in 1965 and Baranov and Melnikov in 1966 (Soviet Union) developed the same principle for three dimensions: Subsequently (1966), Baranov suggested the use of $3 D$ CPC's for the concentration of solar energy. Baranov obtained in 1967, Soviet patents on several CPC configurations. Axially symmetric CPC's were described by Ploke (Germany) in 1967 with generalizations to designs incorporating refractive elements in addition to the light-guiding reflecting wall. In 1969 Ploke obtained a German patent for various photometric applications. Hinterberger and Winston (1968) noted the thermodynamic limit of the attainable concentration, but it was not until some time later (1970), that the theory was developed fully by Winston ${ }^{3}$. In this paper he derived the pertinent equations, based on generalized phase space considerations, and showed how the CPC approaches the theoretically maximum concentration.

An important and very detailed work was done by Rabl ${ }^{4}$ of Argonne National Laboratory with the title "Optical and Thermal Properties of Compound Parabolic Concentrators", published in. 1976. In this work the convective and radiative heat transfer 
through a CPC are calculated, and formulas for evaluating the performance of solar collectors based on the CPC concept are presented. A simple analytical technique for calculating the average number of reflections of radiation passing through a CPC is developed to obtain a practical method for computing the optical losses.

Rabl, Goodman and Winston ${ }^{5}$ have reported a study addressed to several practical problems that arise in the design of solar collectors with CPC's. In this work they discuss the criteria. for the selection of a receiver type, the optimum method for introducing a gap between the receiver and the reflector to minimize optical and thermal losses, and the effect of a glass envelope around the receiver. This paper also discusses the effects of mirror errors and receiver misalignment on the overall performance.

Rabl ${ }^{6}$ in his recent work compares a variety of solar concentrators in terms of their most important general characteristics, concentration, acceptance angle, sensitivity to mirror errors, size of reflector area and the average number of reflections. Same work includes sections on the relation between concentration, acceptance angle and operating temperatures of a solar collector from an apjication point of view.

Welford and winston ${ }^{7}$ have recently published a text in which they present a detailed analysis of the optical properties of non-imaging concentrators. This is the first exposition of this subject in a textbook form. 
Ortabasi and Bueh $7^{8}$ analyzed the optical performance of a slightly concentrating, CPC cusp reflector inside an evacuated tubular glass envelope with a cylindrical heat pipe as the solar absorber. Some of the advantages of this modular collector are, the protection of the mirror surface against atmospheric damage, and the reduction of heat losses by the evacuation of the complete unit.

A semi-empirical method related to the performance evaluation of evacuated collectors was published by ortabasi ${ }^{9}$. He reported a relatively simple, but general transient method to determine the performance of collectors by measuring the overall heat transfer coefficient of the collector at various temperatures.

Kreith and Kreider 10 discuss in detail the optical and thermal analysis of tubular evacuated solar energy collectors. They also deal with specific items related to the experimental testing of this type of collectors. 


\section{CHAPTER II I \\ REVIEW OF SOLAR ENERGY THERMAL COLLECTORS}

Solar energy collectors, the devices used to convert the sun's radiation into thermal energy, have as their main component a surface that efficiently absorbs the solar radiation. A part of this absorbed energy is converted into useful heat that is removed from the absorbing surface by means of a heat transfer fluid that may be either liquid or gaseous. The other part of the absorbed energy is lost to the ambient surroundings. The heat loss mechanisms are conduction, convection and radiation. The first two mechanisms are dominant at temperatures nearly above ambient and are driven by the temperature difference between the absorber and ambient surroundings. The third one becomes significant at higher temperatures and it is driven by the difference of the absolute temperature and the ambient "sky" temperature both raised to the fourth power.

Solar energy thermal collectors may be divided into two generic classes: Concentrating and Nonconcentrating (FlatPlate collectors). Flat-Plate collectors are adequate for heating a working fluid up to about $180^{\circ} \mathrm{F}$. This is at present the most common way to use solar energy. The temperature limit for a nonconcentrating collector can be approximated by simple laws of physics: Radiation energy received from the sun at the earth's surface, often denoted by I, are at most $350 \mathrm{Btu} /$ $h r-f^{2}$. Assuming this energy will he collected by a black 
body imbedded in absolute vacuum, the equilibrium temperature T of the black body will be given by

$$
I=\sigma\left(T_{p}^{4}-T_{s k y}^{4}\right)
$$

where $\sigma$ is the Stefan-Boltzmann constant, $0.1713 \times 10^{-8} \mathrm{Btu} /$ $\mathrm{hr}-\mathrm{ft}^{2}-{ }^{\circ} \mathrm{R}$. Assuming a sky temperature of $65^{\circ} \mathrm{F} \cdot\left(20^{\circ} \mathrm{F}\right.$ lower than ambient), calculation from Equation 3.1 indicate that with no concentration, temperatures above $275^{\circ} \mathrm{F}$, are impossible with a perfect black body. In practice somewhat higher temperature are achievable with selective absorbers (materials whose absorptivity for solar wave lengths is high while emissivity at infrared wave lengths is low). In order to achieve much higher temperatures, it is necessary to increase the radiation density on the absorber.

There are innumerable applications requiring temperatures up to $550^{\circ} \mathrm{F}$ in the industrial sector. Typical examples are: space cooling, cooking, food processing, distilation, and electric generation (via steam or some other working fluid). To get temperatures in the range of $550^{\circ} \mathrm{F}$, radiation power density (I) should increase by a factor of about 5 to 10 to compensate for radiative and thermal losses. This is why a concentrator is needed.

In the design of a concentrating collector heat losses are reduced by using an absorber area smaller than the area that intecepts the sun rays, called the aperture area. 
A. Concentrating Collectors

Concentrating collectors may be divided into two broad categories: Image forming and Non-image forming. The image forming are the ones that concentrate the radiation by projecting the image of the sun on the receiver, in other words, the rays are concentrated in an organized form determined by the optics of the mirror shape. An example is a photographic lens. In this case the radiation distribution at the aperture coincides closely with the distribution on the exit aperture (the film). on the other hand the non-image forming concentrators, funnels the radiation to the receiver, but the radiation distribution at the aperture and on the receiver are completely different.

An important parameter that characterizes a concentrator is the concentration ratio (CR). This quantity is usually defined as the ratio of the aperture to the receiver area. Another parameter used in describing the optical features of a concentrator is the acceptance angle $\left(2 \theta_{c}\right)$ i.e, the angular range over which all solar rays are accepted without moving any part of the collector.

It can be shown from the second law of thermodynamics and by radiation exchange factor consideration ${ }^{3,6}$, that the maximum concentration ratio for a given acceptance angle is

$$
C R_{\text {ideal } 2 D}=\frac{1}{\sin \theta_{C}}
$$

for a trough like (line focus) concentrator. Equation 3.2 indicates that the concentration ratio decreases with increasing 
acceptance angle. Since the angular radius of the sun and the earth is approximately $0.25^{\circ}$, the maximum limit of the ratio is approximately 200. In practice, there are other factors which result in this concentration ratio falling short of this maximum figure, some of them are the tolerance in the receiver alignment, imperfection of the mirror specularity and errors in reflective surface shape.

The most common image forming concentrator is the simple parabolic lens reflector' shown in Figure 3.1 for a cylindrical absorber. It is symmetric about the line from source to absorber, and the aperture of the parabola is determined by the rim angle $\emptyset=\Varangle A O B$. If, the radius $r$ of the absorber is chosen as small as possible without losing any radiation, then the concentration is

$$
C R_{2 D} \text { parabolic }=\frac{2 X_{A}}{2 \pi r}
$$

If $\theta_{c}$ is considered small $\left(<p^{p}\right)$, equation $(3.3)$ becomes

$$
C R_{2 D} \text { parabolic-max }=\frac{\sin \emptyset}{\pi \sin \theta_{C}}
$$

which has its maximum value corresponding to the rim angle $\emptyset=90^{\circ}$, where $\sin \emptyset=1$. Therefore, Equation 3.4 at maximum reduces to

$$
\mathrm{CR}_{2 \mathrm{D}} \text { parabolic-max }=\frac{i}{\pi \sin \theta_{C}}
$$

Compared to Equation 3.2, it is seen that the maximum 


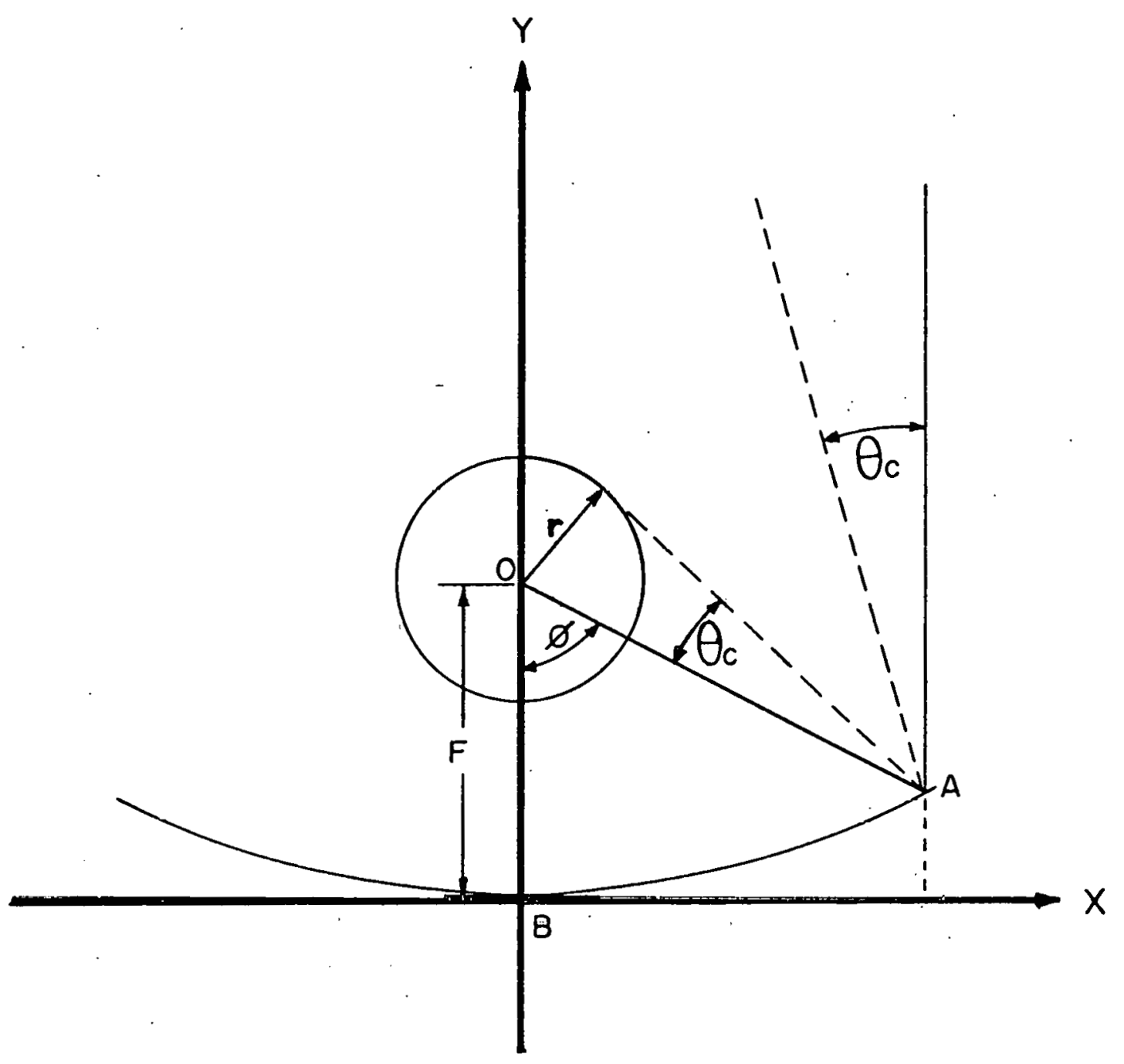

Figure 3.1

PARABOLIC CONCENTRATOR WITH CYLINDRICAL ABSORBER 
concentration ratio for a two dimensional parabolic concentrator is reduced by a factor of $1 / \pi$ compared to the thermodynamic I imit.

There are, however, a non-imaging type of concentrator collectors that approach and, in some cases, reach the ideal limit. These are generically known as Compound Parabolic Concentrators $(C P C)$. For the same acceptance angle they have a largerconcentration ratio than the simple parabolic reflector. Conversely, for a given concentration ratio they have a wider acceptance angle. For this reason thus accept and concentrate more diffuse radiation than image forming concentrators. This is an obvious advantage in tropical regions, such as the Caribbean, where there is a high diffuse to total insolation ratio $(38 \%$ yearly ave. for Mayaguez station) throughout most of the day 11 (see Appendix A for solar data measürements).

Another advantage of the non-imaging concentrator is that for low concentration ratios (less than 10), daily tracking is not even required ${ }^{6}$; only minor seasonal adjustments are necessary to compensate for solar declination. For example, the change in solar elevation during the central seven hours of the day is at most $\pm 6^{\circ}$ (see Figure 4.11). Thus, a CPC through arranged in the east-west direction can achieve a max imum concentration ratio of about $1 / \sin 6^{\circ}=10$ without any diurnal tracking. By contrast, a simple parabolic trough with a cylindrical absorber would have to track the sun to an accuracy better than $\pm 2^{\circ}$ to achieve comparable performance. 


\section{B. Compound Parabolic Concentrators}

Figure 3.2 shows the cross section of the original CPC concept. It consists of two distinct parabolic segments, the foci of which are located at the opposing receiver surface end points. The axes of the parabolic segments are oriented away from the CPC axis by the angle $\theta_{C}$. All light that impinges the aperture at an angle $\theta_{i}$ (measure from the axis of $C P C$ ), and that $\left|\theta_{i}\right| s \theta_{c}$, is accepted and hits the absorber. Radiation outside the acceptance angle (i.e. $\left.\left|\theta_{i}\right|>\theta_{c}\right)$, is rejected; it bounces back and forth between the reflectors walls until it emerges again through the aperture.

Below the general case of the non-planar absorber in two dimensions is considered. The collector is displayed in Figure 3.3. The most important principle behind the design of this concentrator, is that all extreme rays (rays entering the collector at angle $\theta_{\mathrm{C}}$ l should be tangent to the absorber surface after one reflection as indicated in Figure 3.3 ; this is known as the Edge Ray Principle. In order to complete the construction for the concentrator surface beyond the point $P_{0}$ an involute of the absorber surface is taken, as indicated by the dotted line, Recalling that the normal of the involute is tangent to the parent curve, it can be shown that a concentrator designed in this way sends to the absorber all rays that enter inside the angle $\theta_{c}$. For a three dimensional concentrator, Figure 3.3 can be rotated about the concentrator axis, but such configuration does not reach the ideal limit. 


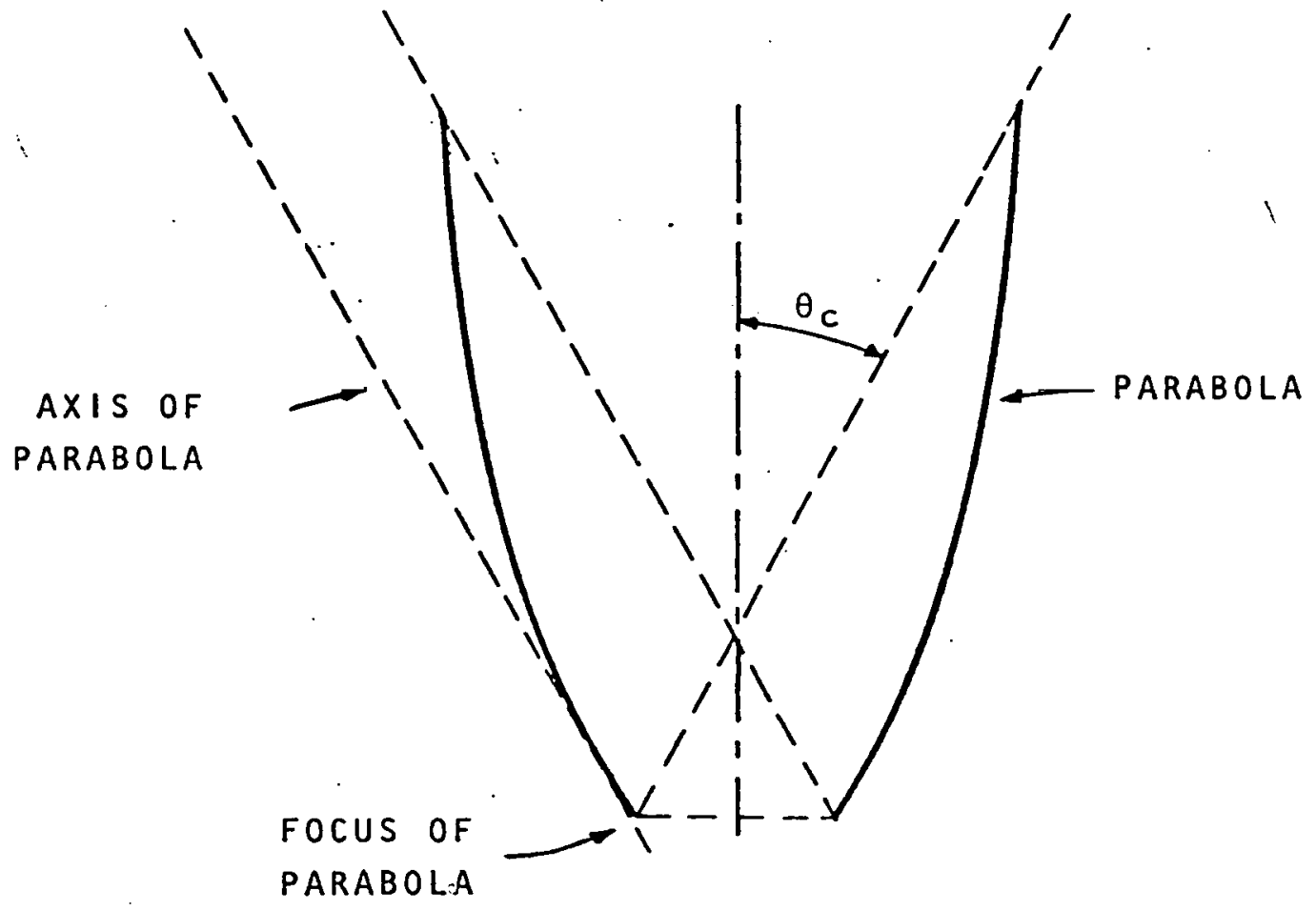

Figure 3.2

ORIGINAL DESIGN FOR A COMPOUND PARABOLIC CONCENTRATOR 


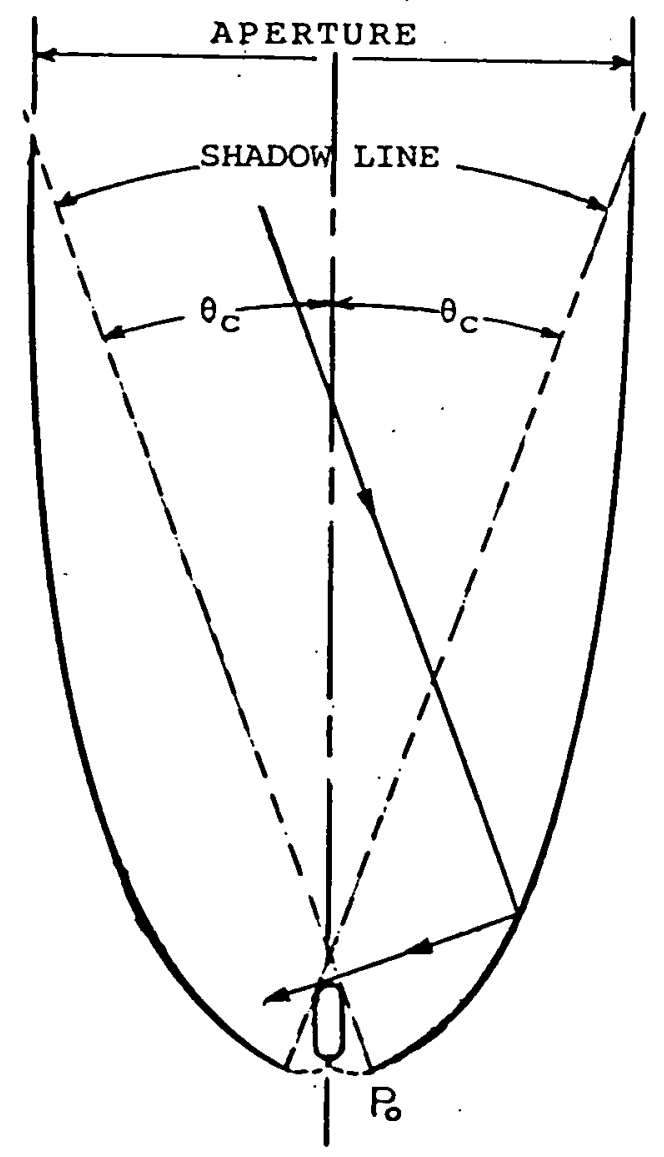

'Figure 3.3

IDFAI CYLINDRICAL CONCENTRATOR WITH ARBITRARY ABSORBER. SHAPE 
Figure 3.4 indicates four specific cases of absorber shape and $i$ ts corresponding CPC shape. Note that all cases satisfy the requirements previously mentioned.

An important modification that is commonly employed in CPC design is truncation. One disadvantage of a full CPC is that usually its reflector area is very large compared to its aperture area. Since the upper portion of the reflective sides of the collector receives just a small fraction of the total incident solar radiation, it is advantageous to truncate the CPC, thus reducing the height and therefore reducing the cost: There can be considerable reduction in height with very little reduction in concentration. This is discussed in more detail in Chapter IV.

\section{Absorbers for Concentrating Collectors}

A very important factor that should be taken into consideration in converting solar energy to high temperature thermal energy is the reduction of heat losses from the absorber of the concentrating collector. These losses must be minimized to have an acceptable conversion efficiency at high temperatures, Losses are caused by convective, conductive, and radiative heat transfer from the absorber to the surrounding ambient. The thermal radiation losses can be reduced by reducing the emissivity of the absorber and/or using radiation shields (additional refleca. tive parallel walls between the absorber and surroundingl. Low level emissivities can be achieved by the use of a so called selective surfaces which have a high absorptivity to the incident 

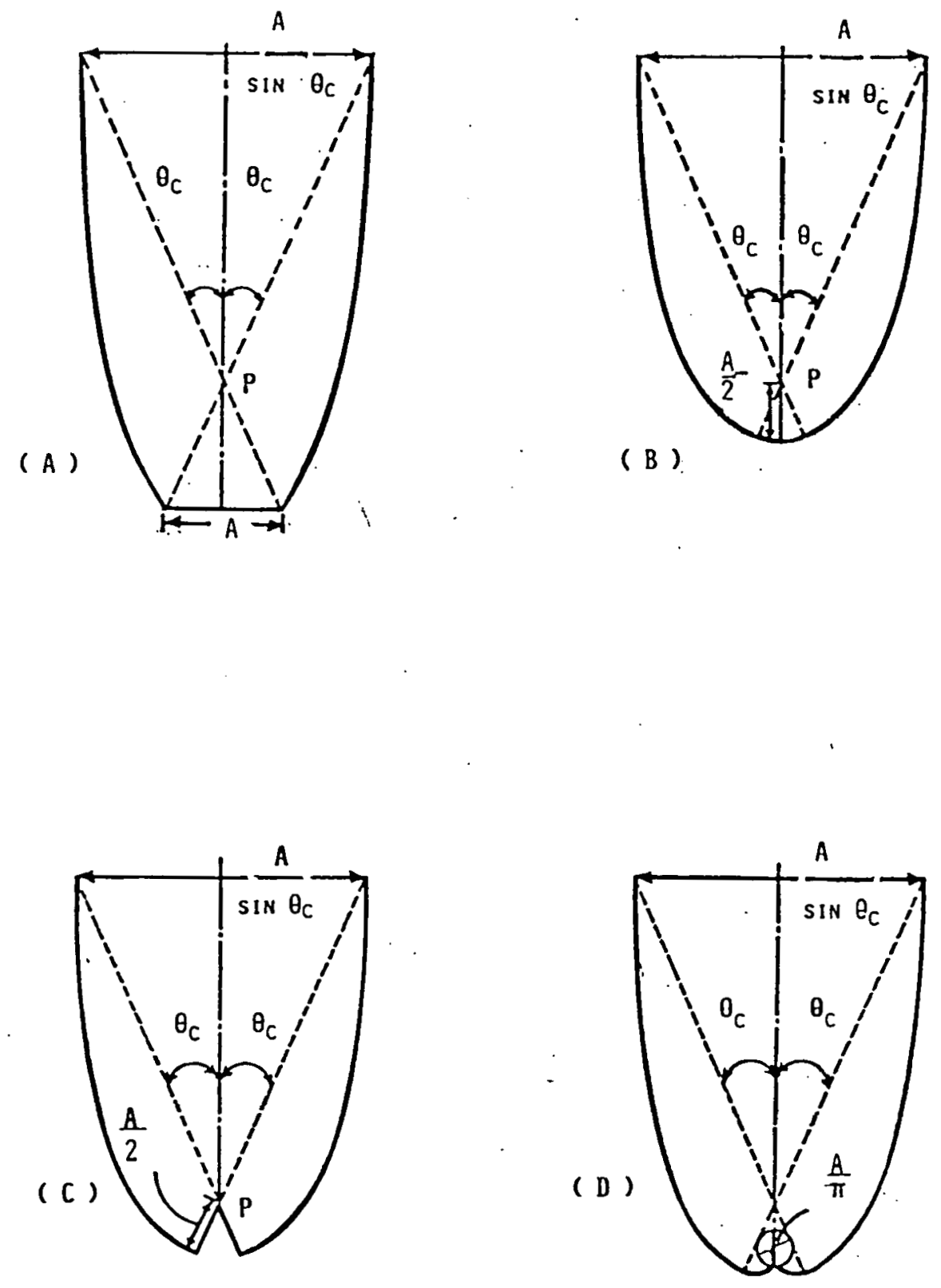

Figure 3.4

CPC CONCENTRATOR WITH VARIOUS ABSORBER SHAPES 
solar energy (short wave radiation) and a low emissivity for the radiation losses (long wave) from the absorber.

As for radiation shields, the only type that one could use would be a glazing material; otherwise the incoming solar radiation would be brocked. Since glass and other glazing materials are opaque to long wave radiation, the addition of glazing as a radiation shield is effective in reduction of heat losses. On the other hand, additional glazing sheets also reduce the incoming solar radiation-by increased reflection and self absorption.

To minimize the convective heat transfer losses, one must reduce the carrier of the convection, i.e. the air surrounding the absorber. This can be accomplished by evacuating the space between the absorber and the glazing; since without air in this space, there can be no convective heat transfer. The flat plate collector configuration presents both sealing and structural technological difficulties which result in high cost to effect these changes. On the other hand, they can be achieved relatively easily in a concentrator absorbers because of the smaller absorber area and the use of a higher strength structure, like glass tube, which can be lighter and cheaper. Absorbers with those configuration, are already developed and commercially available. They are generally known as Evacuated Tubutaricollectors or Evacuated Receivers. Figure 3.5 shows some of the most common configurations of evacuated receivers. 

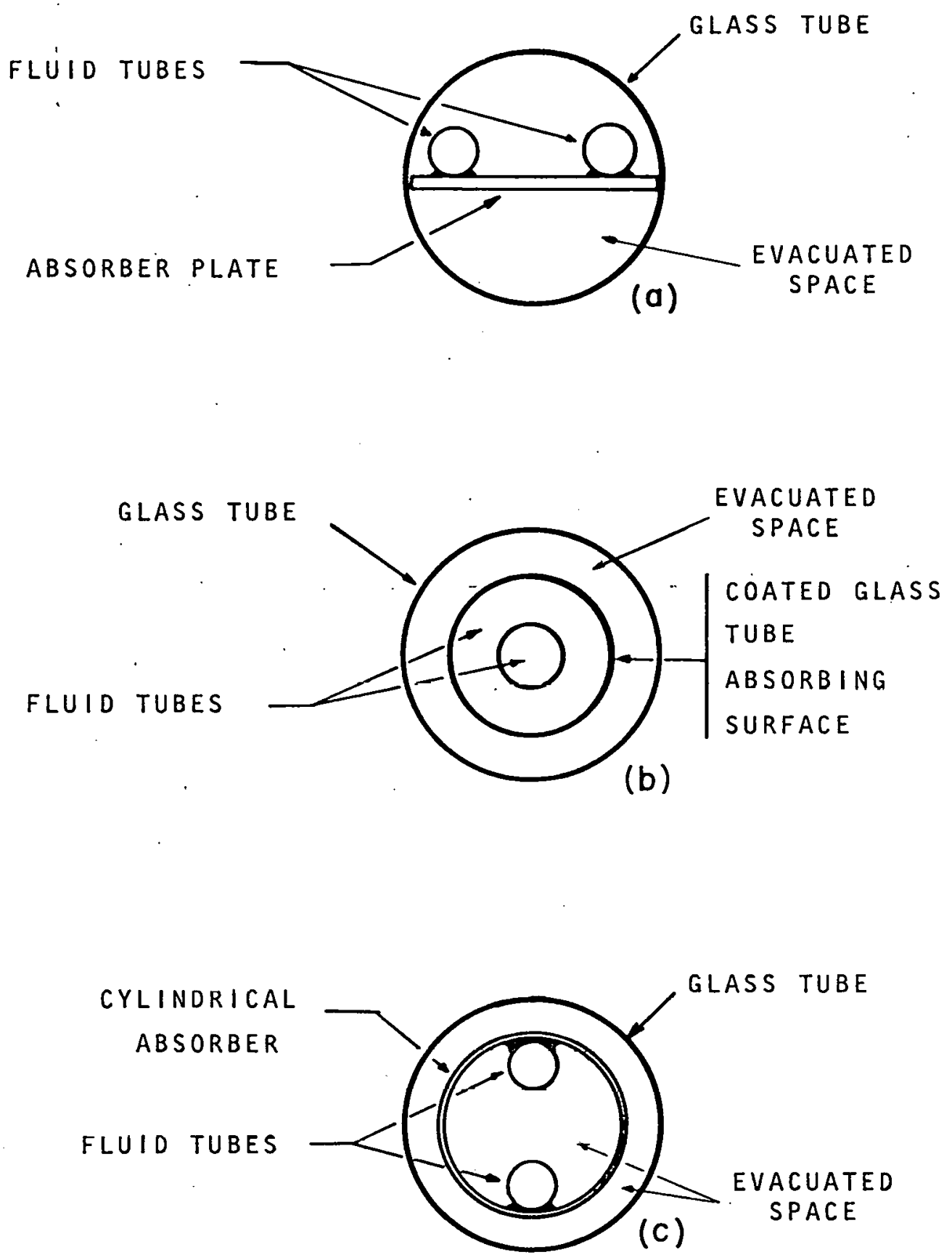

Figure 3.5

CROSS SECTION OF VARIOUS TYPES OF EVACUATED TUBULAR COLLECTORS 


\section{CHAPTER IV \\ CONCEPTUAL DESIGN OF THE FACETTED COLLECTOR}

A. Characteristics of the Facetted CPC

CPC mirrors are now being manufactured by several companies for different purposes covering a large range of concentration ratios. The method of fabrication used varies from one manufacturer to another, however, all of them are essentially integral mirrors (constructed with a continuous reflective surface). Although highly accurate surfaces can be achieved with this kind of approach, the inherent structural requirements for this type of collector increase the cost of the final product.

A new idea that presents some advantages over the existing method for CPC fabrication has been proposed by ortabasi ${ }^{12}$. Figure 4.1 shows a cross section diagram of this new concept. The development and analysis that is presented here was done as part of the "Industrial Process Heat" project at CEER. The fullowing is a discussion of the conceptual design of the prototype collector that was built under this program.

The segmentation and encapsulation of the reflective surface of the $C P C$ are the fundamental modifications to reduce fabrication and material cost, as well as to increase the useful life of the collector. The analytical contour of the ideal mirror surface is approximated by linear segments of about 2" width sealed in fluorescent lamp tube blanks of 2.080 " outside diameter and .035" wall thickness. This method of encapsulation 


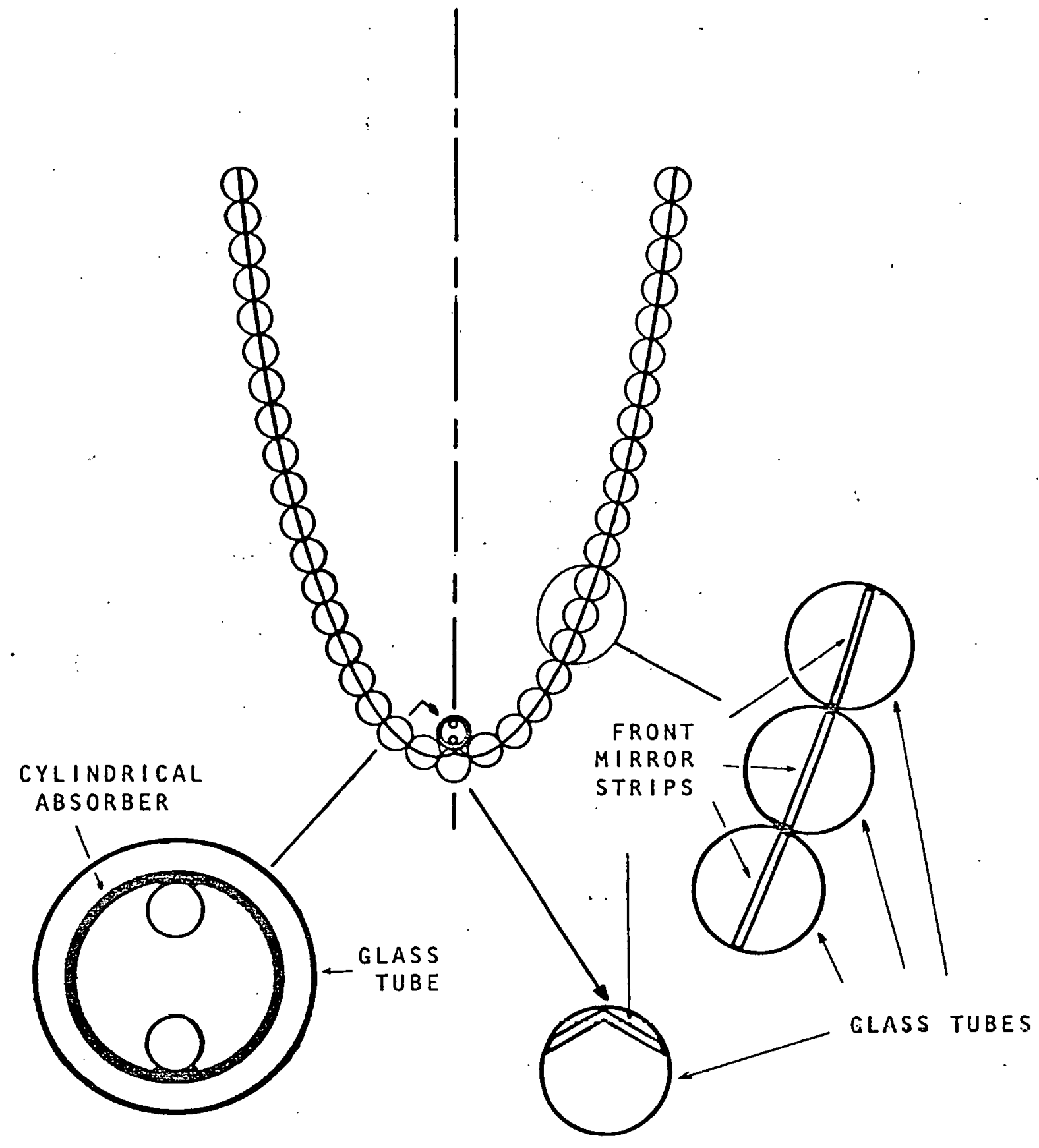

Figure 4.1

PRINCIPAL DESIGN FEATURES OF FACETTED CPC 
uses very cheap tubes serving two purposes. First, the tubes protect the otherwise sensitive mirrors against ultraviolet radiation, ozone, salt spray, acid rains and other airborne chemicals. Second, a rigid, self supporting, lightweight structure is obtained.

The key to cost reduction is the use of fluorescent lamp tube blanks to protect the mirrors. The technology for producing these tubes is a very mature one. Fast, efficient, highvolume production results in very low prices: The tubular geometry is inherently strong permiting the use of a thin glass wall, thus reducing collector weight and cost. Another advantage of mirror encapsulation is that it results in a modular unit which is easier to handle, transport and assemble.

Maintenance and operational costs are also reduced by the use of a $9^{\circ}$ half acceptance angle CPC. If, the collector'slong axis is oriented in the east-west direction it does not need diurnal tracking and only requires 10 adjustments per year to compensate for solar elevation ${ }^{6}$. In the majority of the cases these adjustments can be done manualiy. The $9^{\circ}$ half acceptance angle results in a maximum concentration ratio of $1 / \sin 9^{\circ}=$ 6.39 which is sufficiently high for the purposes of reaching a $550^{\circ} \mathrm{F}$ design temperature.

Truncation of the CPC, as mentioned previously, is another means to reduce the cost. The small reduction in concentration ratio is well-compensated by the reduction in material cost, Figure 4.2 presents how concentration ratio is affected by 


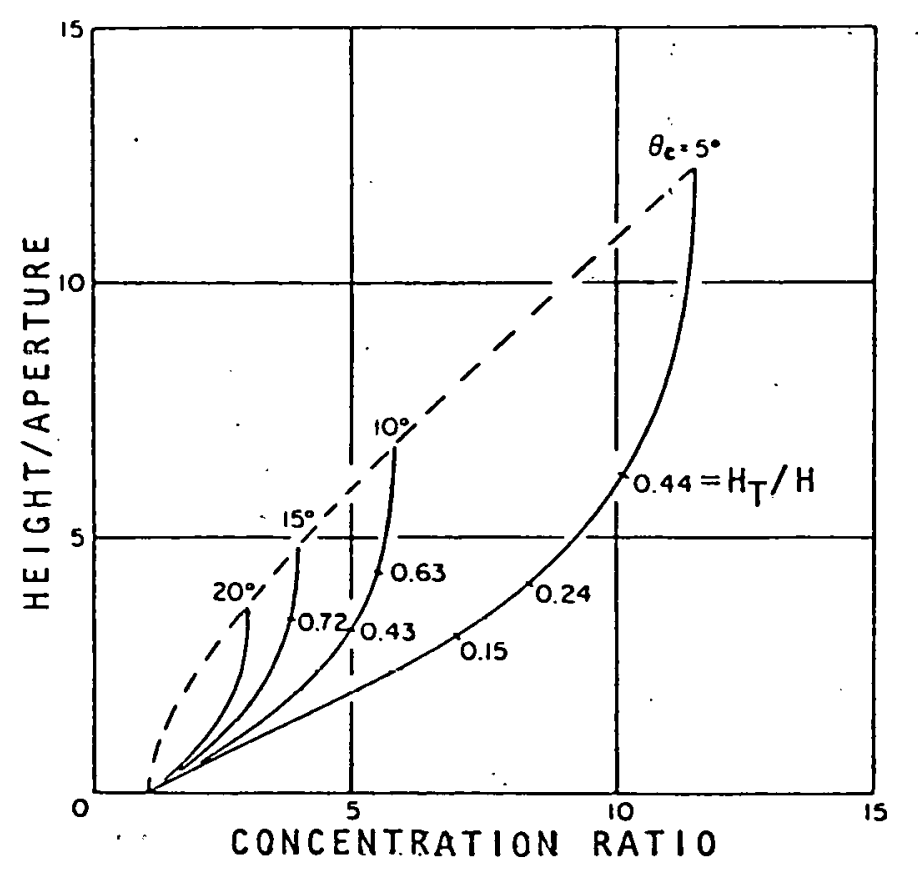

Fig.4.2a Height as a function of concentration ratio for truncated concentrator. $\mathrm{H}_{\mathrm{T}} / \mathrm{H}$ represents the ratio of truncation.

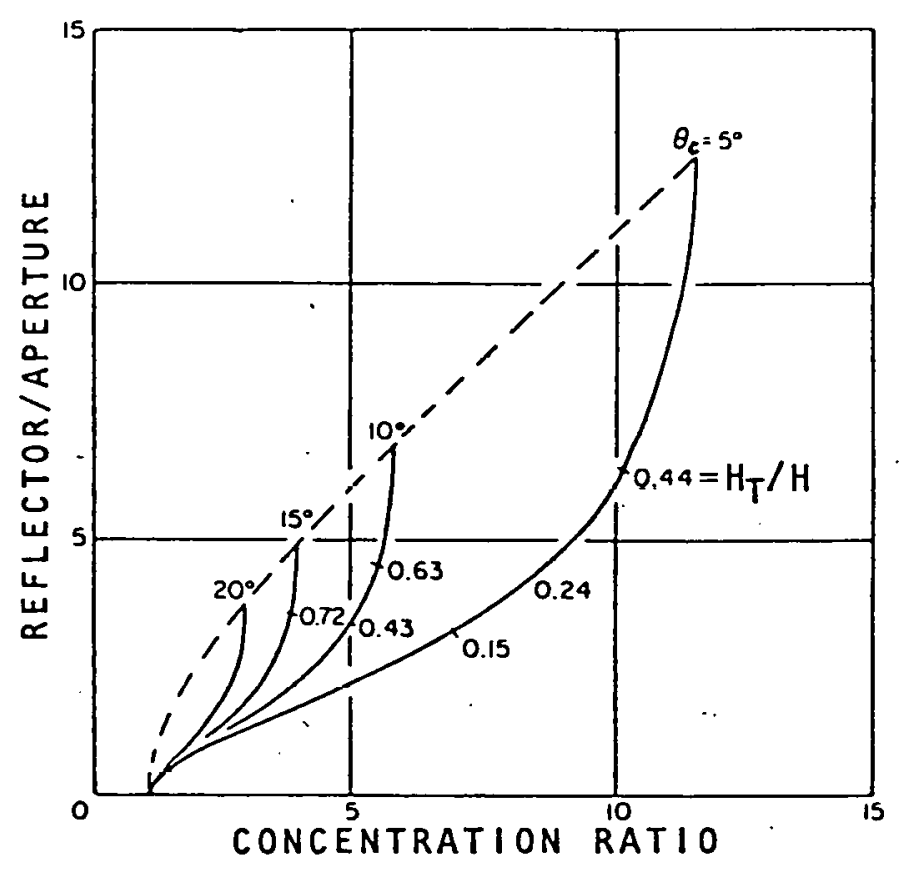

Fig. 4.2b Reflector surface as a function of concentration ratio for 2D truncated concentrators, $\mathrm{H}_{\mathrm{T}} \mathrm{H}$ repre sents the ratio of truncation.

Figure 4.2 
truncation. The graphs shown are presented in normalized form for convenience. Figure 4.2 a shows height to aperture ratio as a function of concentration ratio; and Figure 4.2 b shows reflector to aperture ratio as a function of concentration ratio. Note that in both cases there are saturation points after which the concentration ratio increase is insignificant.

After the analysis of the truncation effects, it was decided to use a $9^{\circ}$ half acceptance angle CPC truncated to a concentration ratio of 5.25 . This saves about $61 \%$ on material cost and collector height with only $18 \%$ reduction in the concentration ratio. Table 4.1 shows some of the most important physical and economical parameters that were considered. The same table also evaluates cost for two different sizes of glass tube.

B. Principle of Absorber Design

Two general methods exist for significantly improving the performance of a solar collector at elevated temperatures (above $200^{\circ} \mathrm{F}$ ). The first method consists of increasing the solar flux incident on the receiver. (The application of this method to the collector under study has been discussed in Chapter III.) The second method involves the reduction of parasitic heat losses from the receiver surface. Tubular receiver design; with its inherently high compressive strength and resistance to implosion, offers the only practical means for completely eliminating collvection losses by surrounding the receiver with a vacuum in the order of $10^{-4} \mathrm{~mm} \mathrm{Hg.} 10$ 
TABLE 4.1

PHYSICAL AND ECONOMICAL PARAMETERS OF THE CPC WITH ENCAPSULATION TUBES

$\left(\theta_{C}=9^{\circ}\right.$, absorber radius $=0.8125 "$, no envelope)

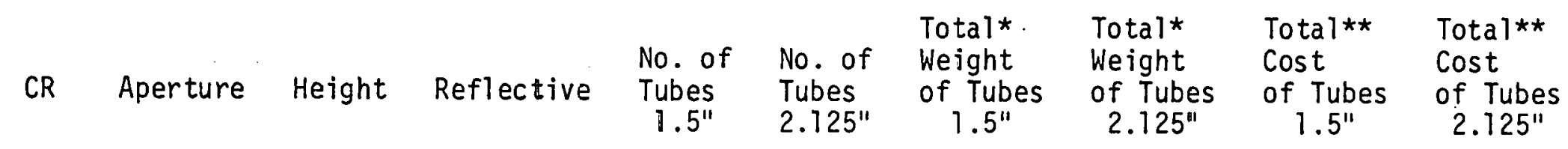

$\begin{array}{llllllllll}5.00 & 25.5 & 32.2 & 75.0 & 47 & 35 & 77.5 & 80.5 & \$ 7.76 & \$ 8.05\end{array}$

$\begin{array}{llllllllll}5.25 & 26.8 & 37.6 & 85.8 & 53 & 39 & 87.5 & 89.7 & 8.75 & 8.97\end{array}$

$\begin{array}{llllllllll}5.50 & 28.1 & 42.8 & 96.3 & 61 & 45 & 100.7 & 103.5 & 10.07 & 10.35\end{array}$

$\begin{array}{llllllllll}5.75 & 29.4 & 52.2 & 115.0 & 73 & 55 & 120.5 & 126.5 & 12.05 & 12.65\end{array}$

$\begin{array}{llllllllll}6.00 & 30.6 & 63.0 & 136.8 & 87 & 65 & 143.6 & 149.5 & 14.36 & 14.95\end{array}$

$\begin{array}{llllllllll}6.25 & 31.9 & 80.3 & 171.3 & 111 & 83 & 183.2 & 790.9 & 18.32 & 19.09\end{array}$

$\begin{array}{lllllllllll}6.39 & 32.6 & 109.5 & 229.7 & 149 & 111 & 245.9 & 255.3 & 24.59 & 25.53\end{array}$

*Weight calculation assumes $0.035 "$ tube thickness, $8 \mathrm{ft}$. length and glass density of $184.1 \mathrm{~b} / \mathrm{ft}^{3}$.

**Cost calculation assumes $\$ 0.10$ per pound of glass. 
Since radiation losses become significant at high temperatures $\left(550^{\circ} \mathrm{F}\right)$, it is important to consider the use of a low emissivity surface (.1 or less) and high absorptance (.85 or higher). It is important also to consider the radiation shape factor (view factor). For example, in Figure 3.4, for the $(A)$ and $(C)$ configurations, the emitting surface is twice the absorbing area; configurations (B) and.(D) of the same figure are more promising because their emitting and absorbing areas are equal. The cylindrical shape was chosen for the collector under study because it is relativelyeasy to fit into a glass tube. Configuration (B) in Figure 3.4 was rejected because it has a poor absorbing capacity due to the large angle of incidence between the rays and the normal to the surface.

Figure 4.3 shows the schematic of the single wall evacuated receiver designed especially for this project. The overall length of the tube is 108 inches and it contains a thin wall $\left(1 / 16^{-1}\right)$, cylindrical copper absorber 96 inches long. The envelope is 7740 PYREX tubing with a diameter of 2-1/8" (54mm) and a wall thickness of .094" $(2.4 \mathrm{~mm})$. The total area of the absorber, $3.40 \mathrm{ft}^{2}$, is coated with a black-chrome film having an absorptance $(\alpha)$ of .94 and a selectivity $(\alpha / \varepsilon)$ of 9.4 . Heat transfer fluid circulates in a "U" shaped copper conduit spot brazed to the inside of the absorber tube at 1 " intervals. Inlet and outlet ports are on the same end of the tube where glass to metal seals are used. A getter flash was provided at the tip of the tube to maintain the high vacuum $\left(10^{-5} \mathrm{~mm} \mathrm{Hg.}\right)$ 


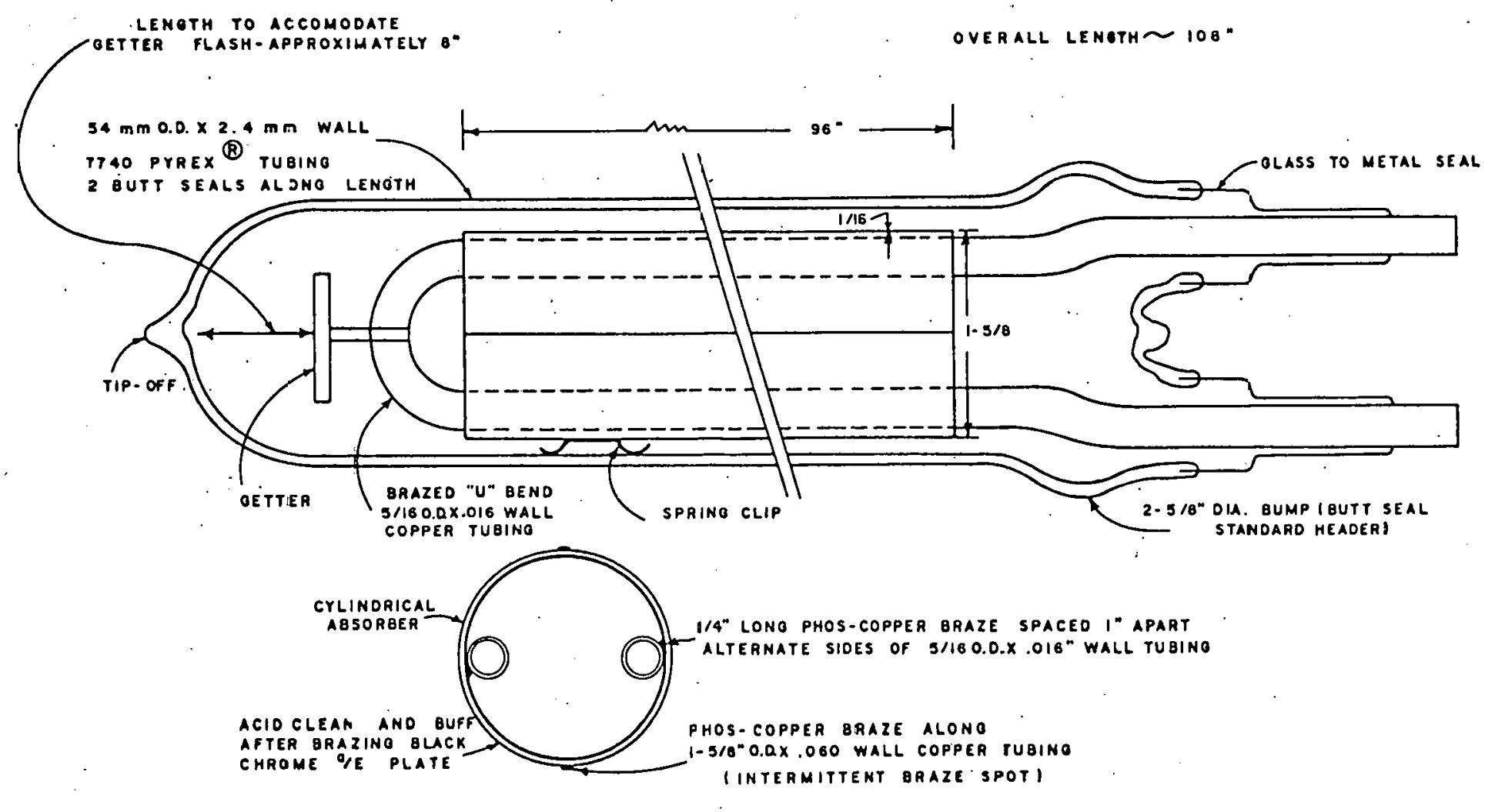

Figure 4.3

SCHEMATIC OF THE EVACUATED ABSORBER TUBE DESIGN 
even at elevated working temperatures. The absorber is supported by three spring rings which fit between the copper tube and the glass envelope.

C. CPC Shape for Cylindrical Absorber with Giass Envelope In Chapter III the requirements for a CPC design was discussed in general terms. Since an evacuated cylindrical absorber is being used for the prototype, the design of the reflector requires some additional modifications.

Below is aisummary of the requirements, conditions and variables that are involved in these calculations. (For parameters involved, see Figure 4.4)

i) For $|\theta|<\left(\theta_{c}+\pi / 2\right)$, any ray emitted tangentially from $\left(x_{e}, y_{e}\right)$ of the absorber toward the reflector must be reflected back. onto itself; hence, the corresponding portion of the reflector is a convolute.

ii) For $\left(\theta_{c}+\pi / 2\right) \leq|\theta| \leq\left(3 / 2-\theta_{c}\right)$ any ray emitted tangentially from a point $X_{e}, Y_{e}$ of the absorber toward the reflector must be reflected so as to make an angle $\theta_{c}$ with the $Y$-axis.

iii) The curve starts at point $A(\theta=\alpha)$ and must be continuous at point $B, \theta=\left(\theta_{C}+\pi / 2\right)$; this provides the boundary conditions.

iv) Only three variables are needed to define the curve: $r$ - absorber radius, $R$ - glass envelope radius and $\theta_{c}$ - half acceptance angle.

The curve $A C$ of figure 4.4 is split into two sections, $A B$ 


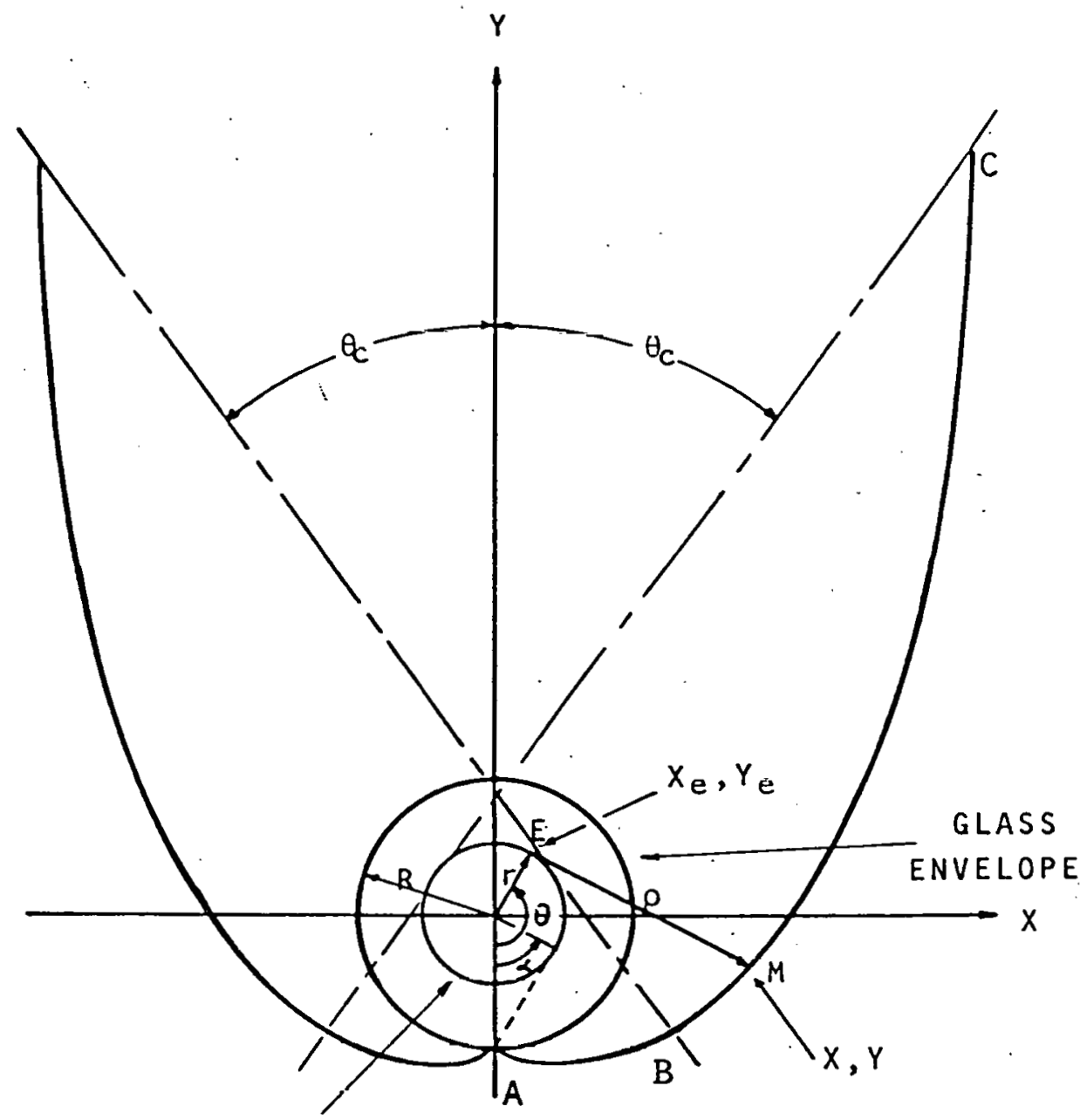

CYLINDRICAL ABSORBER

Figure 4.4

DEFINITION OF SOME IMPORTANT PARAMETER

FOR A CPC WITH CYLINDRICAL ABSORBER INSIDE A GLASS ENVELOPE 
and $B C$, each described by a separate set of equations. The dividing point between the two curves occurs at point $B$, where the extreme ray tangent to the absorber intersects the mirror curve.

The origin of the coordinate system is taken at the center of the cylindrical absorber. It is convenient also to describe the absorber by polar coordinates $(r, \theta)$ and to characterize any point $M$ on the reflector by its distance $\rho=$ ME from point E. The angle $\theta$ is measured from the negative $Y$-axis as shown in Figure 4.4. By means of simple geometry, it can be shown that the coordinates $X$ and $Y$ of the cusp mirror can be expressed in the following form.

$$
\begin{aligned}
& x(\rho, \theta)=r \sin \theta-\rho(\theta) \cos \theta \\
& Y(\rho, \theta)=-r \sin \theta-\rho(\theta) \cos \theta
\end{aligned}
$$

1. Solution for section $A B$ :

Solution for $A B$ section of the curve in a conyolute of the absorber plus a constant $C$ that depends on the eyacuated envelope and absorber's radius, i,e, $R$ and $r$. The equation is

$$
\rho=r \theta+c
$$

where

$$
c=r \tan \alpha-r \alpha
$$

and

$$
\dot{\alpha}=\cos ^{-1}(r / R)
$$

The equation describing the section $A B$ of the cusp mirror then have the following explicit form: 


$$
\begin{aligned}
& X=r \sin \theta-(r \theta+r \tan \alpha-r \alpha) \cos \theta \\
& Y=-r \cos \theta-(r \theta+r \tan \alpha-r \alpha) \sin \theta
\end{aligned}
$$

where $\theta$ covers a range from $\theta=\alpha$ to $\theta=\left(\pi / 2+\theta_{C}\right)$ :

2. Solution for $B C$ section:

Solutions for the $B C$ section involves a more elaborate calculations that are presented in detail in Appendix $B$. This is the result in polar notation:

$$
\rho=\frac{r \pi / 2+\theta_{c}+\theta-\cos \left(\theta-\theta_{c}\right)+2 c}{1+\sin \left(\theta-\theta_{c}\right)}
$$

In explicit parametric form the equations are:

$$
\begin{aligned}
& X=r \sin \theta-\frac{r \pi / 2+\theta_{c}+\theta-\cos \left(\theta-\theta_{c}\right)+2 c}{1+\sin \left(\theta-\theta_{c}\right)} \cos \theta(4.9) \\
& Y=-r \cos \theta-\frac{r \pi / 2+\theta_{c}+\theta-\cos \left(\theta-\theta_{c}\right)+2 c}{1+\sin \left(\theta-\theta_{c}\right)} \sin \theta(4.10)
\end{aligned}
$$

where $C$ is calculated from equation (4.4) and $\theta$ covers a range from $\left(\theta_{c}+\pi / 2\right)$ to $\left(3 \pi / 2-\theta_{c}\right)$.

Figure 4.5 shows the CPC shape and the values of absorber radius, glass envelope radius and acceptance angle of the prototype built.

The reflector length was determined by numerical integration of the equation (4.9) and (4.10). Figure 4.6 presents the results in a graphical form as a function of the concentration ratio. This is useful for truncation analysis that was discussed in the previous sections in this chapter. 


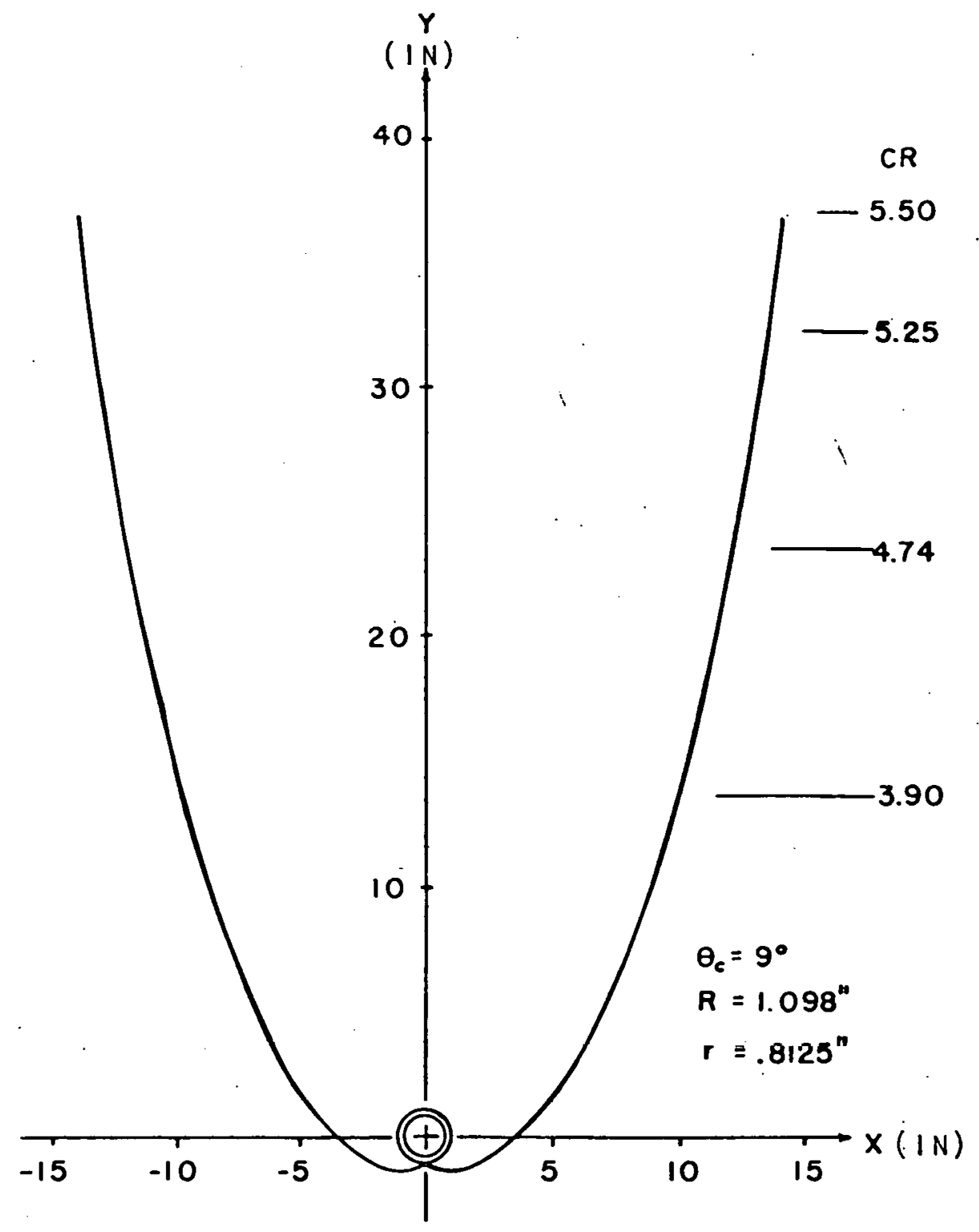

Figure 4.5 


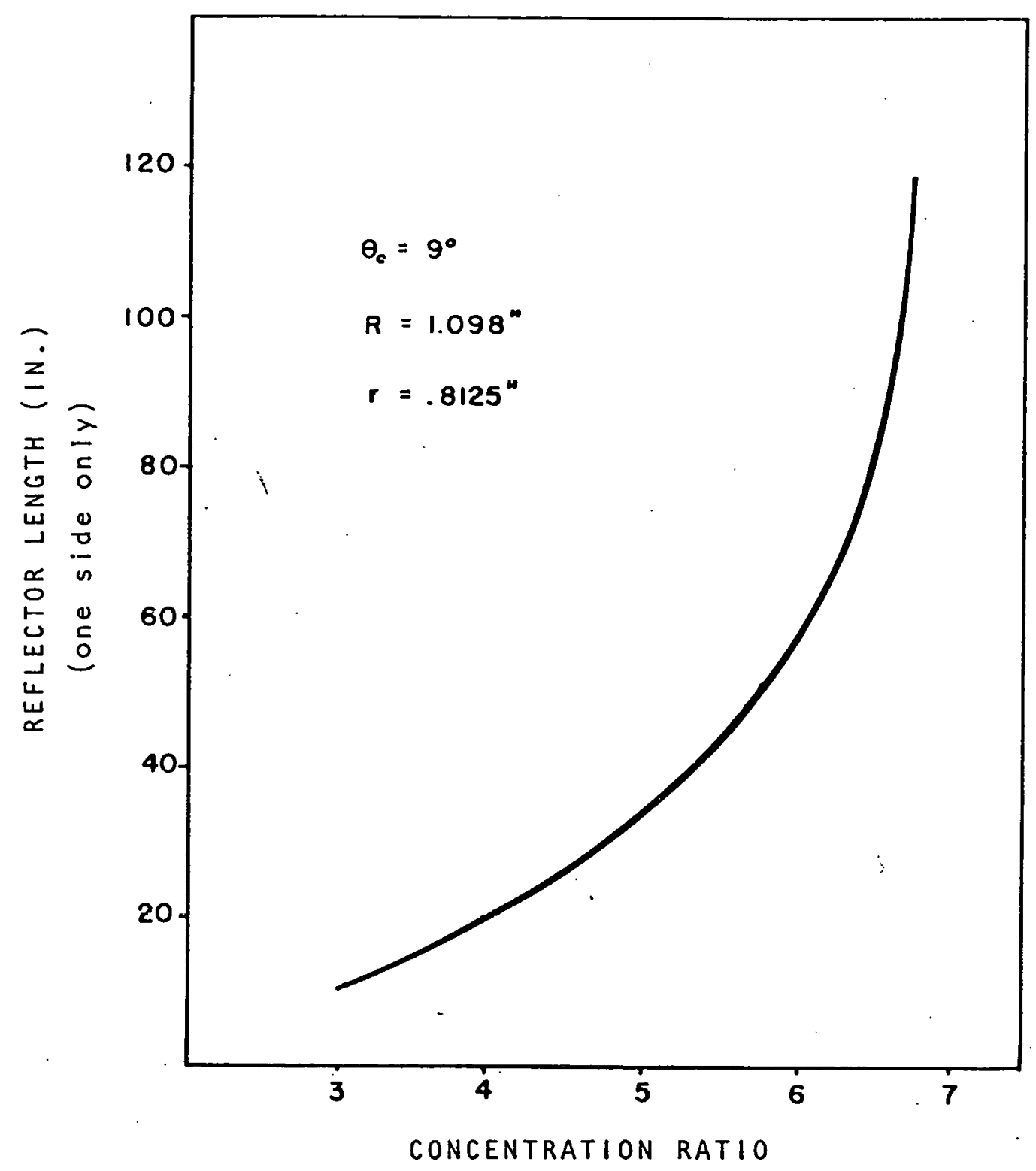

Figure 4.6

VARIATION OF REFLECTOR LENGTH

WITH CONCENTRATION RATIO. 
D. Computer Simulation for Optical Performance

The major question in segmenting the mirror as shown in Figure 4.1 is the total loss introduced by the linear segments and their alignment errors. As a part of the overall project, this was analyzed by Dr. Roland Winston of the University of Chicago and CEER's Solar Division using a Monte-Carlo Ray Tracing Method. The computer program developed for this purpose simulated three different combination of acceptance angle $\theta$ and concentration ratio. $C R$ :

$$
\begin{array}{ll}
\theta_{C}=8^{\circ} & C R=5.19 \\
\theta_{C}=18^{\circ} & C R=2.98 \\
\theta_{C}=34.33^{\circ} & C R=1.49
\end{array}
$$

For all computation the width of the mirror segments was chosen to be $(O D-2 d)$, where $O D$ is the outer diameter of the tube ( $\left.1 / 8^{\prime \prime}\right)$ and $d$ is the wall thickness. The gap width, i.e. the separation between two mirror segments, was varied. The digital ray tracing program computes the thruput intercepted by the cylindrical absorber for various wall thickness of the glass mirror envelope. The absorber itself is assumed to have no evacuated glass envelope in contrast with the real design. A flow diagram of the program is shown tn figure 4,7.

For all computational steps refraction effects are ignored to avoid excess computer time.

1. Computations for Compound Parabolic Concentrator with Encapsulated Straight Segments. 


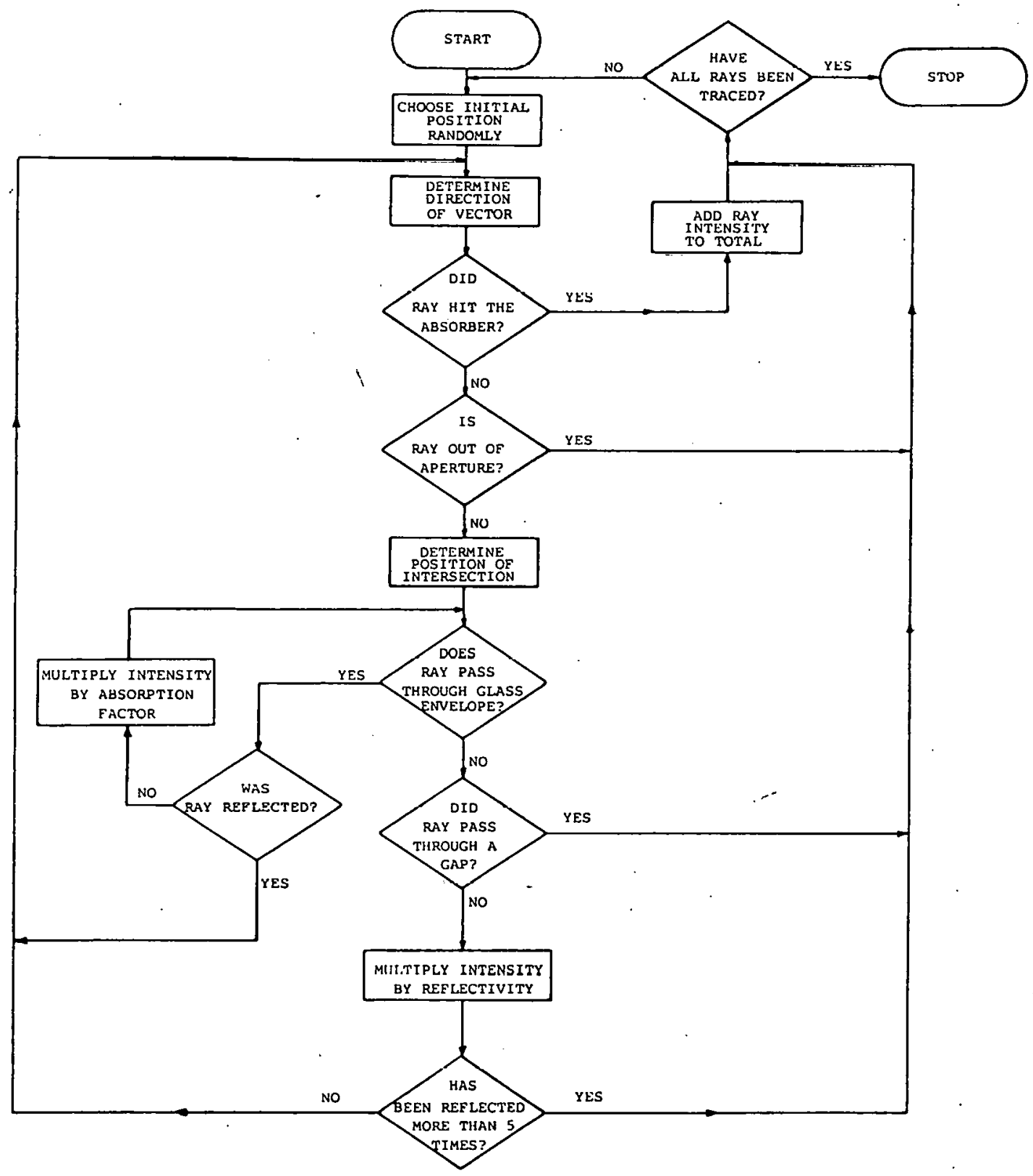

Figure 4.7

FLOW CHART FOR COMPUTER SIMULATION 
Extensive calculations were carried out to determine the effect of the concentration ratio, glass wall thickness and angle of incidence on the optical performance. Table 4.2 shows the angle-averaged light thruput for several concentration ratios at a constant glass wall thickness of .030".

The decline in the thruput as concentration ratio increases is due to the increased average number of reflections the light beam undergoes until it is intercepted by the absorber. Figure 4.8 displays the average fractional thruput as a function of the glass wall thickness for several concentration ratios. The bottom straight line is the fractional thruput for $C R=5.25$. This is the same concentration ratio used for the experimental prototype built in Mayaguez (See Chapter VI). The dotted extrapolation of this curve intercepts the ordinate at $61 \%$. This point simulates the performance of a segmented $C P C$, where the refractive index and absorption of the glass walls are assumed to be 1 and 0 , respectively. Thus the additional loss due to the .030" thick glass walls is only $5 \%$. This result is very promising, but must be taken with caution. As mentioned above, the computer program does not include any aberration effects. Also, defocusing of the light by imperfections as well as light trapping in the tube are not considered.

2. Computations Including Antireflective Treatment of Mirror Tubes.

Antireflective coating or treatments can be used for 
TABLE 4.2

ANGLE AVERAGED LIGHT THRUPUT

$\begin{array}{ccccc}\begin{array}{l}\theta_{C} \\ \text { Max Angle of }\end{array} & \begin{array}{c}\text { CR } \\ \text { Concentration } \\ \text { Ratio }\end{array} & \begin{array}{l}\text { Fractional } \\ \text { Intensity } \\ \text { Thruput }\end{array} & \begin{array}{c}\text { Fraction of } \\ \text { Rays } \\ \text { Reflected }\end{array} & \begin{array}{c}\text { Fraction of } \\ \text { Rays Saved }\end{array} \\ 34.33 & 1.5 & .73 & .16 & .43 \\ 18.0 & .3 .0 & .64 & .21 & .30 \\ 8.0 & 5.2 & .56 & .24 & .21\end{array}$




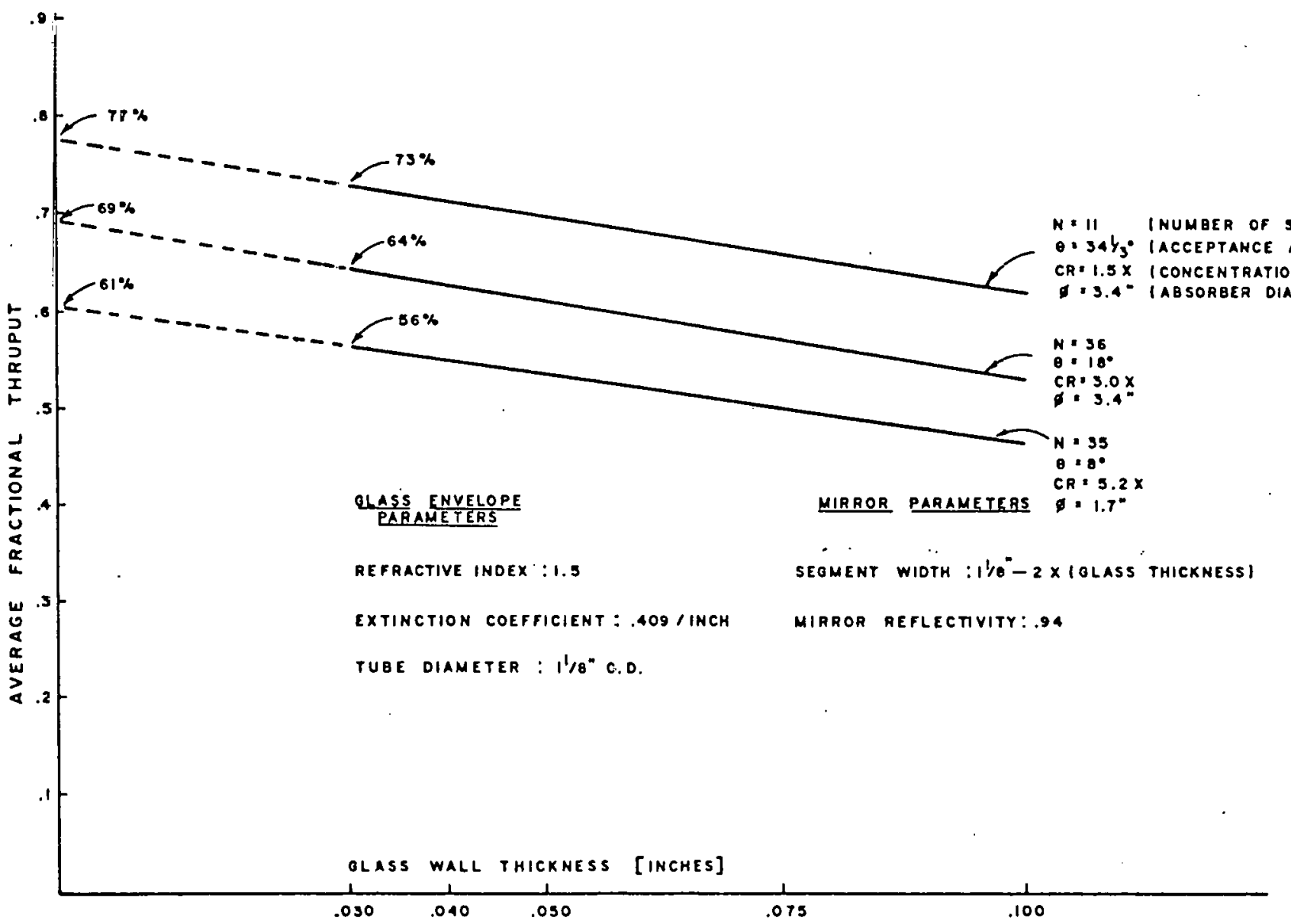

Figure 4.3

THRUPUT INTERCEPTED BY ABSORBER FOR VARIOUS WALL THICKNESS 
substantially reducing the reflective losses.caused by the fluorescent tube blanks surrounding the mirror segments. This kind of treatment could improve the optical performance of the collector without affecting the cost of the unit appreciably. The effect of using antireflective coated tubes on the performance of the segmented collector was studied by a verified version of the compuler simulation described above.

Figure 4.9 shows the results of these studies for a $5.2 \times$ concentrator with mirror tubes of $21 / 8 "$ diameter and $0.035^{\prime \prime}$ glass wall thickness. The graph displays the dependence of the fractional light thruput with the incidence angle. A marked improvement is seen when the antireflectively treated tubes are used especially in the region around $0^{\circ}$ incidence angle. The averaged thruput over the angle of incidence improves by $12.1 \%$, if compared with the untreated system.

E. Collector Orientation Studies

One of the main advantages of the CPC design is the possibility of doing away with continuous tracking of the sun thus reducing complexity and cost: This is because a CPC can collect radiation incident over an extended range of angles as shown in Ejgure.4:10. Present CPC design is an ideal $6.39 \times$ concentrator truncated to $5.25 \mathrm{X}$. The theoretical half acceptance angle $\left(\theta_{\mathrm{C}}\right)$ of the ideal concentrator is $9^{\circ}$. An actual device never has a perfect theoretical shape due to random deviations of its surface from the "ideal" surface. This changes its acceptance 


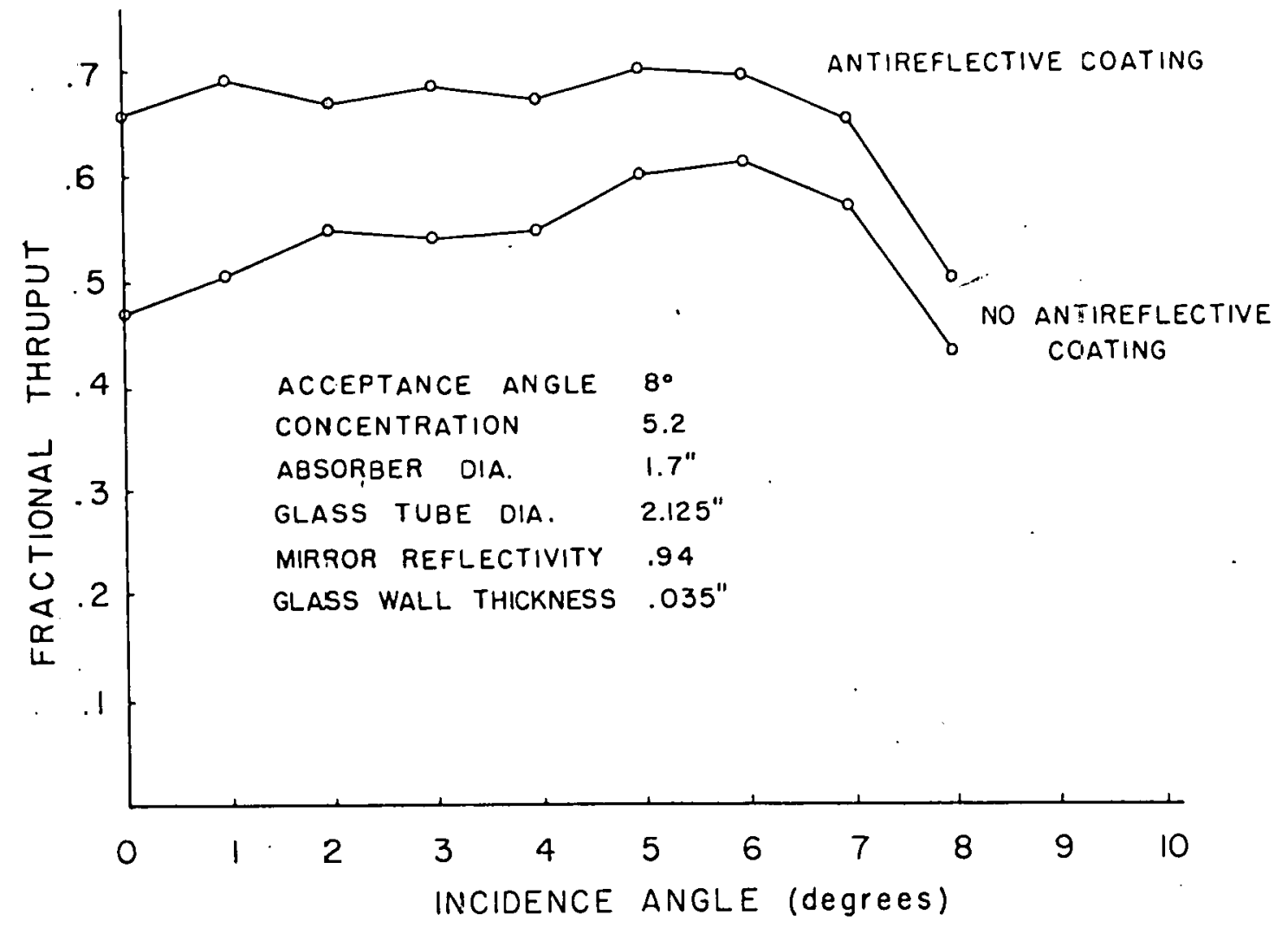

Figure 4.9

FFACTION THRUPUT VS INCIDENCE ANGLE 


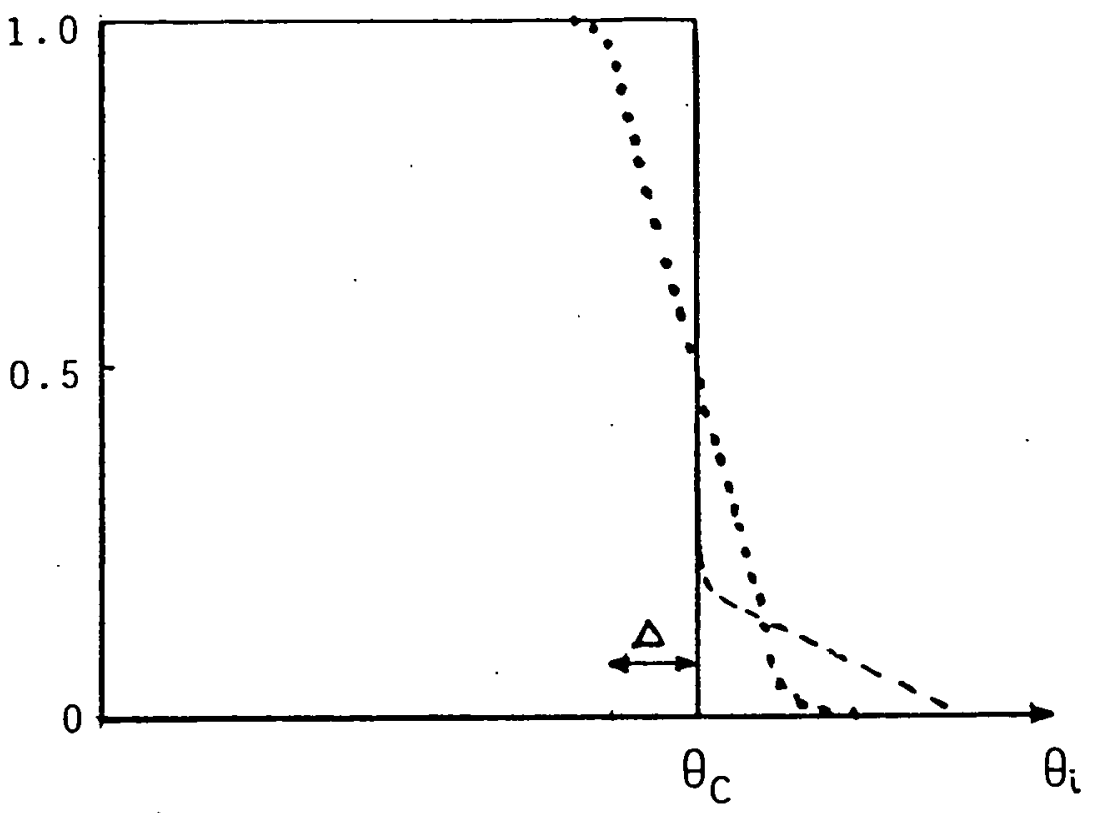

Figure 4.10

FRACTION OF THE RADIATION INCIDENT ON THE APERTURE OF A CPC AT ANGLE $\theta_{j}$ WHICH REACH THE ABSORBER

untruncated ideal concentrator

....... truncated ideal concentrator

....... untruncated concentrator with average surface error $\Delta$. 
characteristics, (see Figure 4.10), however, this change can be approximated as a reduction in the acceptance angle. For this reason, this study will consider three cases $\left(7^{\circ}, 8^{\circ}\right.$, and $9^{\circ}$ ) of acceptance angle.

The idea then, is to orient the collector so that the direct radiation is incident at an angle less than or equal to the acceptance angle. Yet this should be done with a minimum amount of tracking. The optimum collection-to-tracking ratio is achieved by orienting the long axis of the collector along the east-west direction. The angle of interest is then the projected incidence on the plane defined by the zenith and the north-south direction. This angle, $\theta_{\text {sp }}$, can be calculated for a particular day and hour by

$$
\tan \left(\theta_{s p}+L\right)=\tan \delta / \cos \omega
$$

where $L$ is the latitude, $\delta$ is the declination and $\omega$ is the hour angle from noon ( $\omega=2 \pi t / 24, t$ in hours). See Appendix $C$ for detajled derivations.

Figure 4.11 is the graph of $\theta_{s p}$ for different days during the year and for Puerto Rico's latitude. A scheme for orienting the collector can be derived from this graph. One first specifies the half acceptance angle $\left(\theta_{c}\right)$ and a minimum daily collection time (e.g. 7 hours/day). Starting at summer solstice, one determines the value of $\theta_{s p}$ at the extreme of the minimum daily collection time (time $=3.5)$. Call this angle $\theta_{e}$. Before and after the solstice the collector would be oriented at 


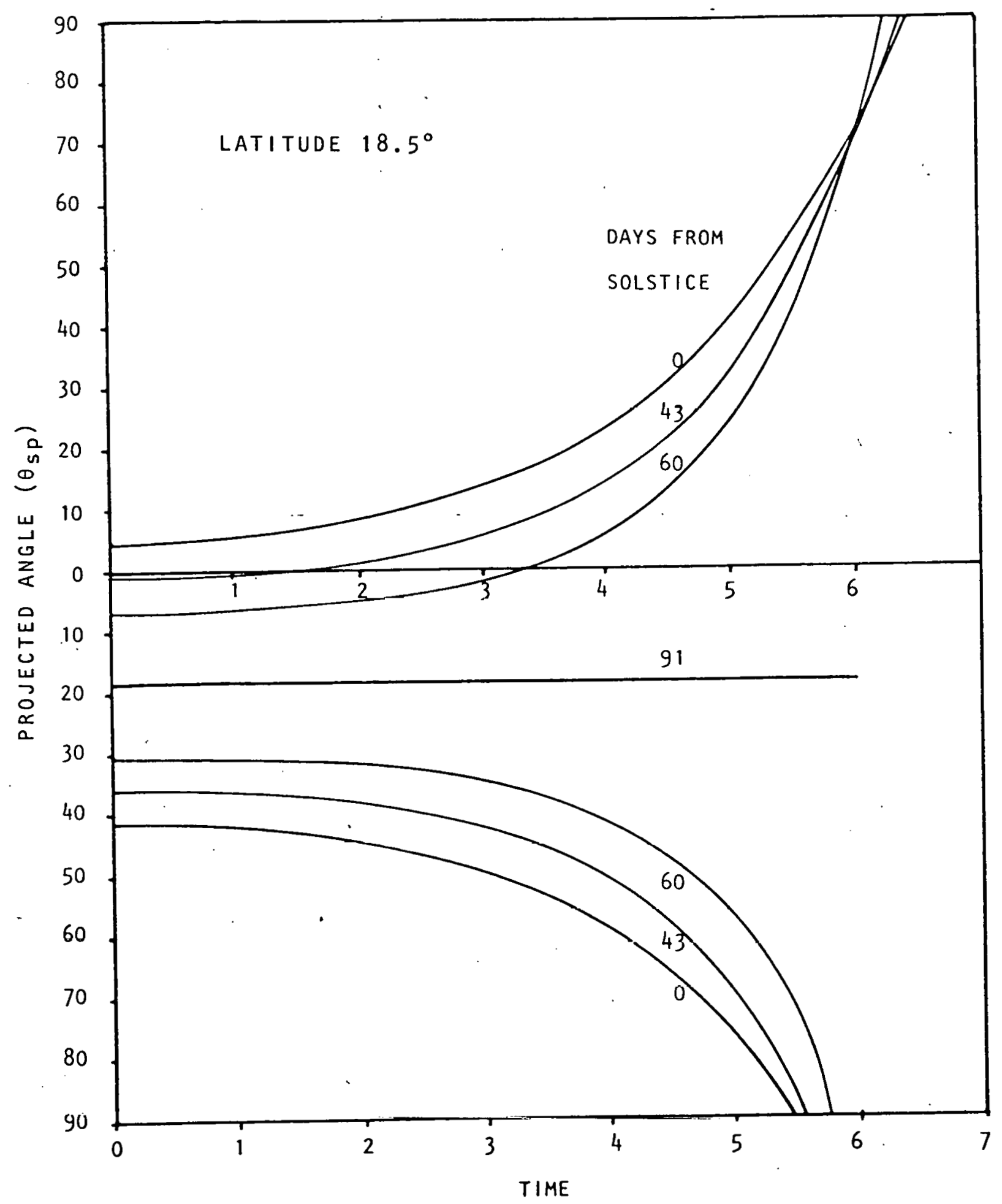

(HOURS AFTER NOON)

Figure 4.11 
an angle $\left(\theta_{e}-\theta_{c}\right)$. For this configuration, the collector would have a high optical efficiency at any hour of the day that satisfied $\left(\theta_{e}-2 \theta_{c}\right)<\theta_{s p}<\theta_{e}$. For several days after the solstice this condition will hold more than 7 hours a day. But there comes a day when it will hold for less than the required 7 hours because it will not hold in the period around noon time. On this day, the collector orientation should be changed. Suppose that the value of $\theta_{\text {sp }}$ at the extremes of the minimum collection time on this day is $\theta_{e}^{\prime}$. The collector is then pointed at an angle $\theta_{e}^{\prime}-\theta_{c}$. This procedure for determining the collector orientation and the dates for changing it is repeated until a full year is mapped out. The result is a chart such as the one shown in Table 4.3: For a half acceptance angle of $9^{\circ}$ and a minimum required collection time of 7 hours per day the collector has to be reoriented only 10 times a year. Figure 4.12 shows an example of the sequence of adjustments for the collector during the year. 
TABLE 4.3

TILT ADJUSTMENT DURING THE YEAR

$$
\theta_{c}=9^{\circ}
$$

\begin{tabular}{|c|c|c|c|c|}
\hline *Start Date & *End Date & $S=\operatorname{south} N=$ north & Length of period & $\begin{array}{l}\text { Declination at } \\
\text { End of period }\end{array}$ \\
\hline Jan. 30 & Feb. 24 & $37^{\circ} \mathrm{S}$ & 25 days & $-10^{\circ}$ \\
\hline Feb. 24 & Mar. 22 & $25.0^{\circ} \mathrm{S}$ & 26 days & 0 \\
\hline Mar. 22 & Apr. 17 & $11^{\circ} \mathrm{S}$ & 26 days & $10^{\circ}$ \\
\hline Apr. 17 & May 12 & $1^{\circ} \mathrm{N}$ & 25 days & $18^{\circ}$ \\
\hline May 12 & JuT. 31 & $9^{\circ} \mathrm{N}$ & 80 days & $18^{\circ}$ \\
\hline Ju1. 31 & Aug. 26 & $1^{\circ} \mathrm{N}$ & 26 days & $10^{\circ}$ \\
\hline Aug. 26 & Sep. 20 & $11^{\circ} \mathrm{S}$ & 25 days & 0 \\
\hline Sep. 20 & oct. 16 & $25^{\circ} \mathrm{S}$ & 26 days & $-10^{\circ}$ \\
\hline oct. 16 & Nov. 11 & $37^{\circ} \mathrm{S}$ & 26 days & $-18^{\circ}$ \\
\hline Nov. 17 & Jan. 30 & $45^{\circ} \mathrm{S}$ & 80 days & $-18^{\circ}$ \\
\hline
\end{tabular}

Number of adjustments/year $=10$

*In a leap year, add one day to dates after Feb. 28. 


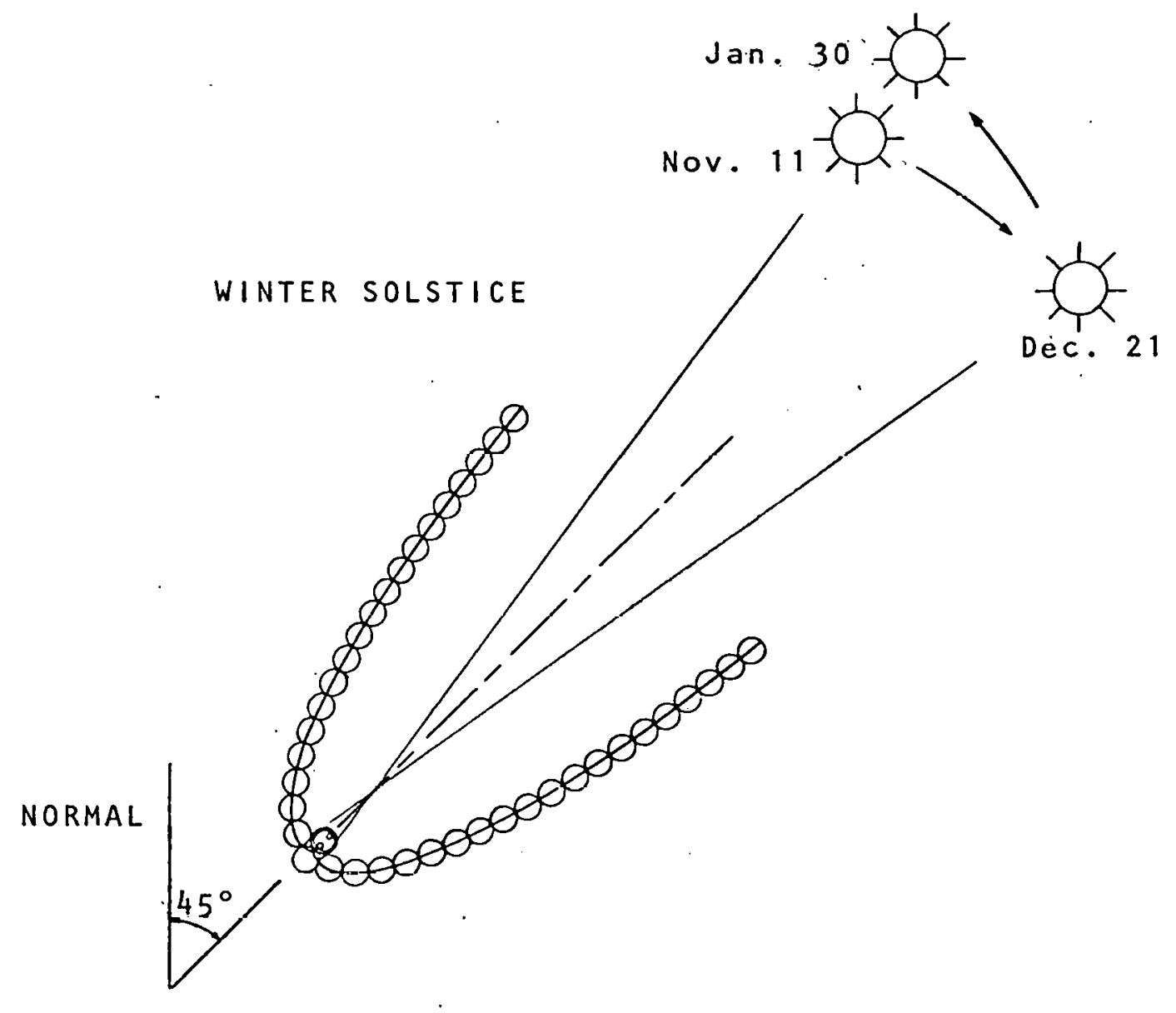

Figure 4.12

SCHEMATIC FOR ORIENTATION

OF THE CONCENTRATOR 


\section{CHAPTER V}

\section{LASER EXPERIMENTS ON A SIMULATION MODEL}

Laser ray tracing experiments consist of taking multiple exposure pictures of a laser beam incident at different points of the aperture on a simulation model. This permits a visual inspection of what happens to light rays when they enter the aperture of the concentrator. These experiments also permita study of the effects of encapsulation of mirror segments separately.

\section{A. Experimental Arrangement for Ray-tracing Studies}

The experimental model is a half scale representation of the prototype concentrating plane.. It consists of an aluminum plate which holds small segments that make up the reflective surface. These segments are $0.56 "$ tall and $0.94 " 10$ ng. The aluminum plate sits on an indexing rotary table (Figure 5.1) to provide angular displacement simulating different acceptance angles. The rotary table is fixed to a large base that supports the camera stand (Figure 5.21. This base is mounted on a sliding table to permit the variation of the point of incidence of the laser beam.

Results from the computer program developed to calculate the shape of the reflector surface for a CPC.with evacuated cylindrical absorber, were used to determine the proper position of the screws which held the mirror segments. The distance between mirror centers was 1.020". The acceptance angle 
Figure 5.1

EXPERIMENTAL MODEL MOUNTED ON INDEXING ROTARY TABLE 


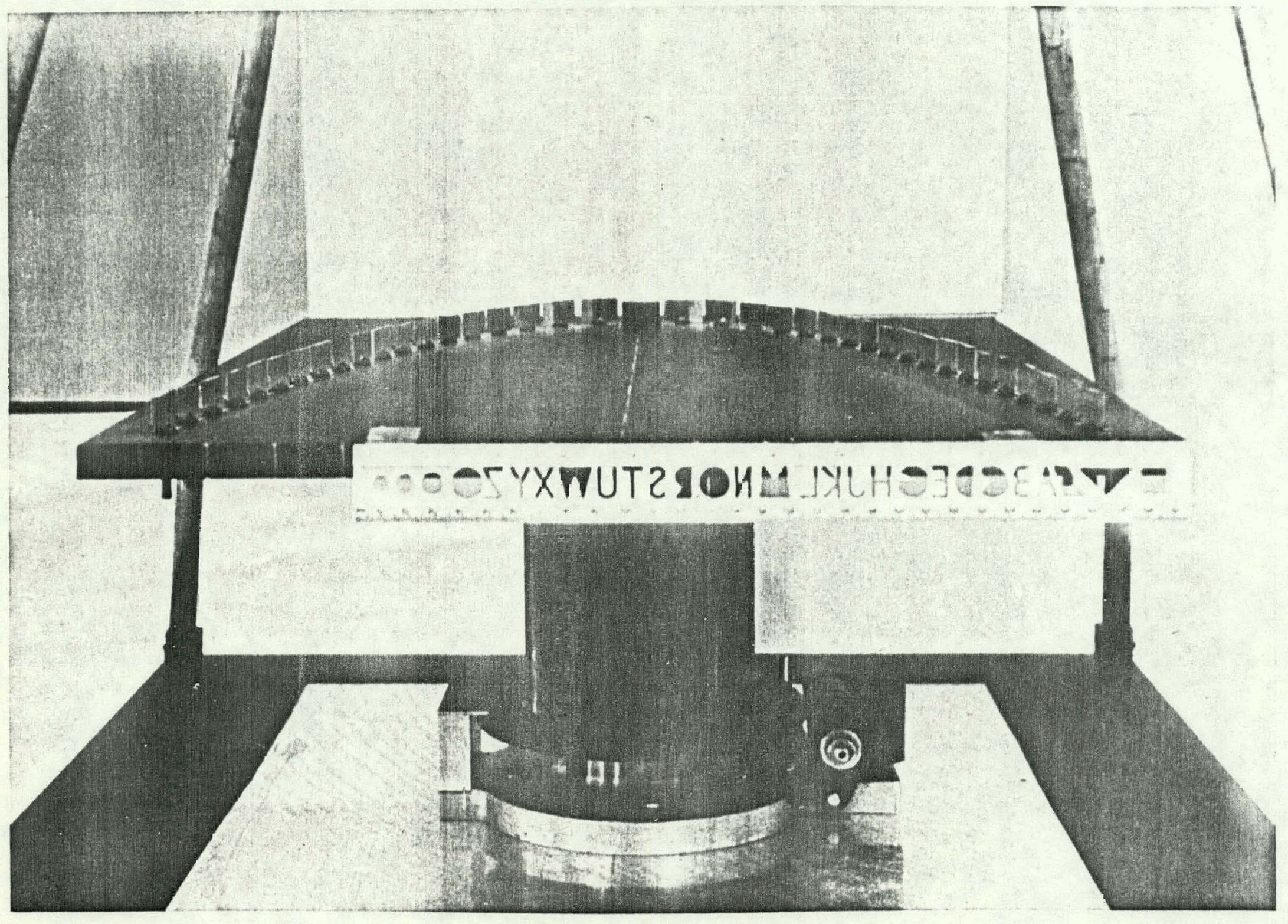


Figure 5.2

EXPERIMENTAL MODEL CAMERA STAND AND SLIDING TABLE 


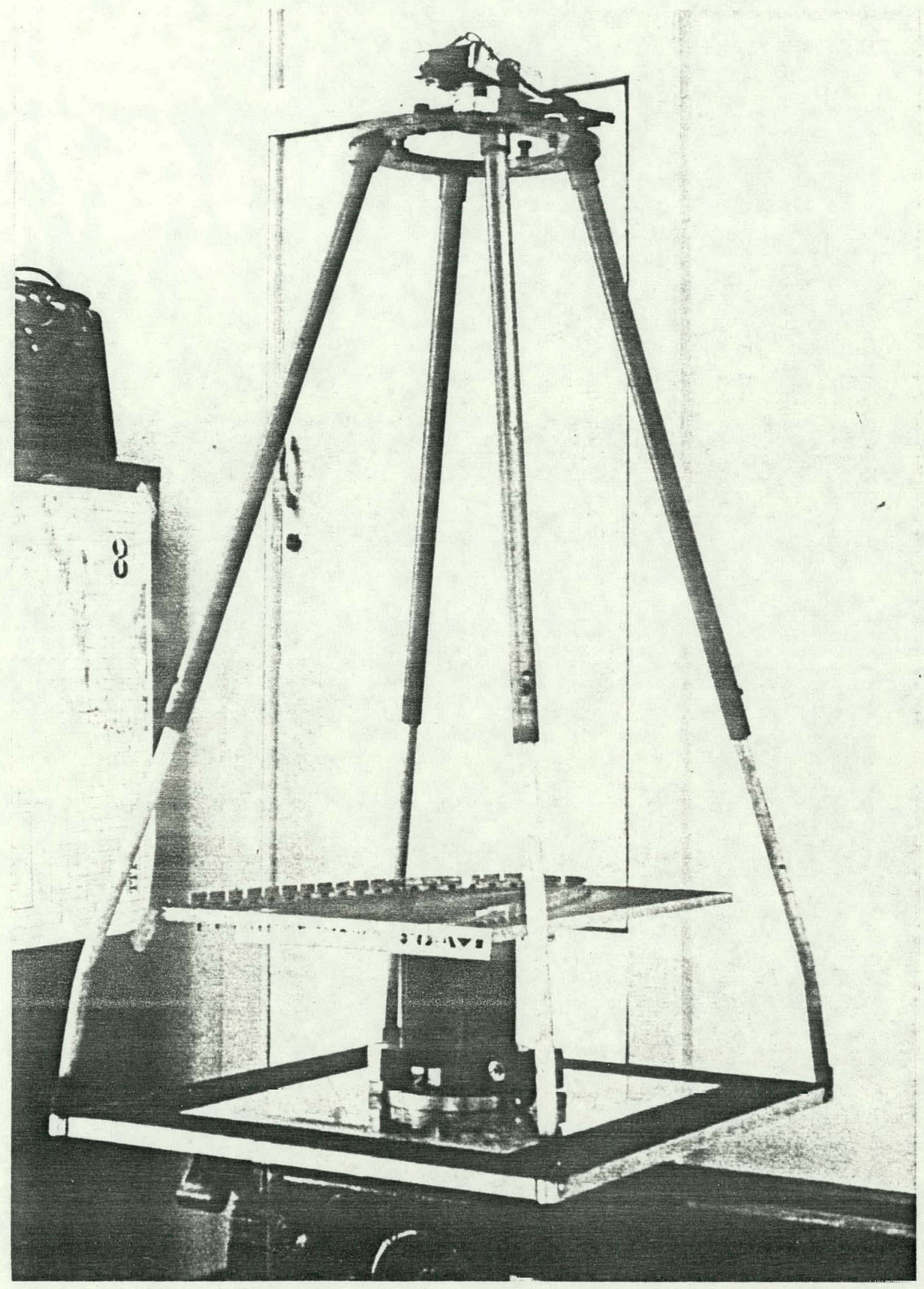


was designed to be $9^{\circ}$ (same as the prototype).

The laser used provided $0.3 \mathrm{~mW}$ of power at a wavelength of $635 \mathrm{~nm}$. It was held fixed and aligned so that its beam ran parallel to the aluminum plate and perpendicular to the direction of travel of the sliding table. The camera was a standard $35 \mathrm{~mm}$ single lens reflex with a close up lens. In order to photograph the laser ray it was found necessary to work in a dark room with a dispersive medium. Various combination of dispersive media and exposure times were tried, but best results were obtained with smoke and a 10 seconds exposure time. The smoky atmosphere was created using "Joke Smoke Bombs".

The experimental procedure was the following. The incidence angle was fixed by means of the rotary table and a center line drawn on the aluminum table. A $10 \mathrm{sec}$. exposure was made in this position. The sliding table was then moved $l$ inch and a $10 \mathrm{sec}$. exposure was made on the same film. This procedure was repeated until the complete collector aperture had been covered.

B. Discussion of Results

1. Segments with no encapsulation

Figures $5.3,5.4$ and 5.5 are photographs of the concentrator model with no encapsulation tubes around the mirror segments. These are for incidence angle $\theta_{i}$ of $0^{\circ}, 9^{\circ}$ and $11^{\circ}$, respectively. For $\theta_{i}=0^{\circ}$ the effect of the linear segments on light collection appears to be neglegible. At $\theta_{i}=9^{\circ}$ $\left(\theta_{i}=\theta_{C}\right)$ some of the light reflected by the segments on the 
Figure 5.3

MULTIPLE EXPOSURE PHOTOGRAPH OF LASER LIGHT INCIDENT AT $0^{\circ}$ WITH NO ENCAPSULATION TUBES 


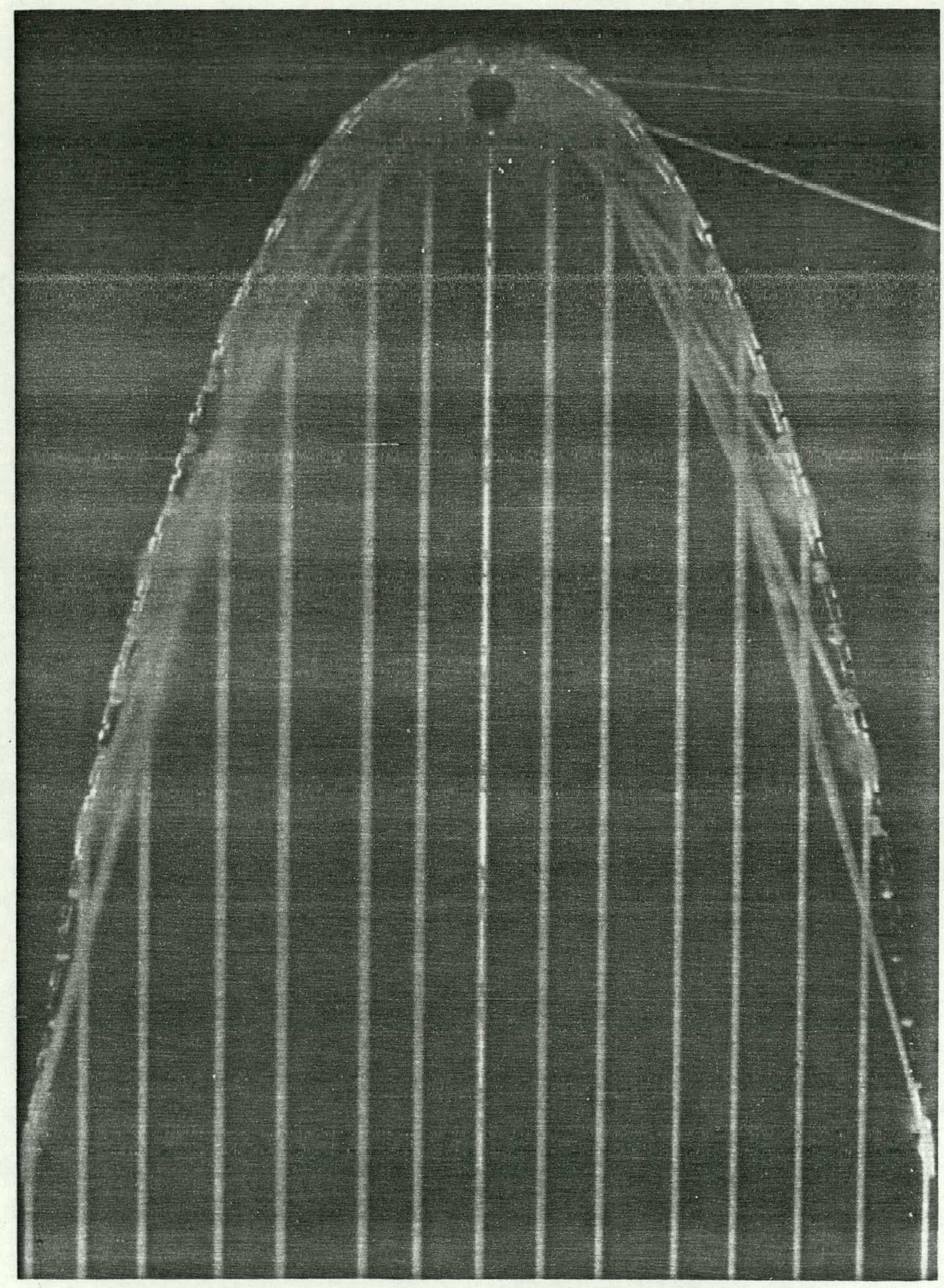


Figure 5.4

MULTIPLE EXPOSURE PHOTOGRAPH OF LASER LIGHT

INCIDENT AT $9^{\circ}$ WITH NO ENCAPSULATION TUBES 


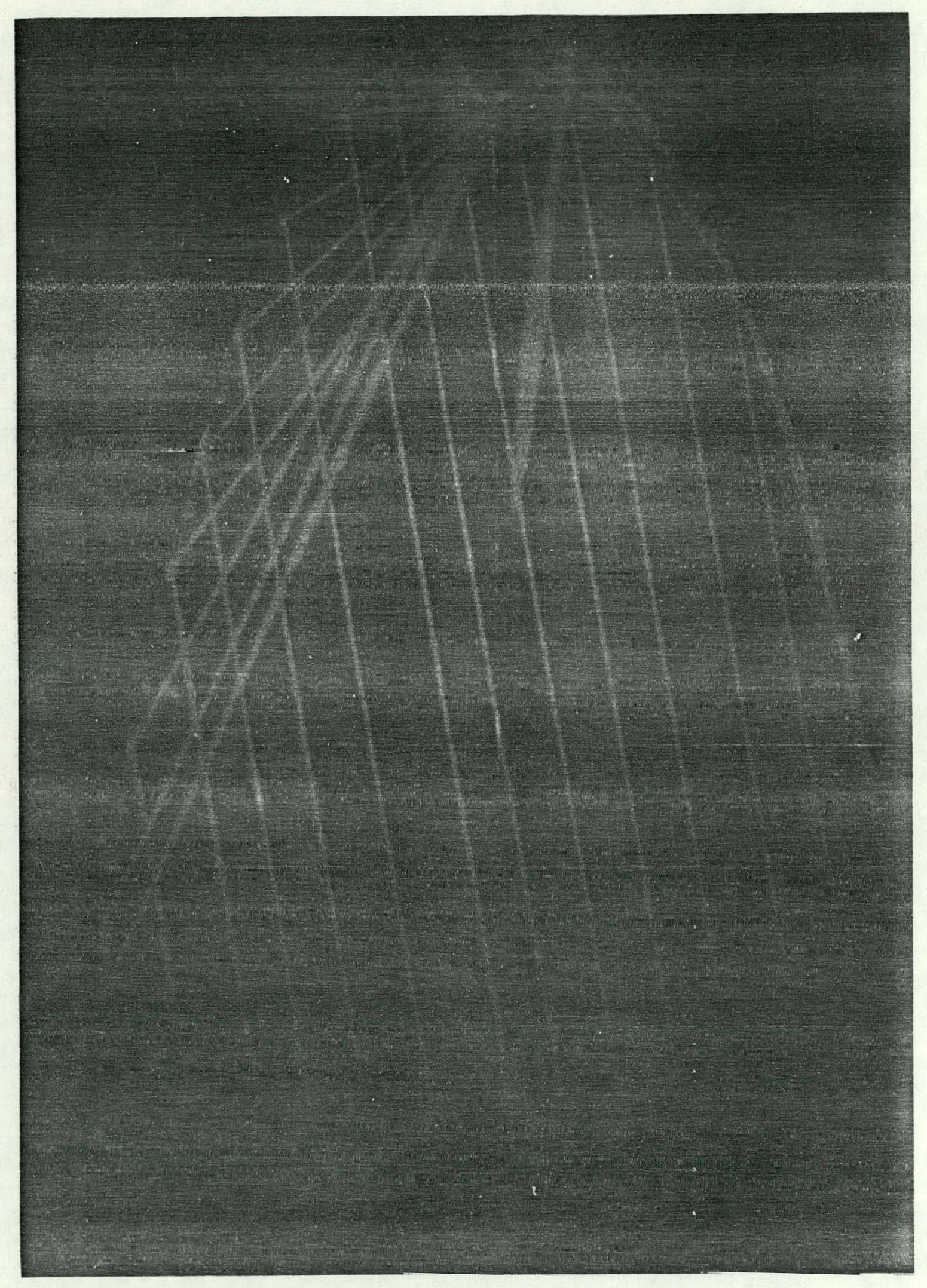


Figure 5.5

MULTIPLE EXPOSURE PHOTOGRAPH OF LASER LIGHT INCIDENT AT $11^{\circ}$ WITH NO ENCAPSULATION TUBES 


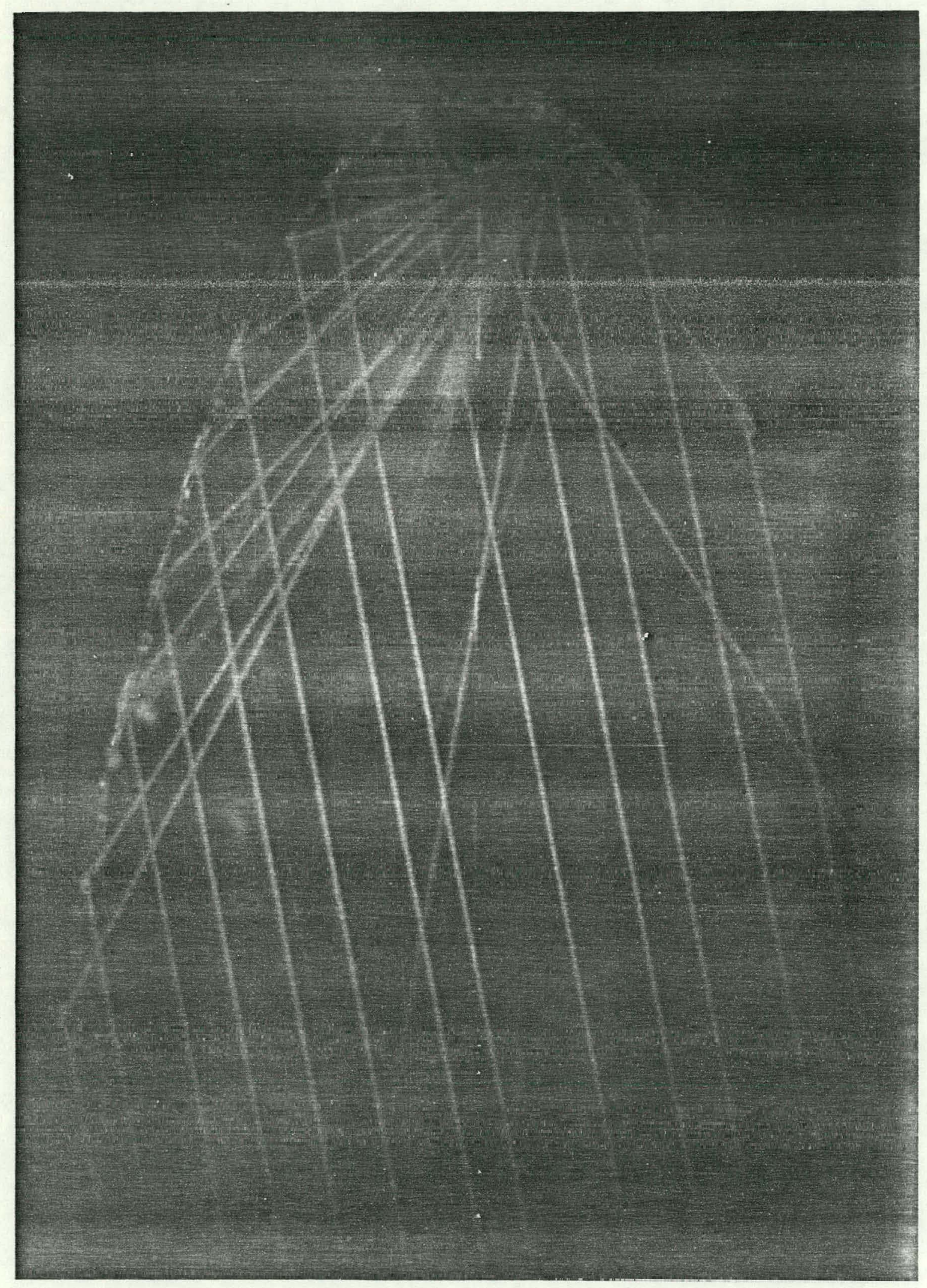


lower part of the mirror surface is not intercepted by the absorber. In this section the radius of curvature changes appreciably within the width of a segment and linearisation is not a good approximation to the theoretical contour. At $\theta_{j}=$ $11^{\circ}$ most of the rays are defocussed and escape the absorber. This is in agreement with the theoretical expectation for any incidence angle $\theta_{i}$ larger than $\theta_{C}$. In summary it can be concluded that although linear segmentation causes some defocussing, overail losses are not expected to be of significance.

2. Segments with Encapsulation

Figure 5.6 shows, on the left, the glass tubes used to model encapsulation tubes. These were of the same height as the mirror segments with an inside diameter of $0.945^{\prime \prime}$ and a wall thickness of $0.035^{\prime \prime}$.

Figures $5.7,5.8$, and 5.9 show the effect of these tubes on the incoming 1 ight. They were taken at the same incidence angle as shown in photographs 5.3 to 5.5 . The presence of the tubes introduces two new phenomena: First, the 1 ight after a pass through a mirror-tube pair is diffused. Second, a large fraction of the light appears to be "trapped" or "light piped" around within the walls of the tubes (see bright rings on Figure 5.8). Both phenomena reduce the thruput appreciably. The amount of light lost in either case is a matter of concern, but above method does not give quantitative results. A method of obtaining quantitative experimental data of the amount of light lost due to encapsulation is now 
Figure 5.6

MIRROR SEGMENTS OF EXPERIMENTAL MODEL WITH AND WITHOUT ENCAPSULATION TUBES 


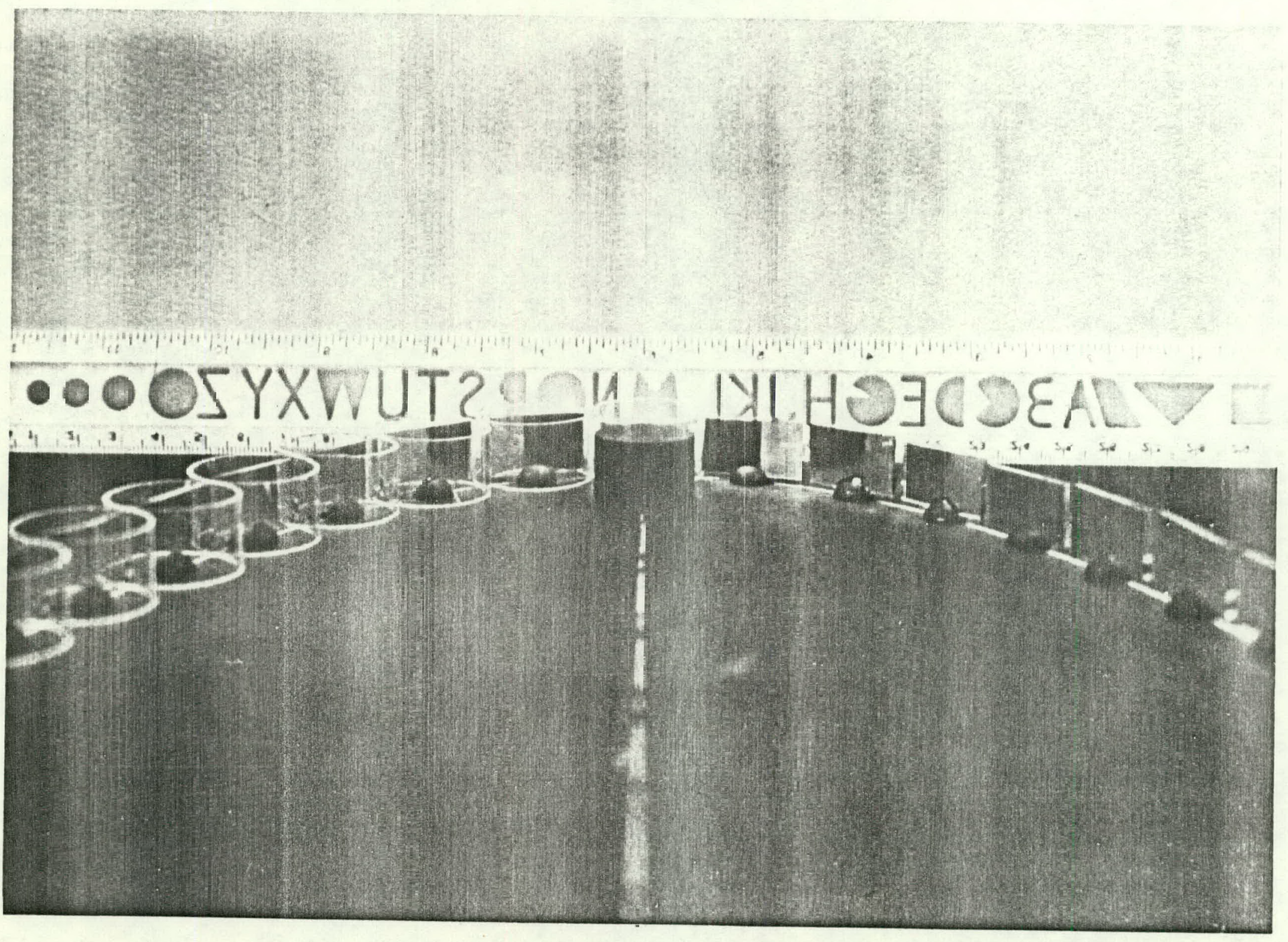


Figure 5.7

MULTIPLE EXPOSURE PHOTOGRAPH OF LASER LIGHT INCIDENCE AT $0^{\circ}$ WITH ENCAPSULATION TUBES 


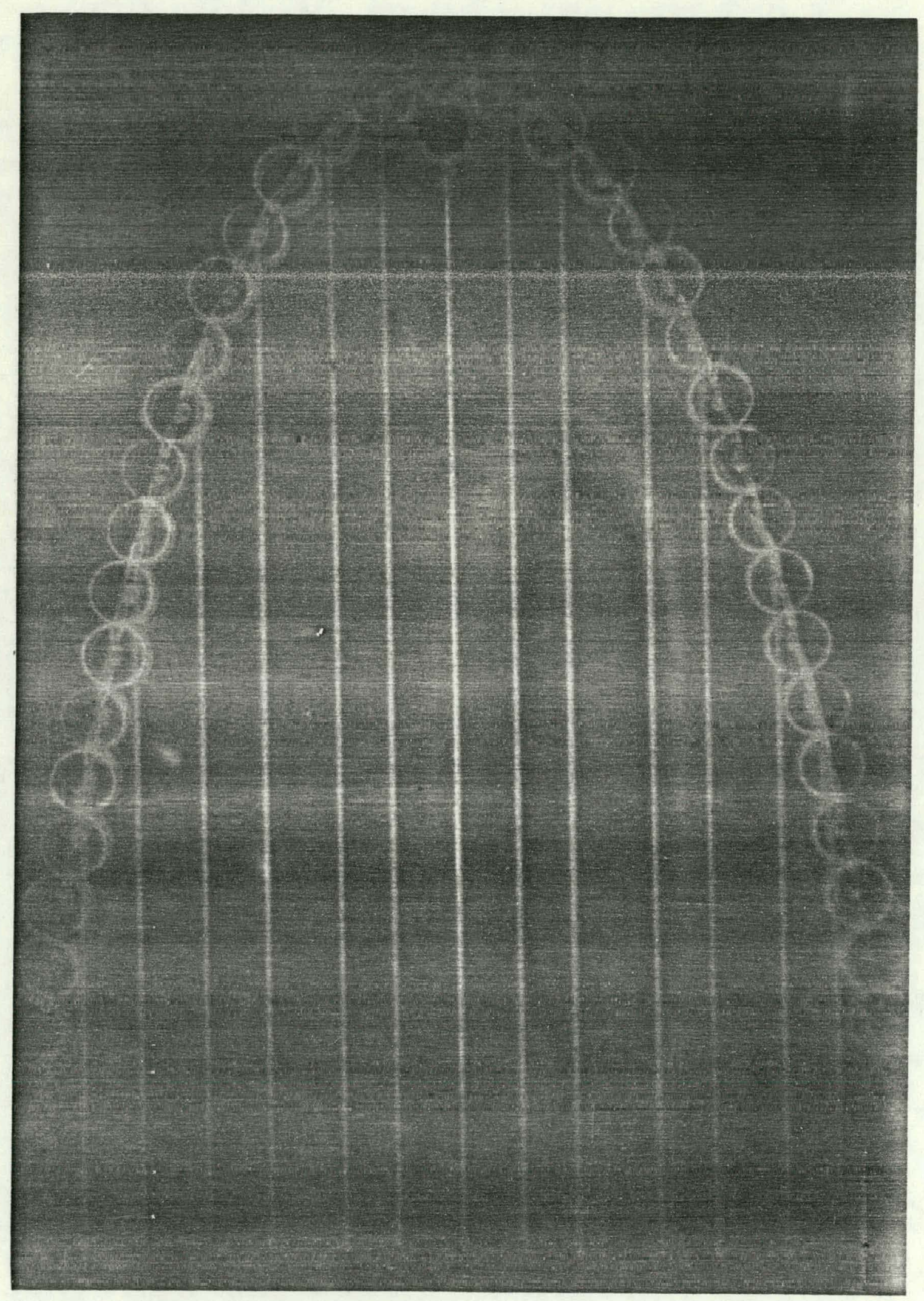


Figure 5.8

MULTIPLE EXPOSURE PHOTOGRAPH OF LASER LIGHT INCIDENCE AT $9^{\circ}$ WITH ENCAPSULATION TUBES 


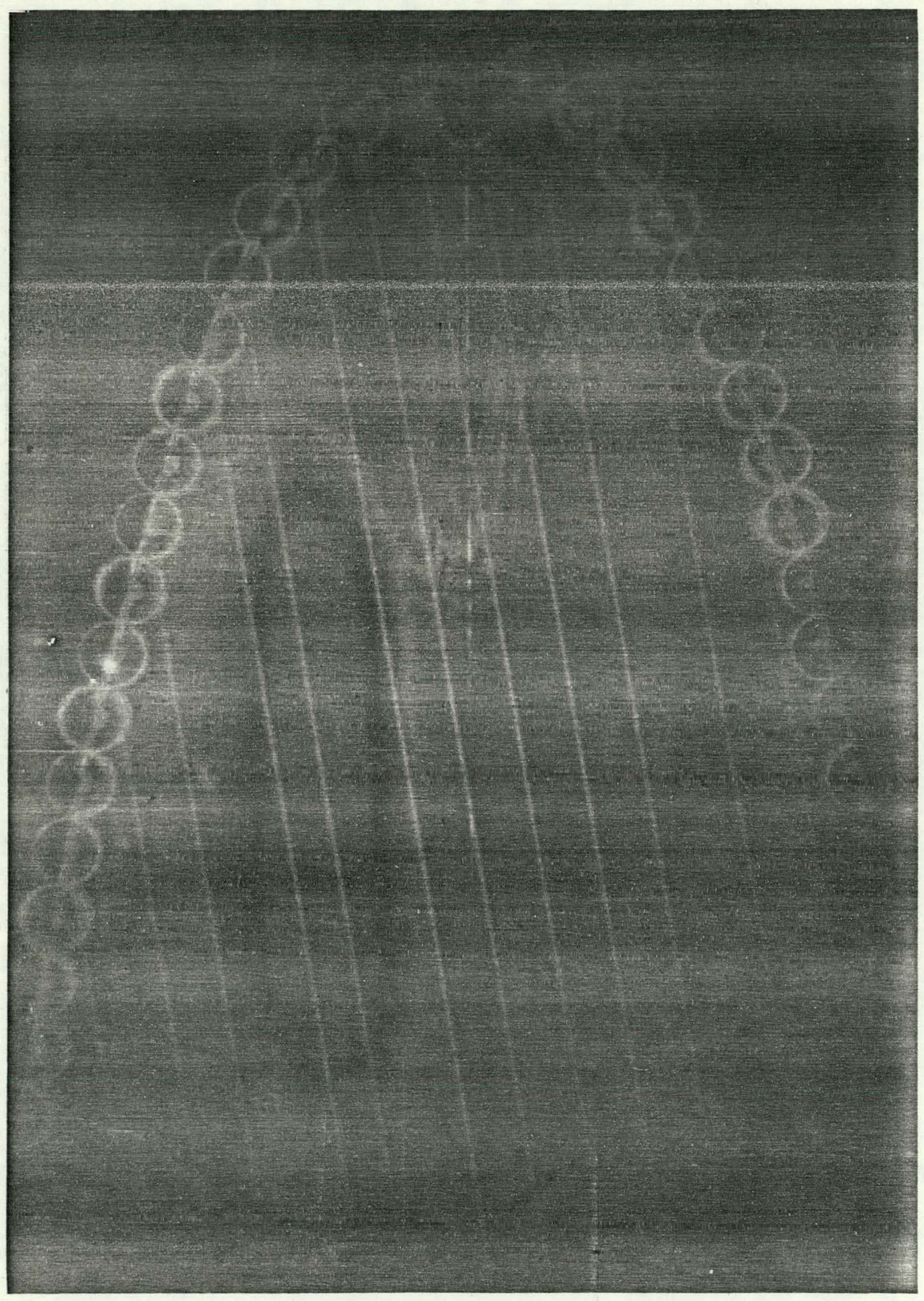


Figure 5.9

MULTIPLE EXPOSURE PHOTOGRAPH OF LASER LIGHT INCIDENCE AT $11^{\circ}$ WITH ENCAPSULATION TUBES 


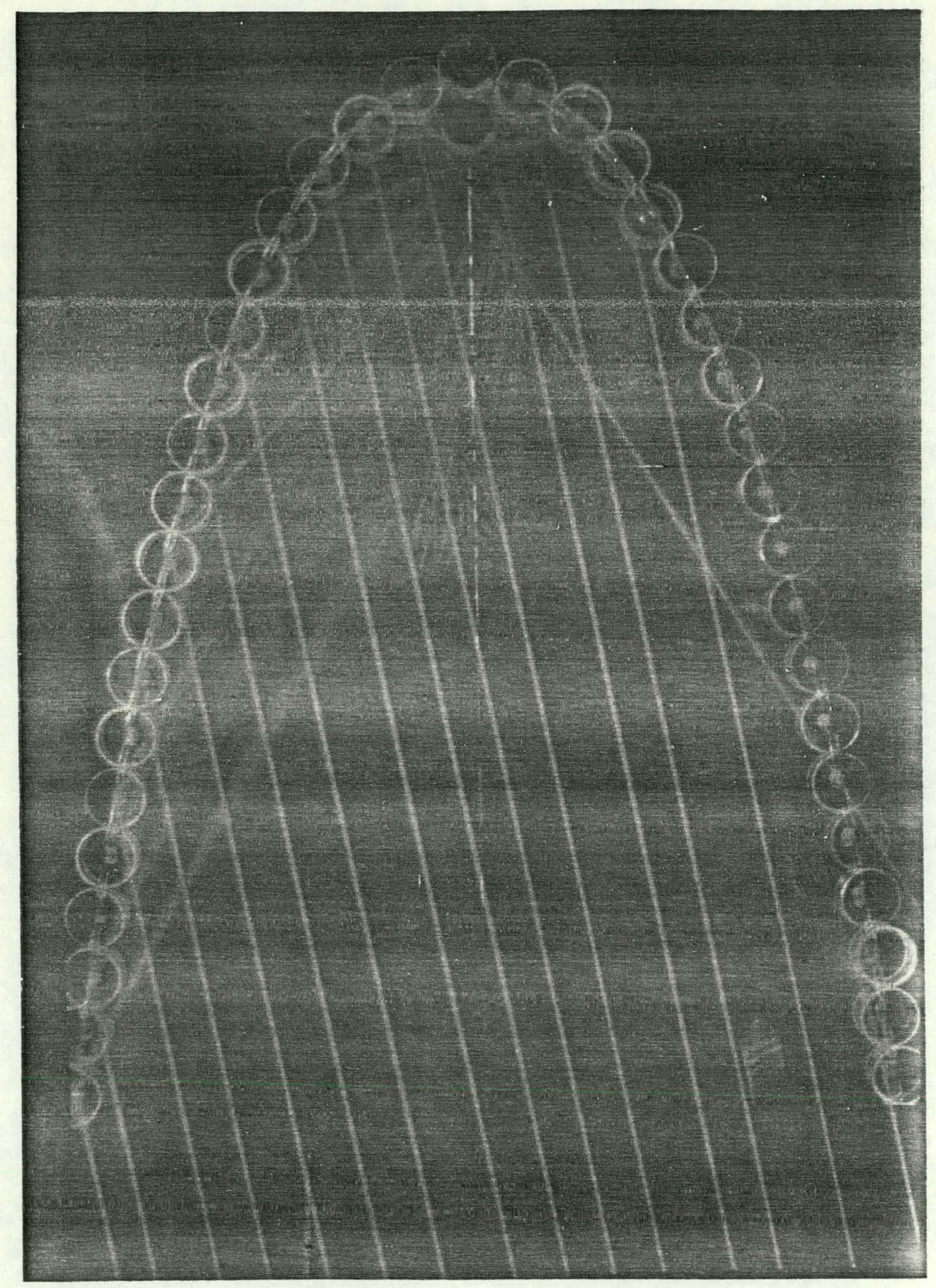


be:ing developed by C'EER.

At this point it is conceivable that antireflective coating of the tubes may turn out to be necessary. The cost involved in the antireflective coating of the tubes by the well known etching method is small and should not alter too much the economic atractiveness of this concept. 


\section{CHAPTER VI}

\section{DESIGN AND CONSTRUCTION OF THE PROTOTYPE}

The major design components of the linearly segmented compound parabolic concentrator under consideration are shown in photographs: in Figures $6.7,6.2$ and 6.3 . These are the evacuated tubular receiver, the segmented encapsulated mirror and collector frame, respectively. The evacuated tubular receiver was built by Corning Glass Works according to design specifications by CEER.

\section{A. Manufacturing of Mirror Units}

A major part of the effort in the construction of the prototype went into developing and building the segmented mirror. Figure 6.4 illustrates the final design of the mirror units. Plexiglass plastic (1/8" thick) was chosen as the material for the mirror substrate. Major considerations in this decision were: light weight, easy machining and smoothness of the surface. The plexiglass was cut into strips $7 \mathrm{ft}$. long and $115 / 16$ in. wide to be fitted into the fluorescent tube blanks.

With regard to the reflective surface it was decided to use a commercially available mirrorized film to be mounted on the substrate chosen.

However, finding a suitable reflective film and a method of bonding to the plexiglass was a major problem. Much effort was spent in trying to bond 200 nun-Chrome $R$, DL-50 metallized polyester film (Dunmore Corp., Newtown, Penn.) to the plexiglass 
Figure 6.1

EVACUATED TUBULAR RECEIVER 


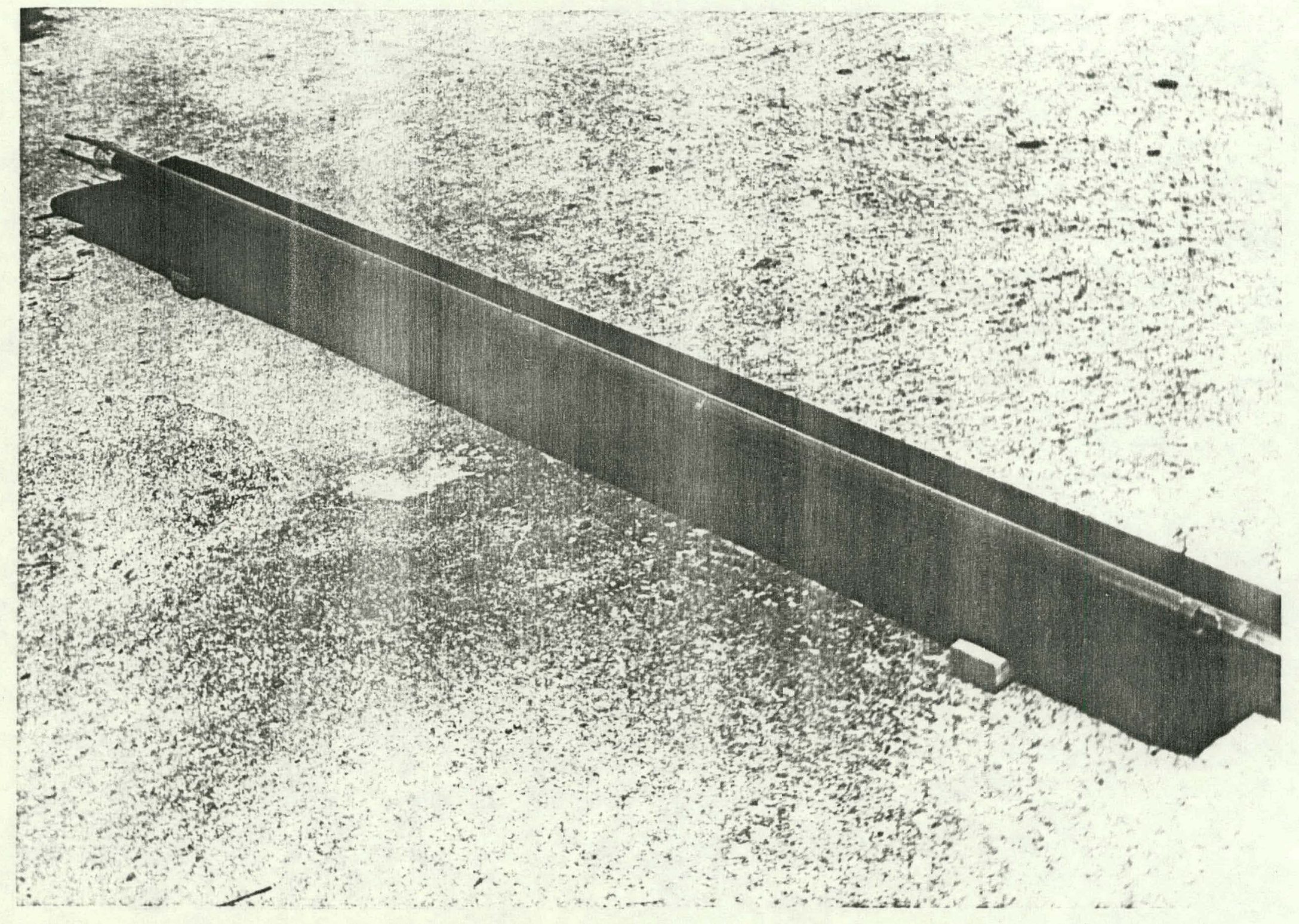


Figure 6.2

\section{ENCAPSULATED MIRROR SEGMENTS}




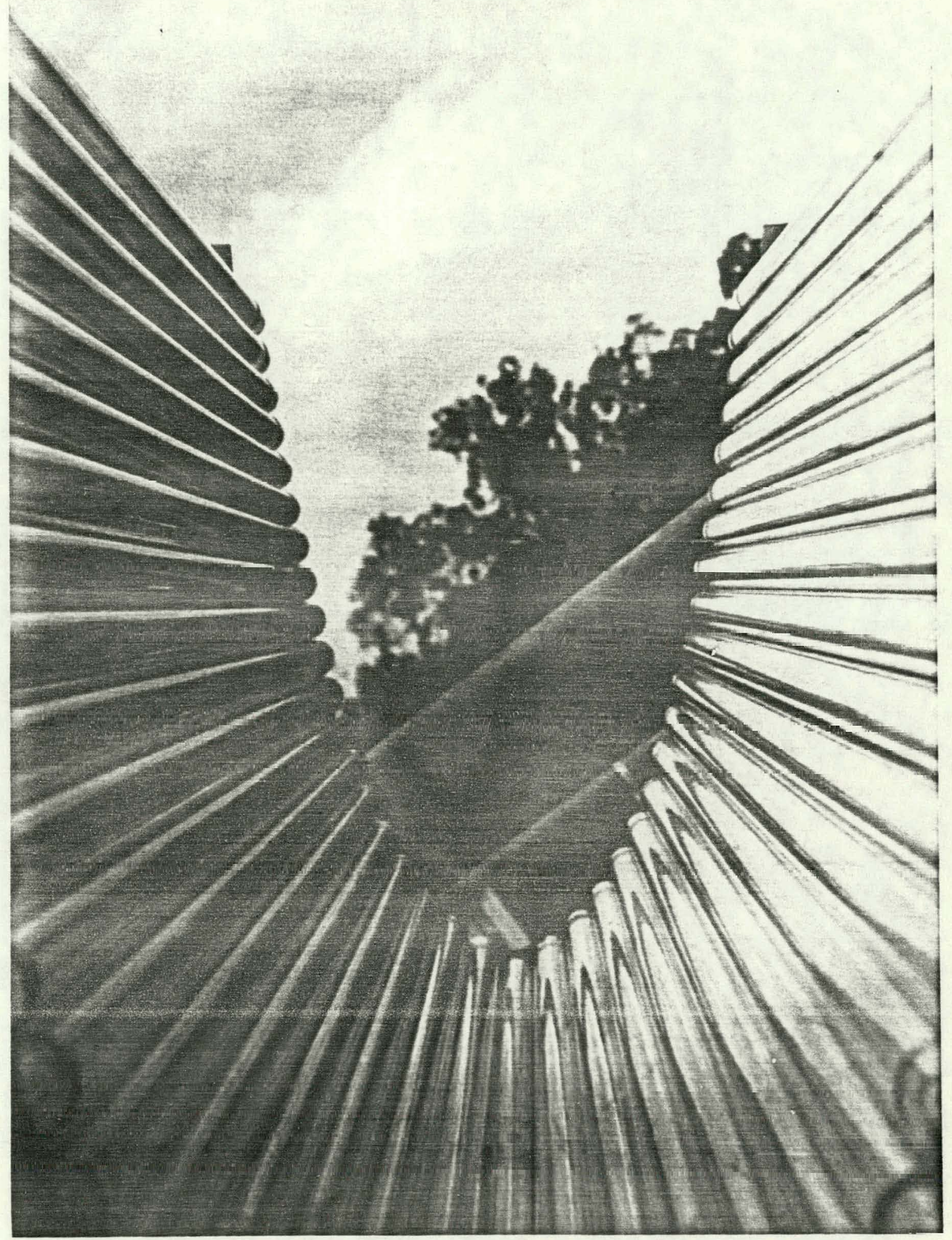


Figure 6.3

COLLECTOR FRAME 


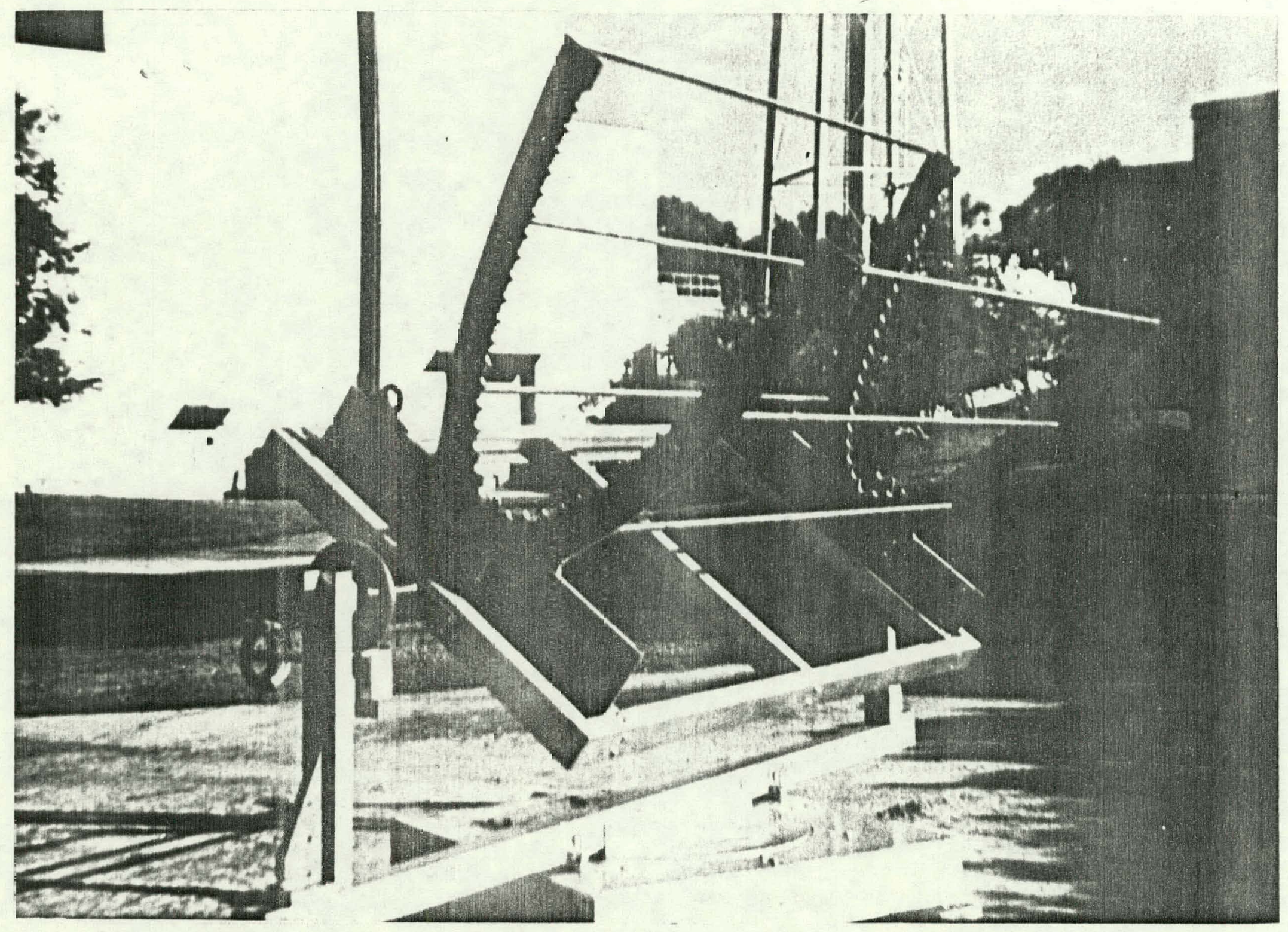


Figure 6.4

SCHEMATIC FOR MIRROR TUBE DESIGN 


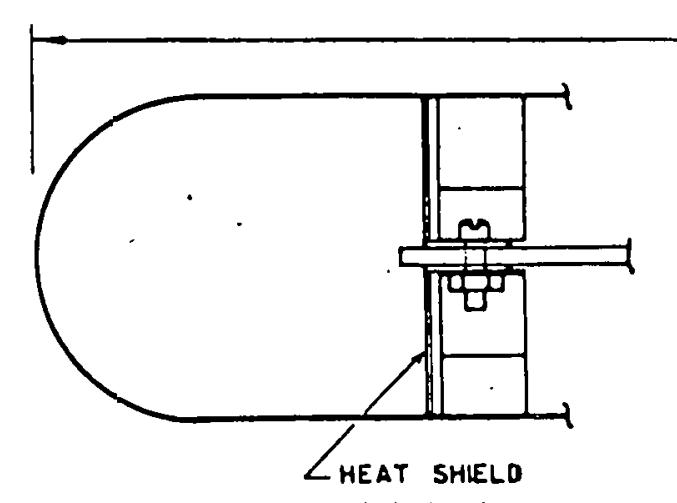

(Aloniman)

-
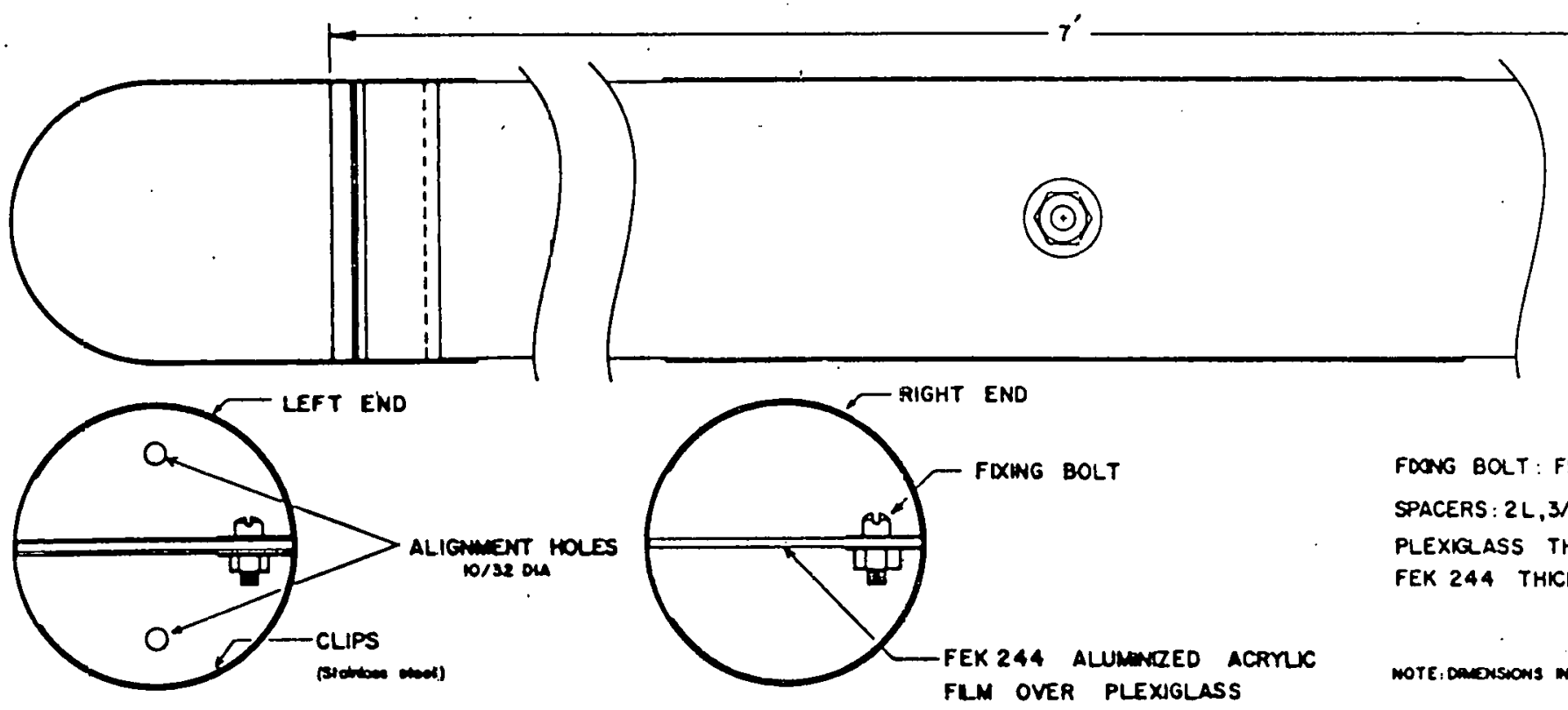

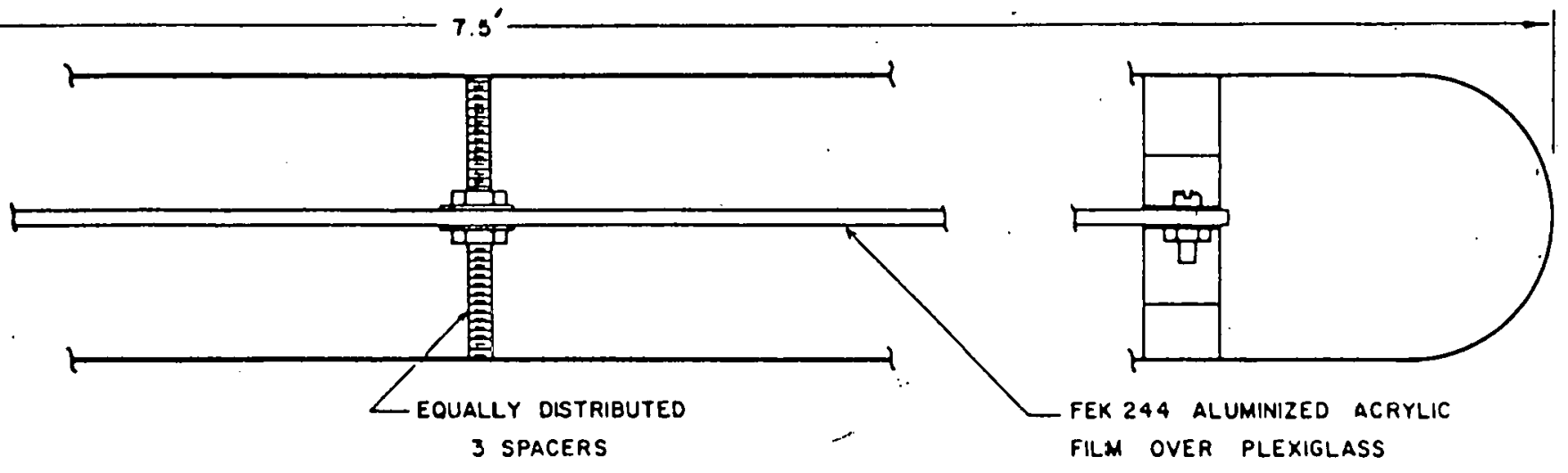

WOTE, DMONSHOW' W MCHES EXCEPT OTMERMSE MOTEO

FDONG BOLT: FILLSSTER HEAD, 0.42L, VBOIA, 16 UNF

SPACERS : $2 L, 3 / 16$ DIA, 24 THRS

PLEXIQASS THICKNESS: $1 / 8$

FEK 244 THICKNESS : 4 MLS

SCALE: $2: 1^{\circ}$ 
with unsatisfactory results. Best results were obtained with 3M's "Scothcal" Brand Film FEK-244, a 0.004" thick aluminumon-acrylic film with $86 \%$ spectral reflectance. This film has a pressure-sensitive adhesive backing and provides stable and smooth layer when applied to the plexiglass substrate.

The encapsulation tubes are flourescent tube blanks obtained from Corning Glass Works. These have an outside diameter of $2.08^{\prime \prime}$ and a wall thickness of $0.035^{\prime \prime}$. The diameter is estimated to have a tolerance of $\pm 0.010^{\prime \prime}$.

The mirror segments are held inside the glass tubes by spring clips at the ends. In order to prevent undue sagging of the mirror, it was found necessary to attach three screw spacers at equal intervals along its length. A metal heat shield was also attached to prevent damage to the mirror when the glass tube was being closed off. After attaching clips, spacers and shields to the mirror, the segment assembly was inserted inside a glass tube (Figure 6.5). The mirror was then checked for possible twisting of the mirror segment. This was done by observing the reflections of a laser beam from the mirror at different points along its axis (Figure 6.6). Since one end of the mirror was accessible it was possible to correct for large twists. The maximum allowable twist of one part of the mirror with respect to any other section was $1^{\circ}$.

Originally it had been planned to close off the glass tubes after they had been evacuated at an elevated temperature and filled with a dry gas (nitrogen). The idea was to eliminate as much 
Figure 6.5

MIRROR ASSEMBLY 


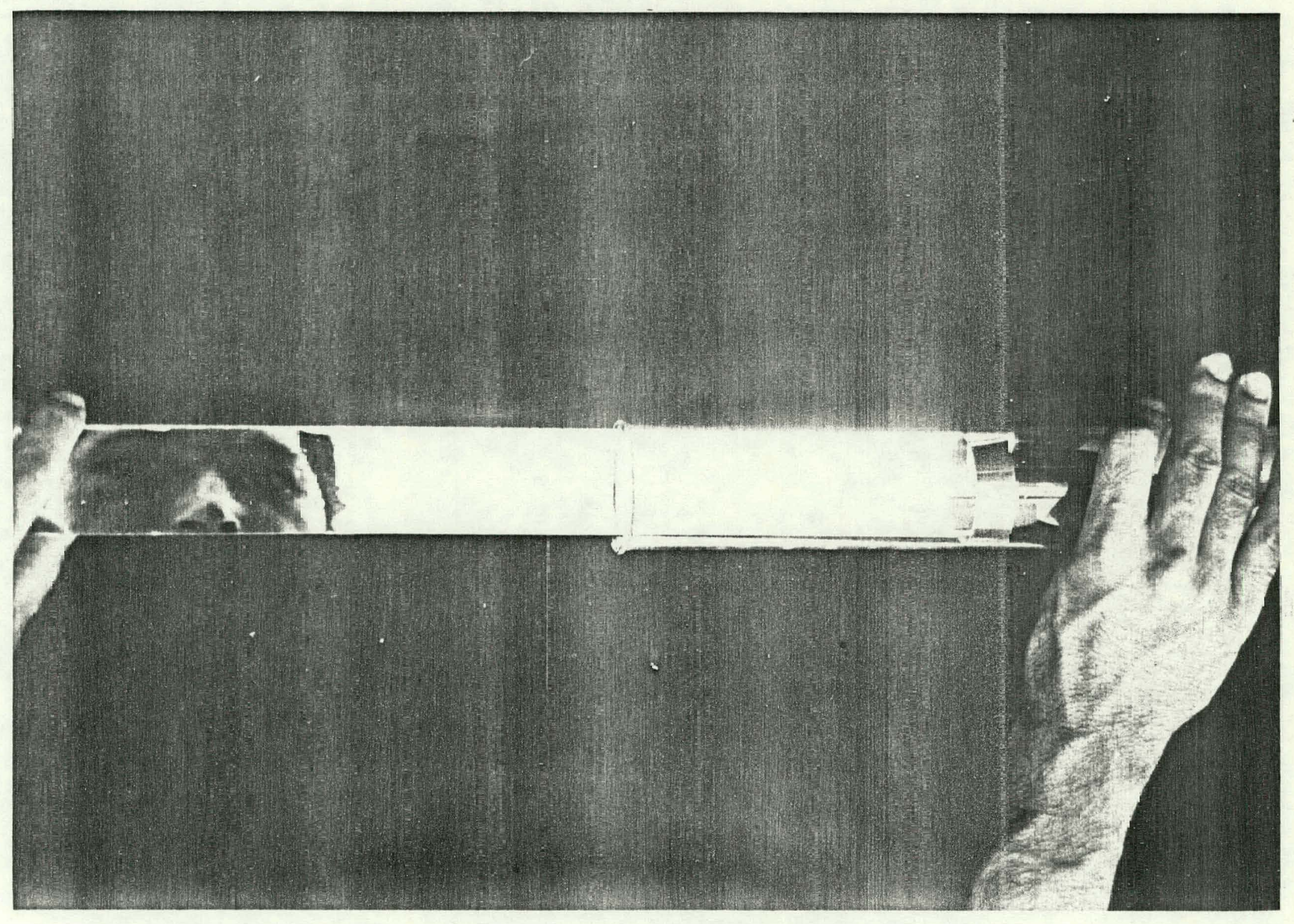




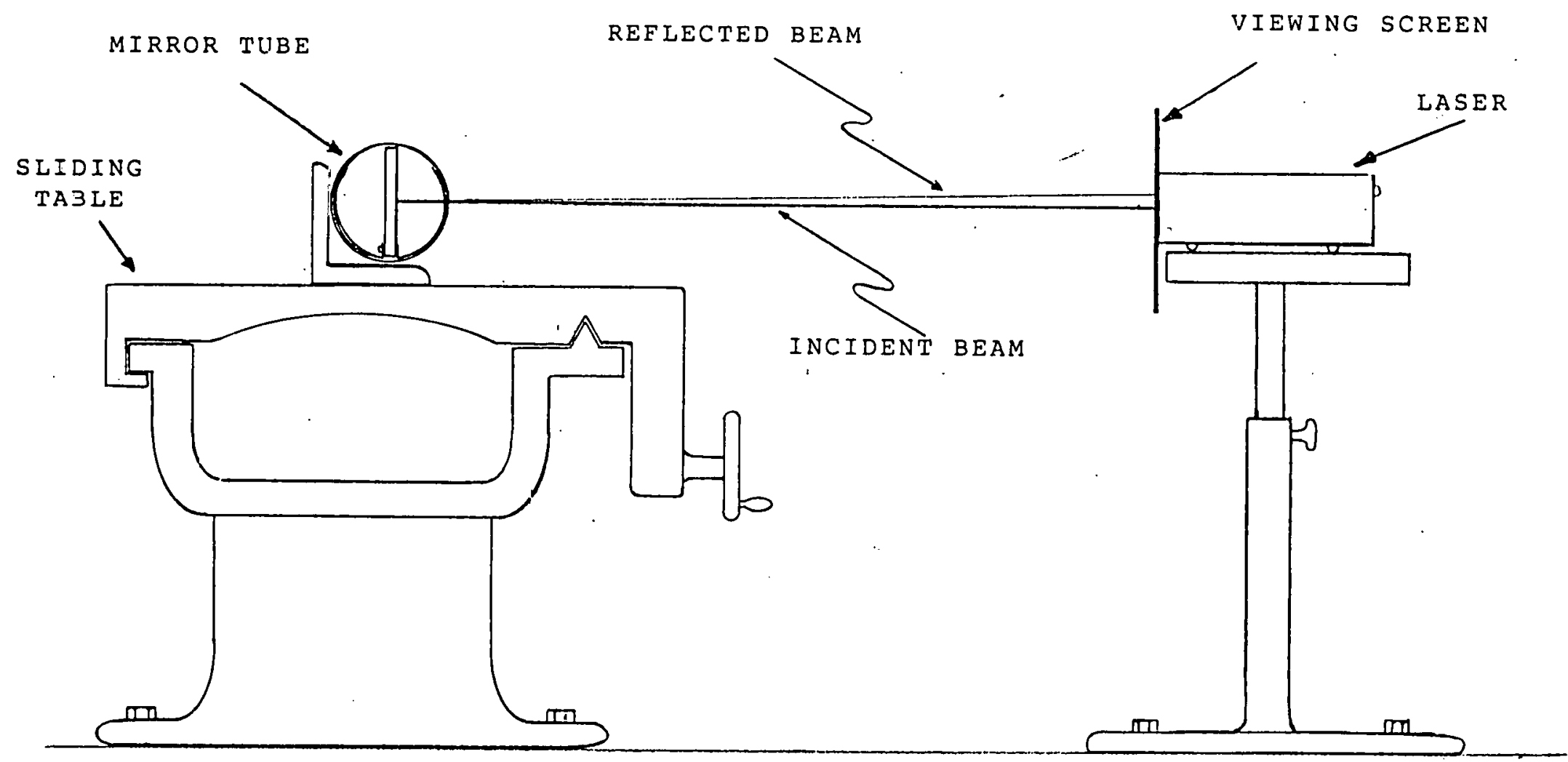

\section{Figure 6.6}

SCHEMATIC OF THE METHOD FOR MEASURING TWISTS OF THE MIRROR ASSEMBLY

The sliding table moves the mirror tube along its length (i.e. perpendicular to the view shown). Any change in the position of the reflected beam as the sliding table moves is an indication of twist. 
moisture as possible from the inside of the tubes. An oven was built and it was determined that the mirrors could withstand $100^{\circ} \mathrm{C}$ without apparent damage. However, when the tubes were evacuated to a pressure of 500 microns of $\mathrm{Hg}$. at $100^{\circ} \mathrm{C}$, immediate damage to the adhesive bond resulted. Finally, it was decided to abandon the evacuation procedure. Tubes were closed off in an air conditioned room. A room dehumidifier brought the relative humidity down to $50 \%$ at $75^{\circ} \mathrm{F}$ which corresponds to a ratio of moisture to dry air of $1.0 \%$ by weight.

Another important problem encountered in the construction of the tubes was the frequent breakage and cracking of the glass at stress points (seals). Since the temperature of the mirrors could not be raised, it was not possible to do oven annealing to relieve these stresses. This problem was alleviated considerably when the evacuation procedure was abandoned. It seems that a large part of the problem was due to differences between the nitrogen pressure inside and atmospheric pressure outside. This resulted in uneven tips which eventually cracked.

\section{B. Collector Frame}

The collector frame (Figure 6.3) may be divided into two parts: the tracking frame (Figure 6.7) and the support structure:for the tubes. (Figure 6.8).

The basic dual axis tracking frame design, developed by the University of Chicago, was altered to increase strength of the overall structure. The modification lead to a more stable and simplified design. 


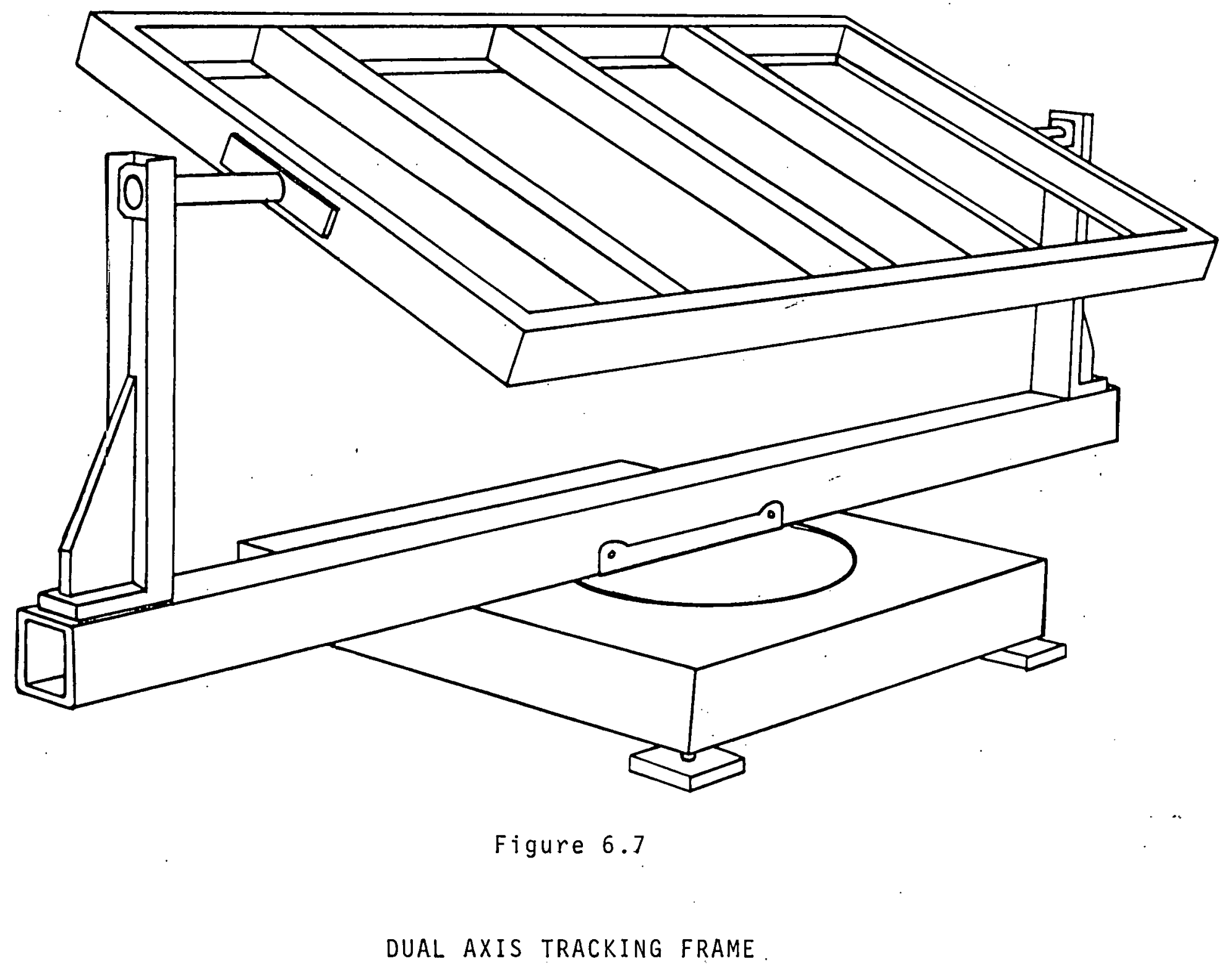

DUAL AXIS TRACKING FRAME

$\infty$ 


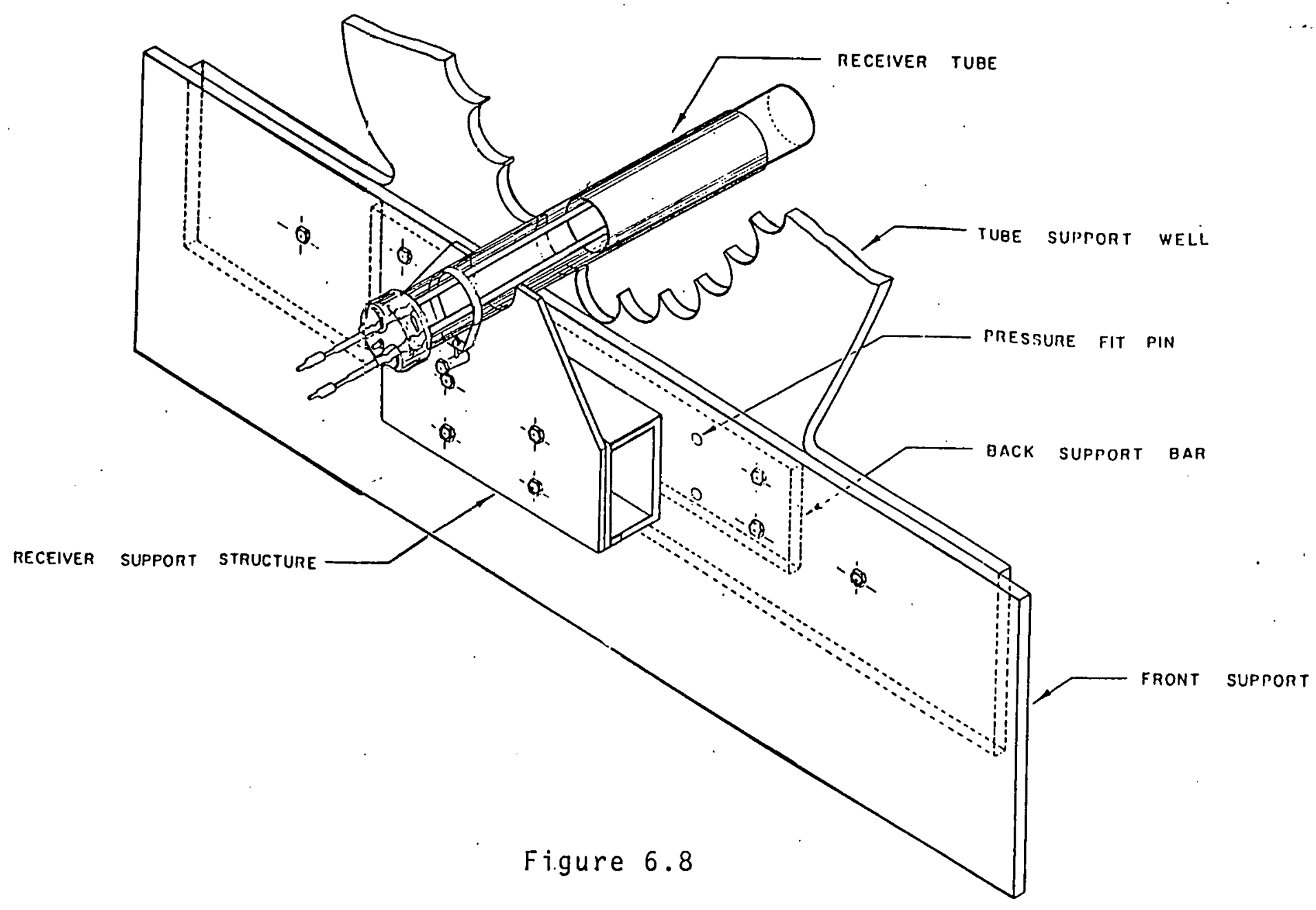

SUPPORT STRUCTURE FOR MIRROR AND ABSORBER TUBES 
In order to measure the collector's tilt angle, two bubble levels with protactor assemblies were installed at each end of the collector frame. The accuracy of the angle measurements was estimated to be in the order $1 / 4^{\circ}$.

Major efforts on the collector frame went into designing and building the support structure for tubes which is shown in detail in Figure 6.9. The limiting factor in this design, as well as in the tracking frame, was rigidity. Since glass is a very brittle material, any torsional or linear deflection could damage all the mirror tubes.

A computer program was developed to calculate the theoretical shape of the reflector surface (see Appendix E). Using the results from the program, the tube wells were precisely machined. Four identical pieces (each was one half a well) were machined simultaneously by stacking them. The raw material for the wells were four pieces of $1 / 2$ " aluminum, 20" wide and 48 " long. The circular holes that hold the tubes have a diameter of 2.09". The straight line distance between circles is $2.11 "$ to allow for the metal bands that grip the tubes. After the tube holes had been machined, excess material was removed to make the structure lighter. The tube holes thus became open semicircles.

Two halves of a well were held together by precisely machined pressure fit pins and by screws and nuts which joined them to the support bar. The pressure fit pins assured alignment to a high degree of precision. The receiver tube is 


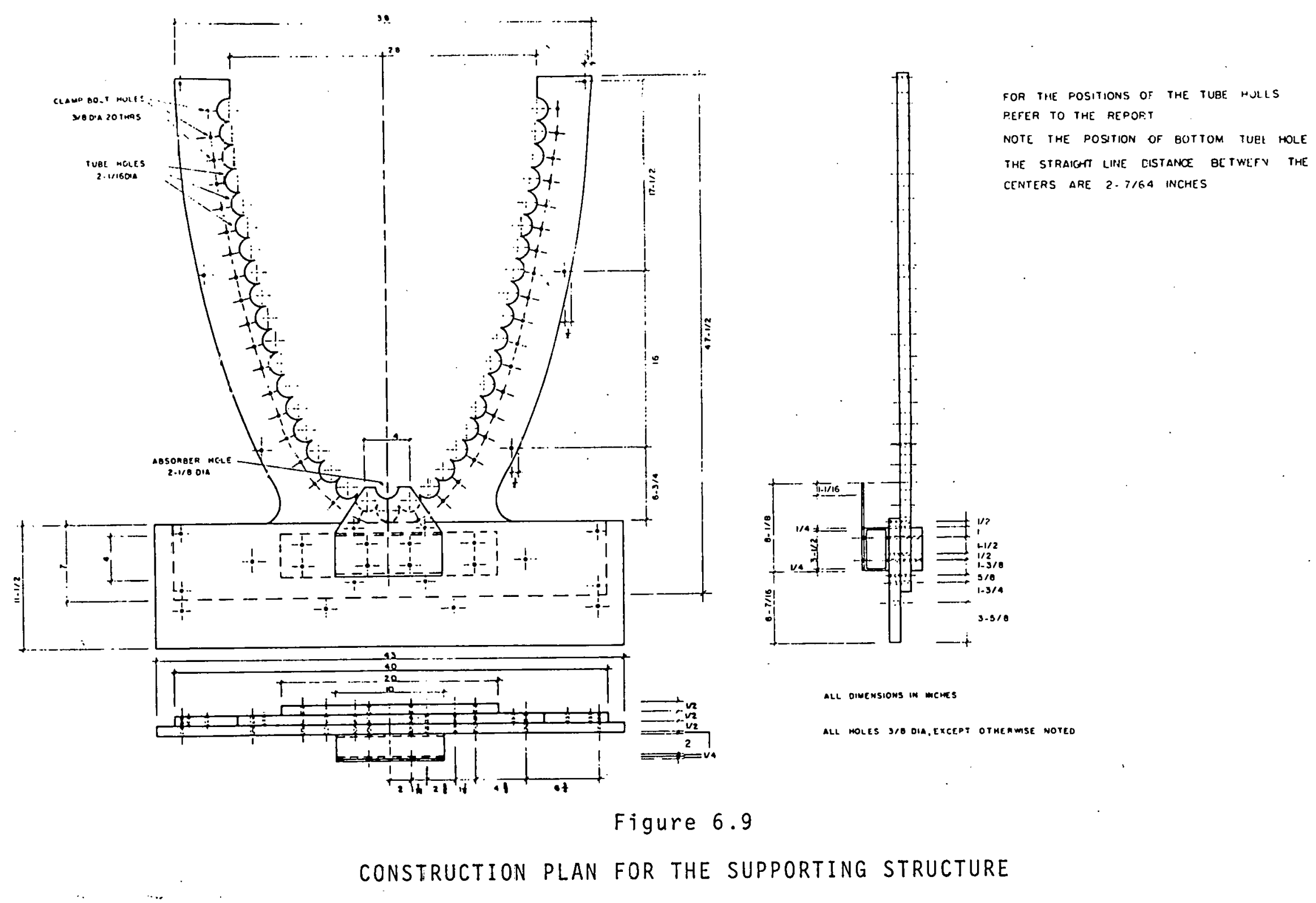


supported by a structure that allows space for the mirror tubes that are close to the receiver. Figure 6.8 shows the support bar and the structure which holds the receiver tube. The mirror tube wells are fastened to cross support members of the frame. Six aluminum bars join the tube wells to each other. These add much rigidity to the structure and the increase in overall weight is neglegible.

The structure for fastening the glass tubes to the wells is shown in Figure 6.10. It consists of a stainless steel band which is pulled tight by a screw which runs through a bolt fastened to the frame. The bands are placed in tandem so that bands from neighboring tubes do not touch each other. Thus the distance between mirror segments is reduced.

C. Final Collector Assembly and Adjustment

The assembly of the collector was rather simple, once all the major system components were completed. As previously stated it is of outmost importance to have a very rigid structure before any glass tubes are fastened to the frame. To prevent cracks due to minor movements or deflecting of the frame a very thin film of silicon sealer is applied to form a layer between the aluminum semicircle and the glass tube. All elements (segments) of the mirror surface are identical and interchangeable with the exception of the bottom tube of the cusp. This is a special tube that contains an inverted "V" shape mirror and is held in place by the surrounding tubes and the 


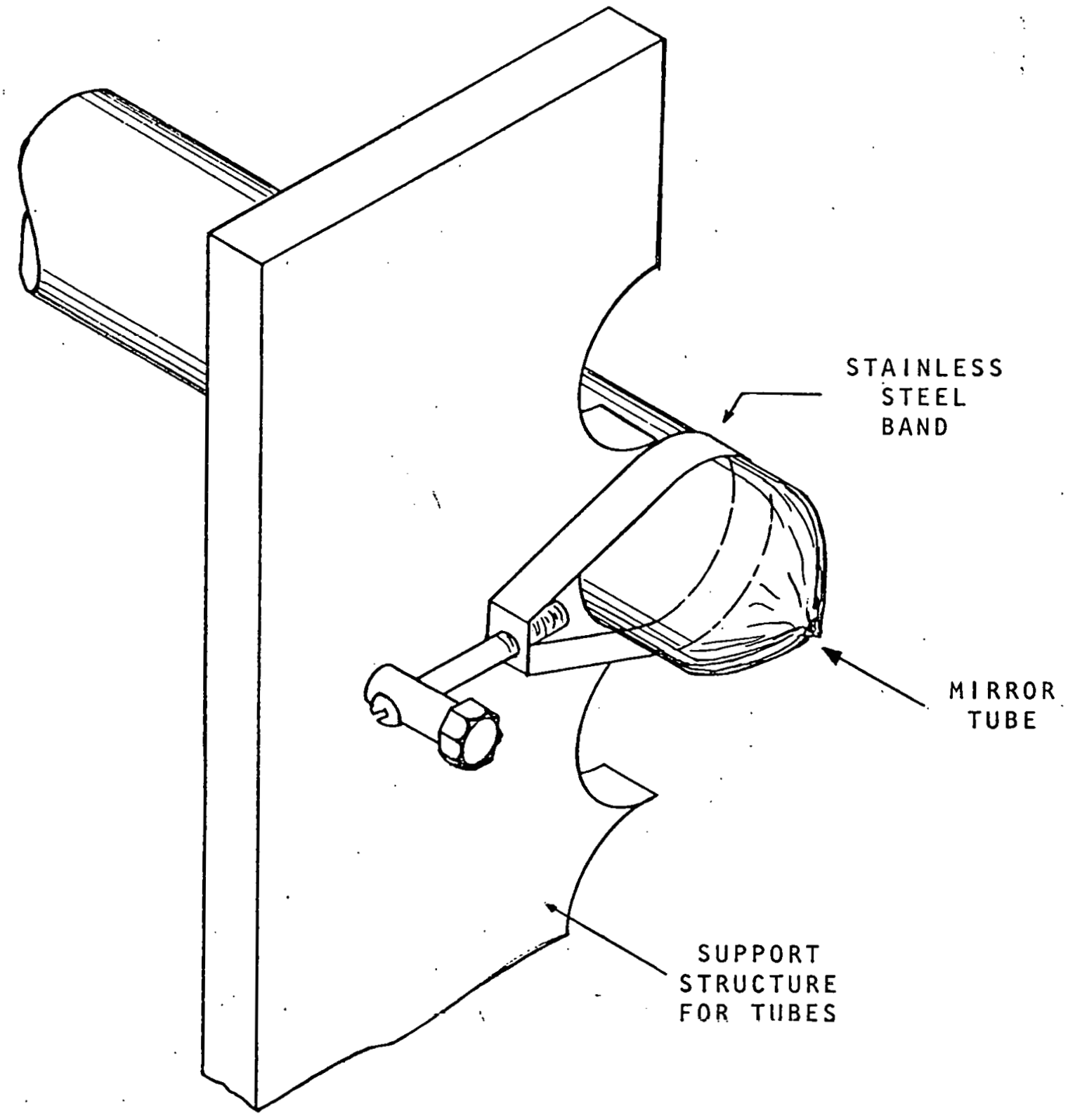

Figure 6.10 
absorber tube.

Once the tubes are mounted on the supporting structure, it is necessary to adjust each mirror tube to a position that approximates the theoretical contour of the CPC shape. This was done by applying the Edge Ray Principle on each mirror segment of the collector. Figure 6.11 shows in schematic form how each mirror was adjusted to its optimum position. A laser beam entering to the collector aperture at an angle $\theta_{c}\left(9^{\circ}\right.$ for the prototype) hits at the center of the mirror segment. The tube is turned until the reflected ray passes tangentially to the absorber surface.

Figure 6.12 presents the collector assembled and properly adjusted. Since the photograph was taken at the acceptance angle, all the mirrors look somewhat black. Note that the mirrors near the absorber tube are darker meaning that this portion of the mirror is less affected by the segmentation of the mirror surface. 


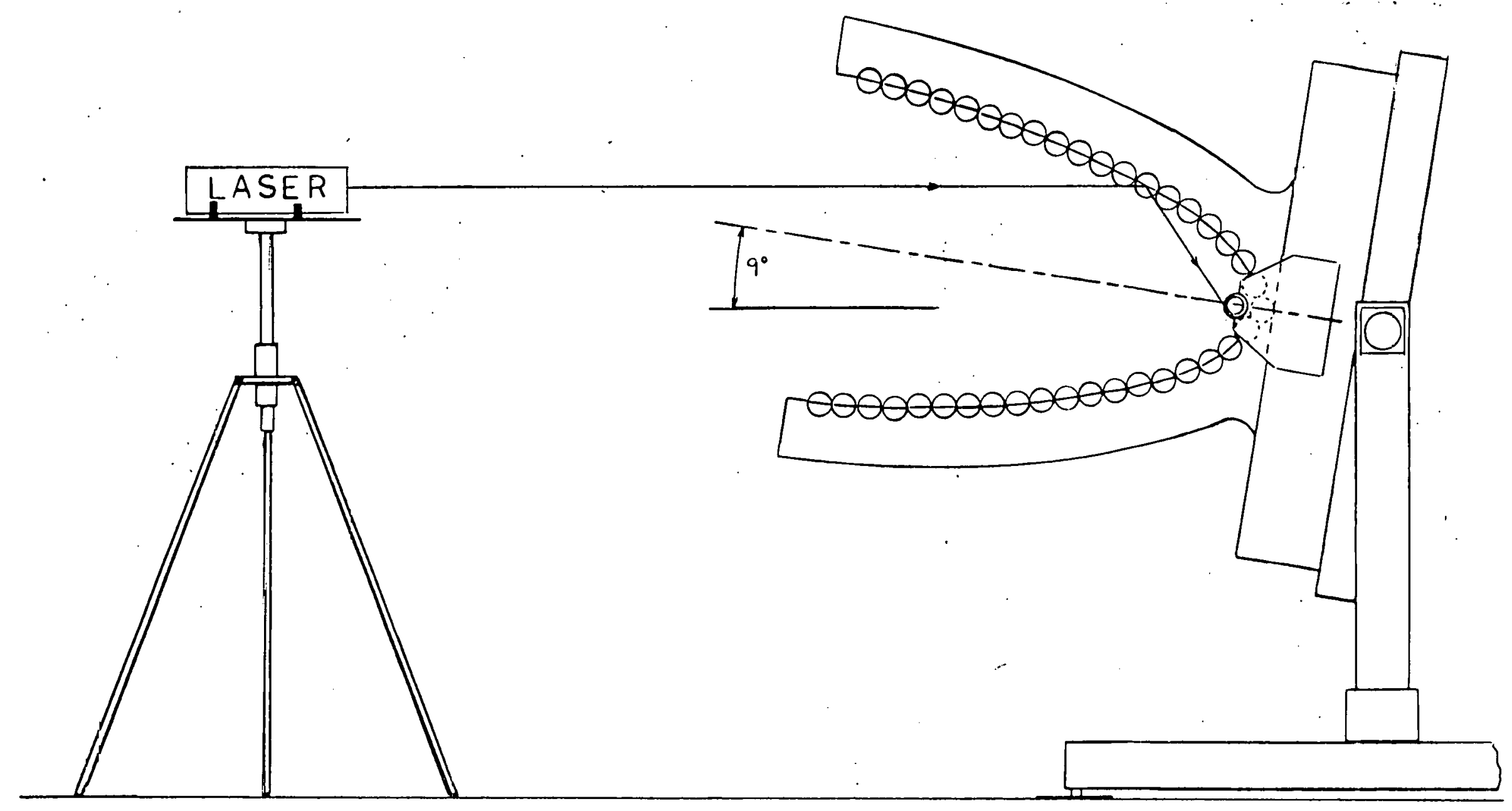

Figure 6.11

SCHEMATIC OF THE METHOD FOR ADJUSTMENT OF THE MIRROR TUBES 
Figure 6.12

SEGMENTED CPC PROTOTYPE 


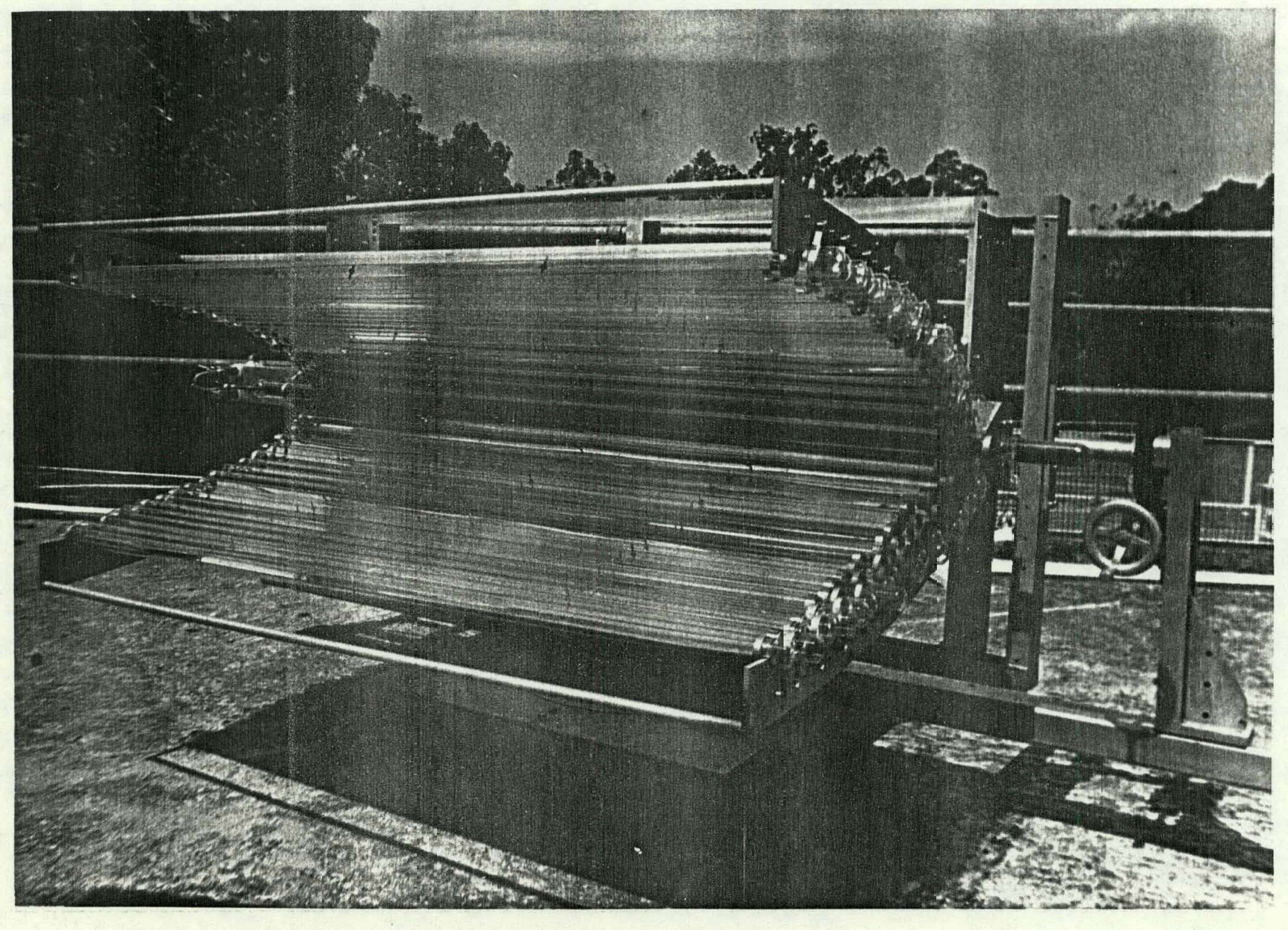


CHAPTER VII

\section{PRELIMINARY EFFICIENCY TEST}

The efficiency of a solar collector operating under steadystate conditions can be described by the relationship

$$
\eta=F^{\prime} \tau \alpha-F^{\prime} U_{L} \frac{T_{f}-T_{a}}{I}
$$

where

$$
\begin{aligned}
n= & \text { solar collector efficiency } \\
F^{\prime} & =\text { collector efficiency factor } \\
\tau= & \text { transmittance of the glass cover } \\
\alpha= & \text { absorptance of absorber plate } \\
U_{L}= & \text { overall heat transfer coefficient } \\
T_{f}= & \text { average temperature of heat transfer fluid } \\
T_{a}= & \text { ambient temperature. } \\
I= & \text { total solar energy flux on the plane of the } \\
& \text { collector }
\end{aligned}
$$

In the CEER collector, the collector efficiency factor can be approximated by unity because of the excellent characteristics of the absorber tube related to this factor ${ }^{12}$. Then Equation 7.1 becomes

$$
\grave{n}=\tau \alpha-U_{L} \frac{T_{f}-T_{a}}{I}
$$

It is apparent from Equation 7.2 that for a fixed value of $U_{L}$, the efficiency plotted against the appropriate values of $\left(T_{f}-T_{a}\right) / I$, result in a straight line. In reality, $U_{L}$ will vary with the operating temperature of the collector. Equation 
7.2 also shows that optical efficiency $(\tau \alpha)$ is the intercept of the efficiency curve. This term can be determined.experimentally by measuring the efficiency at $T_{f} \approx T_{a}$.

Testing solar collectors for medium high temperatures (up to $550^{\circ} \mathrm{F}$ ) according to NBS standards requires very expensive and specialized equipment. A solar thermal test facility for evaluating performance of medium to high temperature solar collectors is now being designed and constructed by CEER ${ }^{13}$.

The standard efficiency test presented here, were all done at low temperatures at Mayagüez CEER's facilities. The performance over the complete range of temperatures that the collector can operate was obtained by combining the results from two type of experimental measurements: the overall heat transfer coefficient $\left(U_{L}\right)$ and the standard efficiency measurements at low temperatures. The method is an adaptation of the method reported in Reference No. 9. Before doing the performance evaluation test, the transient behaviour of the absorber tube and its optical efficiency were studied.

Tap water was used as the heat transfer fluid. In order to reduce variations in flow rate, a constant head method was used. Water (heat transfer fluid) was fed to the absorber tube from an elevated open container which in turn was filled constantly with cold tap water to over flow. The flow rate variations for this set up is within $\pm 0.5 \%$. The flow rates were measured by weighing the water mass ejected at the output of the absorber tube during one minute intervals. 
Measurements of the inlet and outlet temperatures were made with platinum RTD's (resistance temperature detectors) in conjunction with a Monitor Labs ${ }^{\text {TM }} 9300$ data logger. The accuracy of temperature measurements is estimated to be $\pm 0.2^{\circ} \mathrm{C}$. The measured time constants for the RTD's was about 5 seconds which is rather fast compared with thermocouples. The data logger also read and recorded the direct insolation data from an Eppley ${ }^{\text {TM }}$ NIP pyrheliometer.

A. Time Constant Measurements

In order to determine the time required.for the collector to reach the steady state condition, the time constant of the absorber tube was measured: On a clear day the absorber tube was placed on a flat black cloth and aligned along the northsouth line with no tilt. At certain intervals the tube was covered and then uncovered. Inlet and outlet temperatures were measured at intervals of 30 seconds until the difference between them had stabilized. Figure 7.1 is a graph of the difference between outlet and inlet temperatures versus time. In this figure: $=0$ indicates the moment when the incident insolation was altered. The two curves shown, display the temperature behaviour after the covering and uncovering, respectively.

The time constant was defined as the time when $\Delta T$ had changed by $63 \%$ from its maximum value. Figure 7.1 shows the results at a flow rate of $0.43 \mathrm{~kg} / \mathrm{min}$ but similar curves were. 


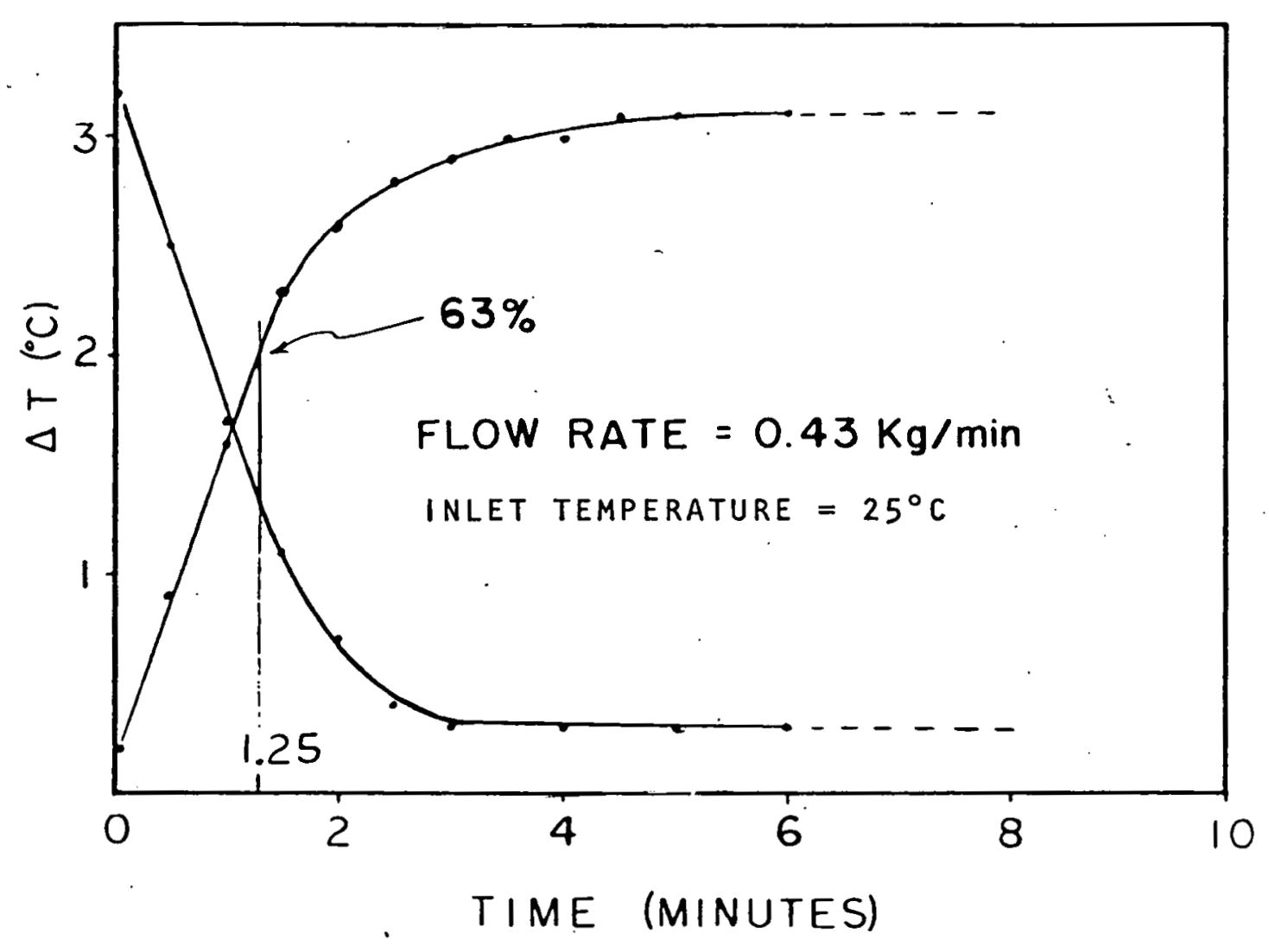

Figure 7.1

$\triangle T$, VS TIME DURING A TYPICAL TIME CONSTANT TEST 
obtained at other flow rates with the upswing and downswing time constants always being consistent. A11 measurements are I isted in Table 7.1 .

B. Optical Efficiency Measurements

1. Absorber Tube Alone

Measurements of the absorber tube efficiency were carried out under the same conditions as with the time constant tests. The pyranometer was placed beside the tube to measure the total horizontal insolation. ( $\left.I_{t h}\right)$ as can be seen in Figure 7.2. A stable period of solar insolation (rithin 1\%) for duration of 5 time constants was required for each data point. The flow rate $(\dot{m})$ measurements were done in:a similar:manner: to: those in the previous test.

The efficiency $(n)$ can be calculated from

$$
n=\dot{m} c_{p} \frac{\Delta T}{I A}
$$

where $A$ is the projected area (diameter $x$ length) and $I$ is given by

$$
\quad I=I_{b} \cos i_{t}+\frac{\pi}{2}\left(I_{t h}-I_{b} \cos i_{h}\right)
$$

where

$$
\begin{aligned}
& \cos i_{t}=\left[1-(\cos L \sin s-\sin L \cos \delta \cos \omega)^{2}\right] \pi / 2 \\
& \cos i_{h}=\sin \delta \sin L+\cos \delta \cos L \cos \omega
\end{aligned}
$$

$I_{b}$ is the beam or direct insolation as measured by the pyrheliometer. $\delta, L$ and $\omega ;$ are solar declination, latitude and solar 
TABLE 7.1

TIME CONSTANT MEASUREMENTS VS. FLOW RATE

\begin{tabular}{lccc} 
Test number & 1 & 2 & 3 \\
\hline $\begin{array}{l}\text { Flow rate }(\mathrm{kg} / \mathrm{min}) \\
\Delta T\left({ }^{\circ} \mathrm{C}\right)\end{array}$ & 0.11 & 0.20 & 0.43 \\
$\begin{array}{l}\text { Average direct } \\
\text { insolation }\left(W / \mathrm{m}^{2}\right)\end{array}$ & 11.0 & 6.4 & 3.0 \\
$\begin{array}{l}\text { Insolation variation } \\
\text { during test }(\%)\end{array}$ & 915 & 910 & 935 \\
Time constant $(\mathrm{min})$ & 2.0 & 3.0 & 0.7 \\
Inlet temperature $\left({ }^{\circ} \mathrm{C}\right)$ & 25 & 2.3 & 1.3
\end{tabular}


Figure 7.2

SET-UP FOR THE OPTICAL EFFICIENCY MEASUREMENT FOR ABSORBER TUBE ALONE 


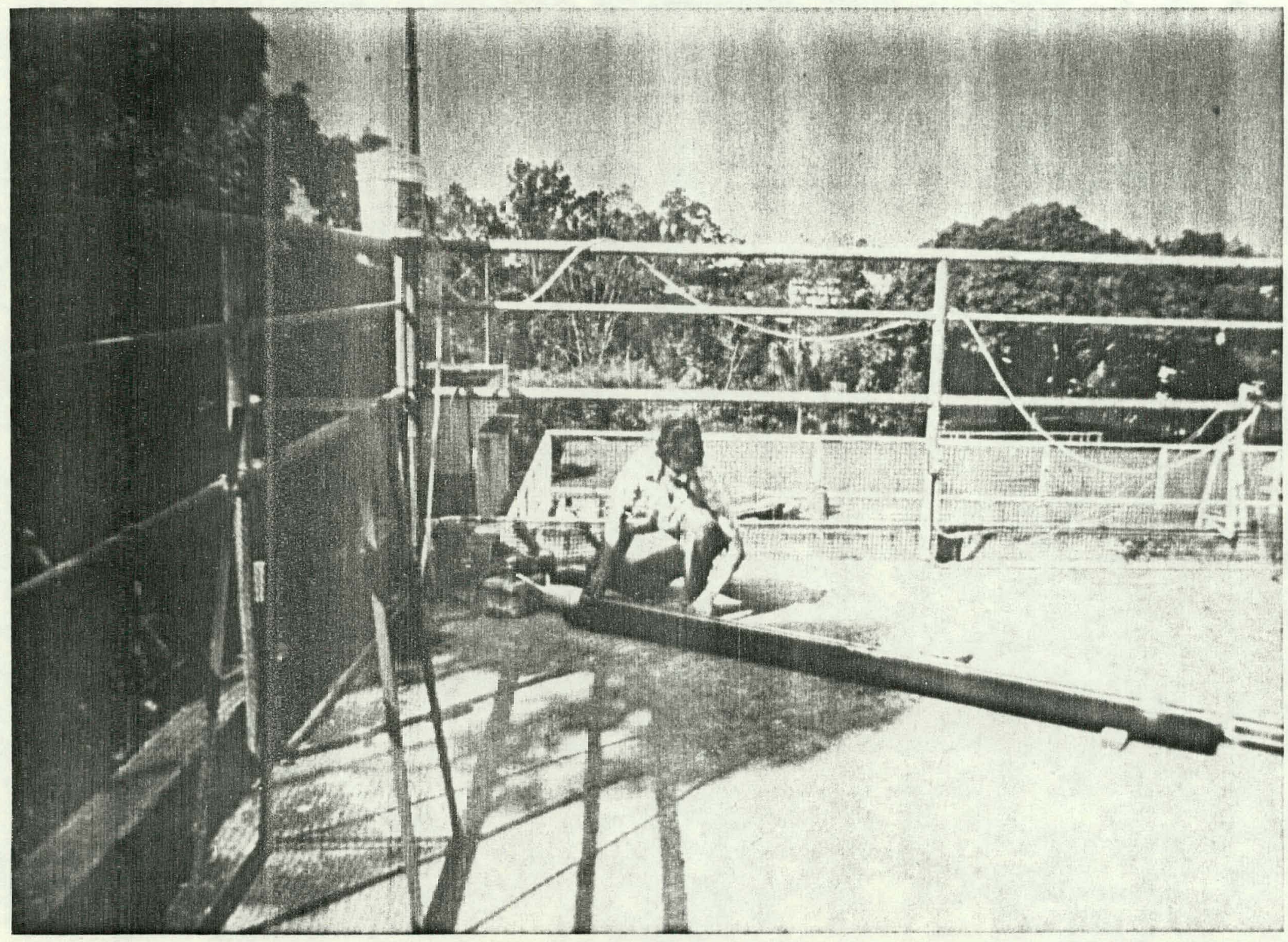


hour angle, respectively.

Table 7.2 1ists the experimental data and the calculated efficiency. A value of $0.80 \pm .02$ was measured consistently at a flow rate of $.30 \mathrm{Kg} / \mathrm{min}$. Since there was little difference between ambient and water temperature, this value can taken as the optical efficiency represented by $\tau$ a.

The experimental value of $\tau \alpha$ agrees well with the values of $\tau$ and $\alpha$ isted by the manufacturer, i.e. 0.86 and 0.94 respectively. This good agreement is rather surprising because of the visual evidence of deterioration of the black chrome coating in certain areas of the tube. That was built early 1978, and was exposed since then to ambient and sun effects. It was concluded that visual color changes of black chrome on copper does not necessarily mean a change in the absorptance and emittance of the coating.

2. Concentrating Collector Assembly

Measurements of the collector optical efficiency $\left(n_{0}\right)$ were carried out for zero degree incidence angle. For this, the collector was manually adjusted every 4 minutes to track the sun. This time interval represents a solar hour angle movement of $i^{\circ}$ which is reasonably small. This continuous tracking permits the determination of the optical efficiency of the collector without the added complexity of edge losses. Equation 7.3 was used to determine $n_{0}$ with $I=I_{b}$ and $A=$ collector aperture. Table 7.3 shows the data and results of the optical efficiency measurements. A value of $26 \% \pm 1 \%$ was 
TABLE 7.2

TEST DATA

OPTICAL EFFICIENCY OF THE ABSORBER TUBE

FLOW RATE $=.30 \mathrm{~kg} / \mathrm{min}$

Standard Time $I_{b}{ }^{*}\left(\mathrm{~W} / \mathrm{m}^{2}\right) \quad I_{t h}{ }^{*}\left(\mathrm{~W} / \mathrm{m}^{2}\right) \Delta T^{*}\left({ }^{\circ} \mathrm{C}\right)$ Efficiency

$\begin{array}{lllll}10: 56 & 806.3 & 879.7 & 4.1 & .81 \\ 10: 58 & 806.9 & 884.3 & 4.1 & .80 \\ 11: 00 & 805.6 & 882.9 & 4.1 & .81 \\ 11: 02 & 793.8 & 884.2 & 4.1 & .81 \\ 11: 04 & 784.7 & 890.2 & 4.1 & .80 \\ 11: 06 & 788.8 & 897.1 & 4.1 & .80 \\ 11: 08 & 781.2 & 903.2 & 4.1 & .79\end{array}$

*Average value during the time interval that finish at the specified time.

Date : March 28, 1980

Declination: $\delta=2.6^{\circ}$

Latitude : $L=18.5$

Silar'noon: $12: 34$ PM AST 
TABLE 7.3:

TEST DATA

OPTICAL EFFICIENCY OF THE COLLECTOR

\begin{tabular}{|c|c|c|c|c|c|}
\hline $\begin{array}{l}\text { Flow Rate } \\
(\mathrm{kg} / \mathrm{min})\end{array}$ & $\left({ }^{\circ} \mathrm{C}\right)$ & $\left(\begin{array}{l}\Delta \mathrm{T} \\
\left({ }^{\circ} \mathrm{C}\right)\end{array}\right.$ & $\left(w / m^{2}\right)$ & $n_{0}=$ & $\frac{m C_{p} \Delta T}{I_{b} A}$ \\
\hline \multirow[t]{3}{*}{1.24} & 25.7 & 4.1 & 946.9 & & .26 \\
\hline & 25.6 & 4.2 & 945.5 & & .26 \\
\hline & 25.6 & 4.2 & 951.1 & & .26 \\
\hline \multirow[t]{2}{*}{1} & 25.6 & 4.2 & 950.6 & & .26 \\
\hline & 25.7 & 4.1 & 150.5 & & .25 \\
\hline \multirow[t]{4}{*}{.83} & 26.0 & 6.1 & 951.9 & & .25 \\
\hline & 26.1 & 6.0 & 954.0 & & .25 \\
\hline & 26.1 & 6.1 & 952.9 & & .25 \\
\hline & 26.1 & 6.1 & 957.1 & & .25 \\
\hline \multirow[t]{5}{*}{.43} & 26.9 & 12.2 & 966.3 & & .26 \\
\hline & 27.0 & 12.3 & 966.9 & & .26 \\
\hline & 27.0 & 12.3 & 962.1 & & .26 \\
\hline & 27.1 & 12.3 & 962.3 & & .26 \\
\hline & 27.2 & 12.3 & 959.3 & & .26 \\
\hline
\end{tabular}

Date: March 19, 1980

Area: $A=1.46 \mathrm{~m}^{2}$ 
consistently measured at flow rates between 0.40 and $1.24 \mathrm{~kg} /$ min.

\section{Transient $U_{L}$ Measurements}

The overall heat loss coefficient $\left(U_{L}\right)$ of the absorber tube was measured with the tube mounted on the collector. There was no liquid flowing through the tubes; instead, six $T$ type thermocouples were placed inside the copper tubing at one foot intervals. The absorber tube was heated to the desired temperature by directing the collector at the sun. Once the temperature reached $500^{\circ} \mathrm{F}\left(260^{\circ} \mathrm{C}\right)$, the collector was then completely screened with a cardboard cover on top and with black cloth on both sides. Thermocouples readings were printed every minute during the test period of about $1-1 / 2$ hours.

Figure 7.3 shows a schematic diagram for the transient thermal analysis of the absorber tube during the cooling process. The whole system can be considered as two bodies losing heat to the surrounding ambient. The corresponding equations are

$$
\begin{gathered}
\text { Body 1: } \quad A_{p} U_{L}\left(T_{p}-T_{e}\right)=-m_{p} C_{p} \frac{d T_{p}}{d t} \\
\text { Body 2: } A_{p} U_{L}\left(T_{e}-T_{p}\right)+A_{e} U_{L e}\left(T_{e}-T_{a}\right)=-m_{e} C_{e} \frac{d T_{e}}{d t}
\end{gathered}
$$

Since the glass envelope is transparent to short wave radiation and the only thermal contact with the absorber is via thin wire spring rings, it is a reasonable approximation to neglect changes in the internal energy of the glass envelope. In addition it is 


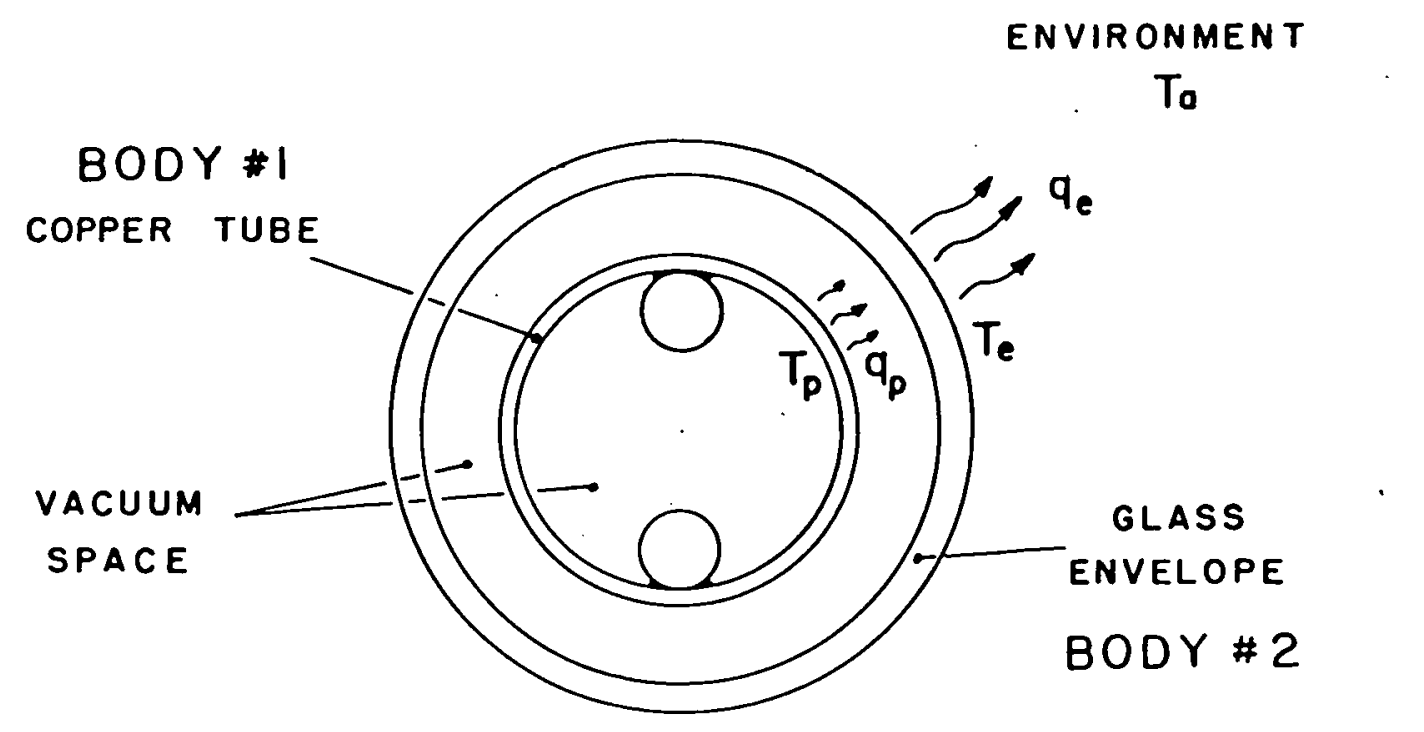

Figure 7.3

THERMAL ANALYSIS DIAGRAM

FOR EVACUATED TUBULAR COLLECTOR 
true for highly evacuated collectors that the envelope temperature is very close to the ambient. Equation 7.8 is reduced to

$$
A_{p} U_{L}\left(T_{p}-T_{e}\right)=A_{e} U_{L_{e}}\left(T_{e}-T_{a}\right)
$$

which means that the heat lost by the absorber is approximately equal to the heat lost by the whole system. Then an expression for the overall heat transfer coefficient can be obtained by applying equation 7.7

$$
U_{L}\left(T_{p}\right)=\frac{m_{p} C_{p}}{A_{p}\left(T_{a}-T_{p}^{i}\right)} \frac{d T_{p}}{d t}
$$

where $T_{p}, m_{p}, C_{p}$ and $A_{p}$ are the copper absorber's temperature, mass, specific heat and area, respectively.

This method has the advantage that $U_{L}$ is measured over a wide range of temperatures during a single test. However, a systematic error is introduced during the test, by the difference between cover temperature and sky temperature. This error has been assumed small since the tube-sky view factor is smali. Values for $d T_{p} / d t$ were obtained by a five point approximation formula using the average thermocouple reading. Figure 7.4 shows the results of the test for three different tubes of the same design. The tube with higher $U_{L}$ values is believed to have lost some vacuum as its getter film has become somewhat transparent.

D. Discussion of Results

According to the computer simulation of the optical performance (Chapter IV) of this new design a $39 \%$ optical efficiency 


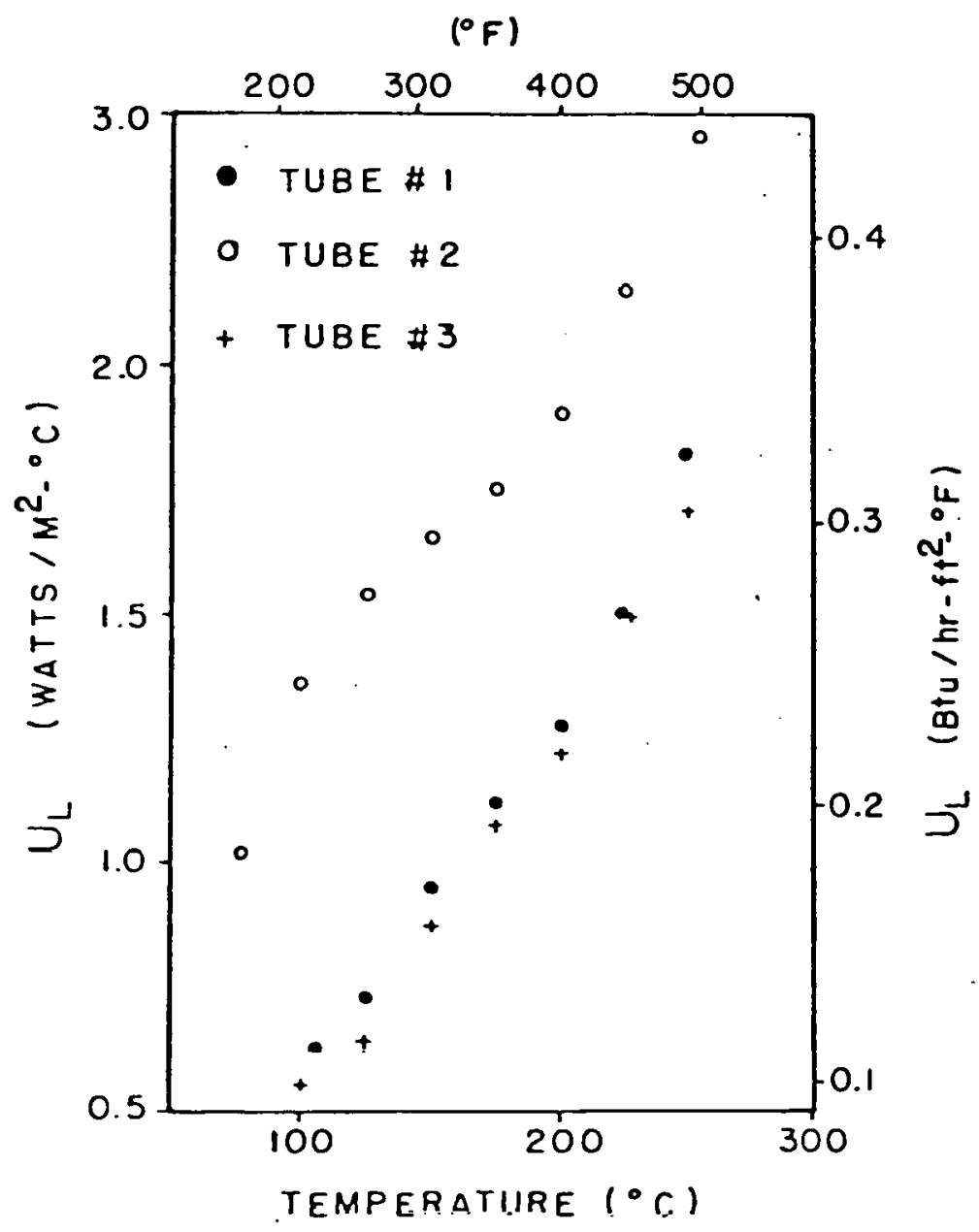

$=$ Figure 7.4

$U_{L}$ AS A FUNCTION OF ABSORBER TEMPERATURE FOR THE THREE DIFFERENT' ABSORBER TUBES 
is to be expected. This prediction was based on the at value of .81 obtained from Corning Glass Work's and the fraction of thruput 1 ight intercepted by the absorber (i.e. .48 as shown in Figure 4.9). In addition, the approximation was made that the optical efficiency is equal to the product of at for the absorber tube times the fractional thruput for the concentrator section. On the other hand, experimental measurements of collector optical efficiency of $26 \%$ does not agree with the computer simulation results.

There are several possible reasons"for the discrepancy between experimental and theoretical results.

(1) Optical misalignment of mirror surface at the time of installation.

(2) Twists and sags of mirror facts.

(3) Dust accumulation in the hard-to-reach spaces between mirror tubas.

(4) Refraction of the incident radiation in the glass envelopes.

Figure 7.5 shows the expected performance behaviour of the prototype based on the results from optical efficiency and $U_{L}$ measurements. In this figure the computer simulation prediction for the no value is also shown. 


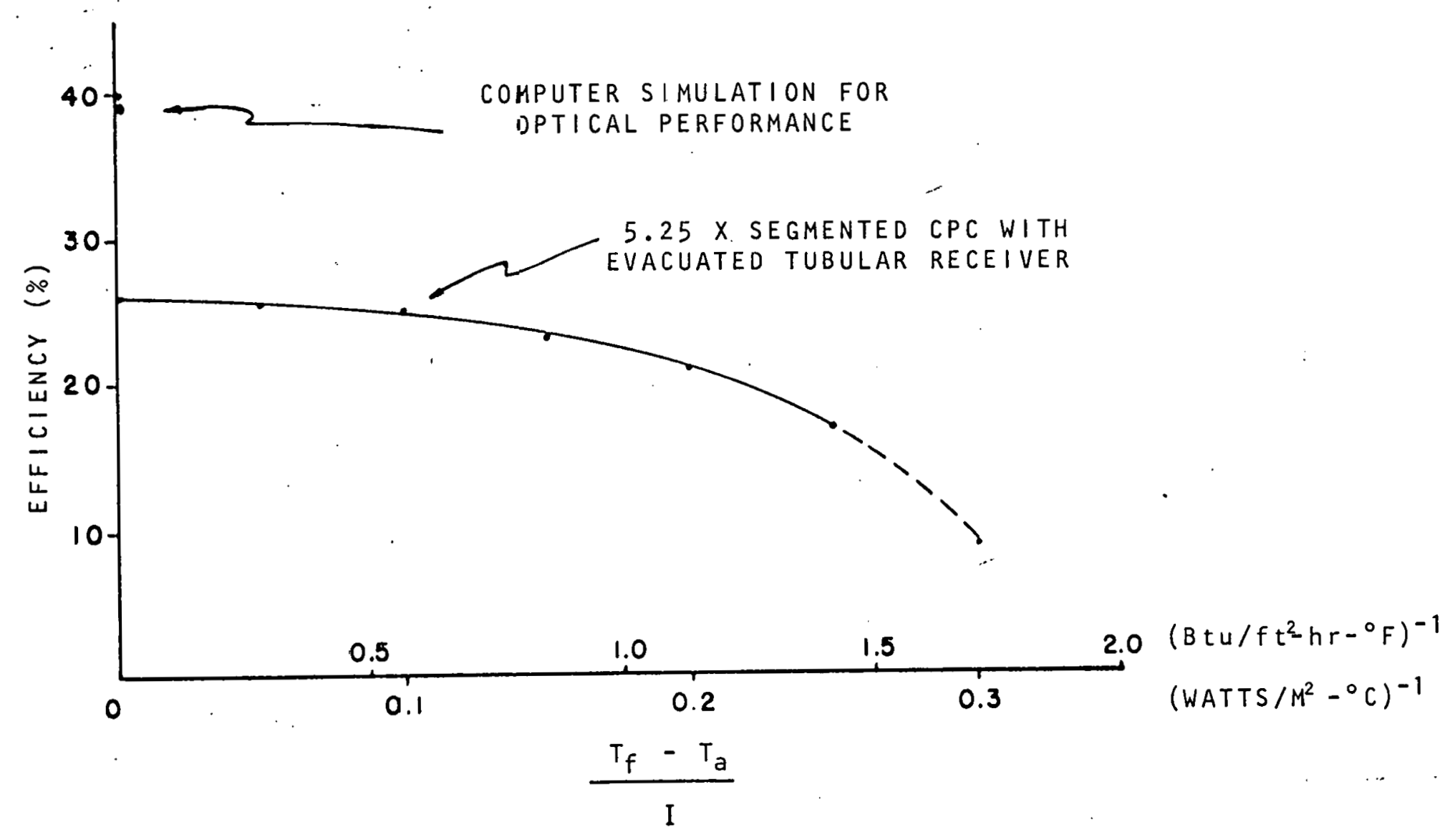

Figure $7: 5$ 


\section{CHAPTER VIII}

\section{CONCLUSIONS}

In accordance with the objectives of this thesis, a unique CPC solar collector was designed, built and tested.

The prototype is now installed at the CEER facilities in Mayaguez and will be undergoing a series of long-term parametric tests at higher temperatures for final evaluation.

A major portion of the work included a detailed analytical study of the facetted reflector geometry, the effects of tubular glass protection for the mirrors, the optimization of truncation and the analysis of tracking needs for diurnal and seasonal movements of the sun.

A set of experiments were carried out to determine the performance characteristics of the collector at low temperatures and the thermal behavior under transient conditions.

Although some discrepancies were found between the theoretically predicted values and the experimental results, the origin of variances has been identified and methods of improvements suggested. Major improvements in the optical efficiency can be achieved by improving the mirror fabrication technology, mirror alignment methods as well as by applying an antireflecting coating to the fluorescent tube blanks that protect the mirrors. On the:theoretical side, the analysis will be more realistic, if refraction effects are incorporated into the simulation program to determine their relative importance. 
The scope of the present work was concentrated on the technical development of the concept idea. However, the successful application of the fluorescent tube blanks as support structure and protection material for the concentrator mirror combined with the practicality of the design promises a low-cost, long-life and efficient collector, once mass manufactured. Based on recent study for a solar demonstration project for industrial process heat for an industry located in the southwestern part of Puerto Rico, a projected total installation cost below $20 \$ / \mathrm{ft}^{2}$ of a perture area seems to be feasible. Assuming a general inflation rate of $5 \%$ and an additional fuel evaluation rate of $9 \%$ per year, the pay-back period for the dry forest regions (southwestern) of Puerto Rico (300,000 BTU/ft ${ }^{2}$-year) will be about 8 years. Further improvements in the pay back period are possible by reducing the cost below $20 \$ / \mathrm{ft}^{2}$. The collector lends itself by design to mass manufacturing and to lower cost in materials by going to cheaper substrate and reflective film configurations.

Also, the use of plastic materials for the support structure will bring down the cost substantially. The associated return on investment could drastically be improved by government incentives. with regard to cost share, tax structure, and loan guarantees.

In this thesis, a rather significant step has been taken towards the generation of industrial process heat by solar energy. However, a full application of the facetted CPC 
collector concept in a commercial sense requires the continuation of the following studies:

1. Improvement of the computer simulation by including effects of refraction aberrations and misalignments.

2. Development of advanced manufacturing techniques for the mass production of the segmented CPC and the evacuated absorber tube.

3. Economic analysis of solar industrial process heat applications in Puerto Rico. 


\section{REFERENCES}

1. "Analysis of the Economical Potential of Solar Thermal Energy to Provide Industrial Process Heat", Vol. 1 , Intertechnology Corp., Warenton, Virginia NTIS C00/2829-1, Feb. 1977.

2. "Putting the Sun to Work in Industry" Solar Energy Research Institute, Technology Commercialization Division for Industrial Process Heat Program; 2nd. ed. Sept. 1979 .

3. Winston R., "Light Collection Within the Framework of Geometrical Optics". Journal of Optical Soc. Vol. 80 , No. 2,.245-247, Feb. 1970 .

4. Rabl, A., "Optical and Thermal Properties of Compound Parabolic Concentrator", Solar Energy Vol. 18, No. 6, $497-511 .(1976)$

5. Rabl, A.,Goodman, N. and Winston, R.,"Practical Design Considerations for CPC Solar Collectors". The Enrico Fermi Institute, University of Chicago, EFI 77-15 (1977)

6. Rabl, A., "Comparison of Solar Concentrators".. Solar Energy Vol. 18. No. 2, 93-111, Dic. 1975.

7. Welford, W.T., and Winston, R., The Optics of Norimaiging. Concentrator, Arademic. Press, New York, 1978.

8. Ortabaşi, U. and Bueh1, W.M., "An Internal Cusp Reflector for an Evacuated Tubular Heat Pipe Solar Thermal Collector" Corning Glass Works Research and Development Laboratory, Corning, N.Y. 1978. (ISES, in print)

9. Ortabaşi, U., "Indoor Test Methods to Determine the Effect of Vacuum of the Performance of a Tubular Flat Plate Collector". ASME Winter Annual Meeting, New York, December. 5, 1976m ASME Publication 76-WA/SOL-24.

10. Kreith, F. and Kreider, J.F., Principles of Solar Engineering, McGraw Hill, 1978 .

11. Soderstrom, K.G., "Modeling of Solar Data in the Tropics" Presented to the Technical Congress of the Association of Engineers and Surveyors of Puerto Rico, San Juan, P.R., May 1979. 
12. Ortabasi, U., Private Communication, Center for Energy and Environment Research, January 1978, 1980.

13. Ozakcay, L.M., Lopéz, A.M. and Ortabasi, U., "A Solar Thermal Test Facility for $60-300^{\circ} \mathrm{C}$. Located in Tropics": Proceedings of the 1980 Annual Meeting of the International Solar Energy Society, Phoenix, Arizona, June 1980 .

14. Winston, R., "Ideal Light Concentrator with Reflector Gap.", Enrico Fermi Institute and University of Chicago, February 1978. 


\section{APPENDIX A}

\section{SOLAR DATA MEASUREMENTS}

TABLE A。1

TYPICAL INSOLATION AND

$K_{D}$ VALUES FOR, DIFFERENT LOCATION

IN PUERTO RICO

\begin{tabular}{lcc} 
LOCATIONS & $I_{\text {tot }}$ & $K_{D}$ \\
\hline \multirow{2}{*}{ PONCE } & 1,757 & $N A$ \\
RIO PIEDRAS & 1,469 & 0.42 \\
CATAÑ & 1,606 & 0.38 \\
MAYAGUEZ & 1,394 & 0.38 \\
& & \\
$I_{\text {tot }}=$ & Daily average insolation on a horizontal \\
& surface (Btu/ft & \\
& &
\end{tabular}


TABLE A.2

MONTHLY AVERAGE OF TOTAL DAILY INSOLATION ON A HORIZONTAL SURFACE (BTU/FT $\left.{ }^{2} / D A Y\right)$ FOR CEER STATIONS IN PUERTO RICO

\begin{tabular}{|c|c|c|c|c|}
\hline STATION & MAYAGÜEZ & RIO PIEDRAS & CATAÑO & PONCE \\
\hline JAN & $1120 \pm 161$ & $1497 \pm 97$ & $1427 \pm 108$ & \\
\hline FEB & $1297 \pm 185$ & $1348 \pm 144$ & $1511 \pm 149$ & \\
\hline MAR & $1397 \pm 199$ & $1540 \pm 191$ & $1714 \pm 198$ & $1866 \pm 161$ \\
\hline APR & $1628 \pm 200$ & $1522 \pm 198$ & $1828 \pm 165$ & $1967 \pm 159$ \\
\hline MAY & $1476 \pm 177$ & $1387 \pm 207$ & $1493 \pm 244$ & $1840 \pm 189$ \\
\hline JUNE & $1589 \pm 177$ & $1440 \pm 208$ & $1510 \pm 230$ & $1969 \pm 153$ \\
\hline JULY & $1408 \pm 182$ & $1830 \pm 172$ & $2198 \pm 110$ & $1918 \pm 164$ \\
\hline AUG & $1407 \pm 192$ & $1677 \pm 206$ & $1872 \pm 213$ & $1984 \pm 164$ \\
\hline SEP & $1416 \pm 177$ & $1552 \pm 193$ & $1627 \pm 212$ & $1828 \pm 1.51$ \\
\hline OCT & $1228 \pm 178$ & $\begin{array}{r}1262 \pm 187 \\
\end{array}$ & $1458 \pm 212$ & $1706 \pm 166$ \\
\hline NOV & $1261 \pm 153$ & $1293 \pm 150$ & $1339 \pm 124$ & \\
\hline DEC & $1175 \pm 120$ & $1302 \pm 109$ & $1305 \pm 104$ & \\
\hline
\end{tabular}

NOTES:

1. For station location, see accompanying map.

2. Measurements were taken over consecutive months as follows: A) Mayagüez-Jul, 1977 to Jun,1978; B) Río Piedras and CatañoJul,1978 to Jun,1979; C) Ponce-Mar,1978 to .Oct,1978.

3. Measurement apparatus for all stations consists of EPPLEY ${ }^{\text {TM }}$ PSP Pyranometers and Integrators (Model 411-6140)

4. Measurement errors quoted are purely statistical and amount to one standard deviation. 


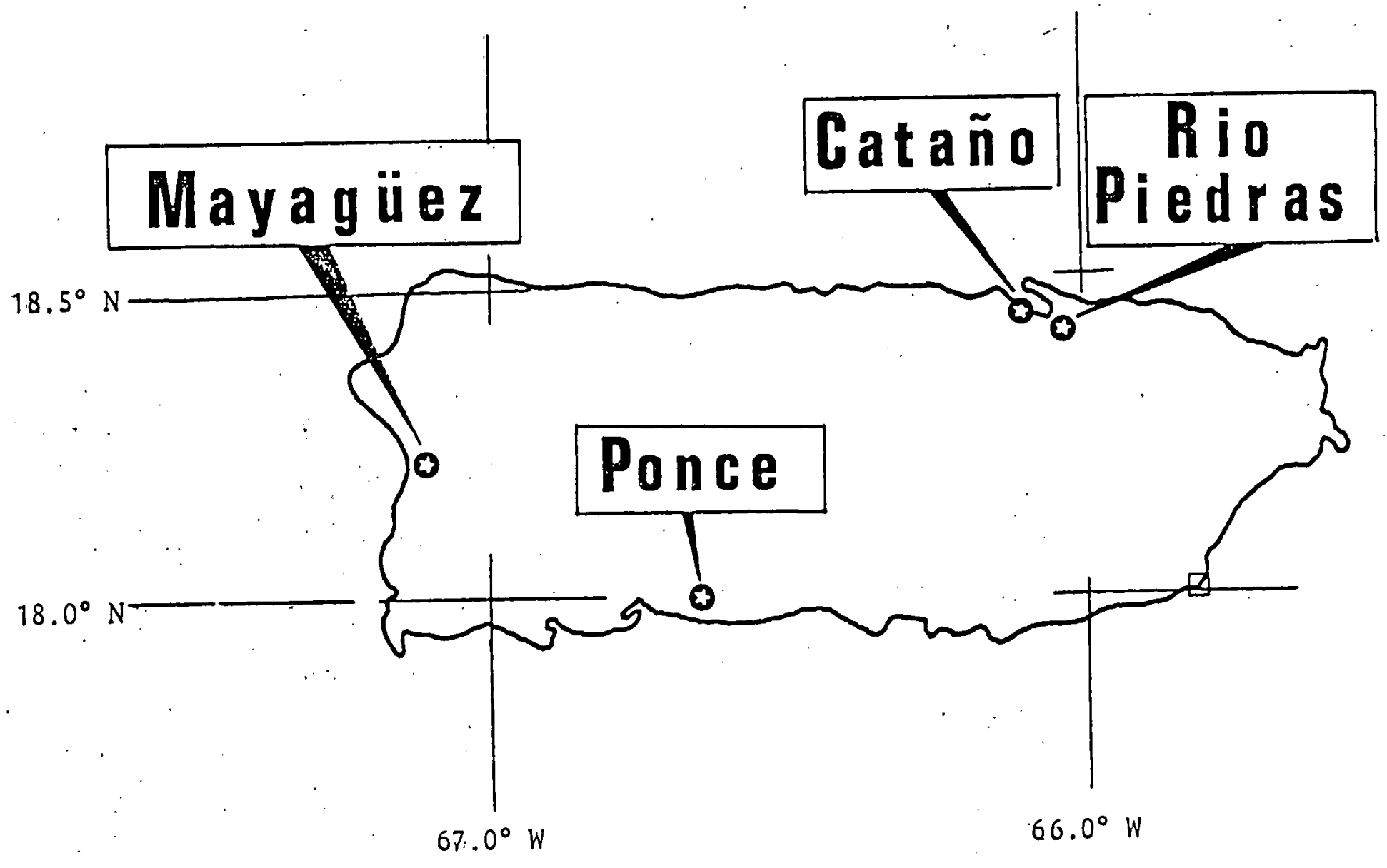

Figure A.1

LOCATIONS FOR SOLAR DATA COLLECTION 


\section{APPENDIX B}

\section{DETAILED DERIVATION OF ANALYTICAL EXPRESSIONS FOR THE CPC SHAPE}

Since it is necessary to use an evacuated envelope for the absorber tube to minimize heat loss, the mirror curve of the tubular CPC has to be modified. This modified collector is called Tubular Absorber With Glass Envelope. The relevant quantities are (Fig. B.1):

$$
\begin{aligned}
R= & \text { radius of the cylindrical glass envelope. } \\
r= & \text { radius of the cylindrical absorber. } \\
X, Y= & \text { coordinates of a point of the mirror surface. } \\
X e, Y e= & \text { coordinates of a point of the cylindrical } \\
& \text { absorber. } \\
\rho= & \text { distance from } X c, Y C \text { to } X, Y . \\
{ }^{\prime}= & \text { angle between } r \text { and the negative } Y \text {-axis. } \\
\Theta_{C}= & \text { critical angel, half acceptance angle } \\
\alpha= & \text { angle corresponding to } \theta \text { for the starting } \\
& \text { position, } i . e \text { point A. }
\end{aligned}
$$

The basic principle underlying the cusp design is the requirement that any ray having an angle of incidence $\dot{\theta}_{\dot{c}}$ or less with the plane of symmetry be reflected onto the cylindrical absorber, either directly or through multiple 


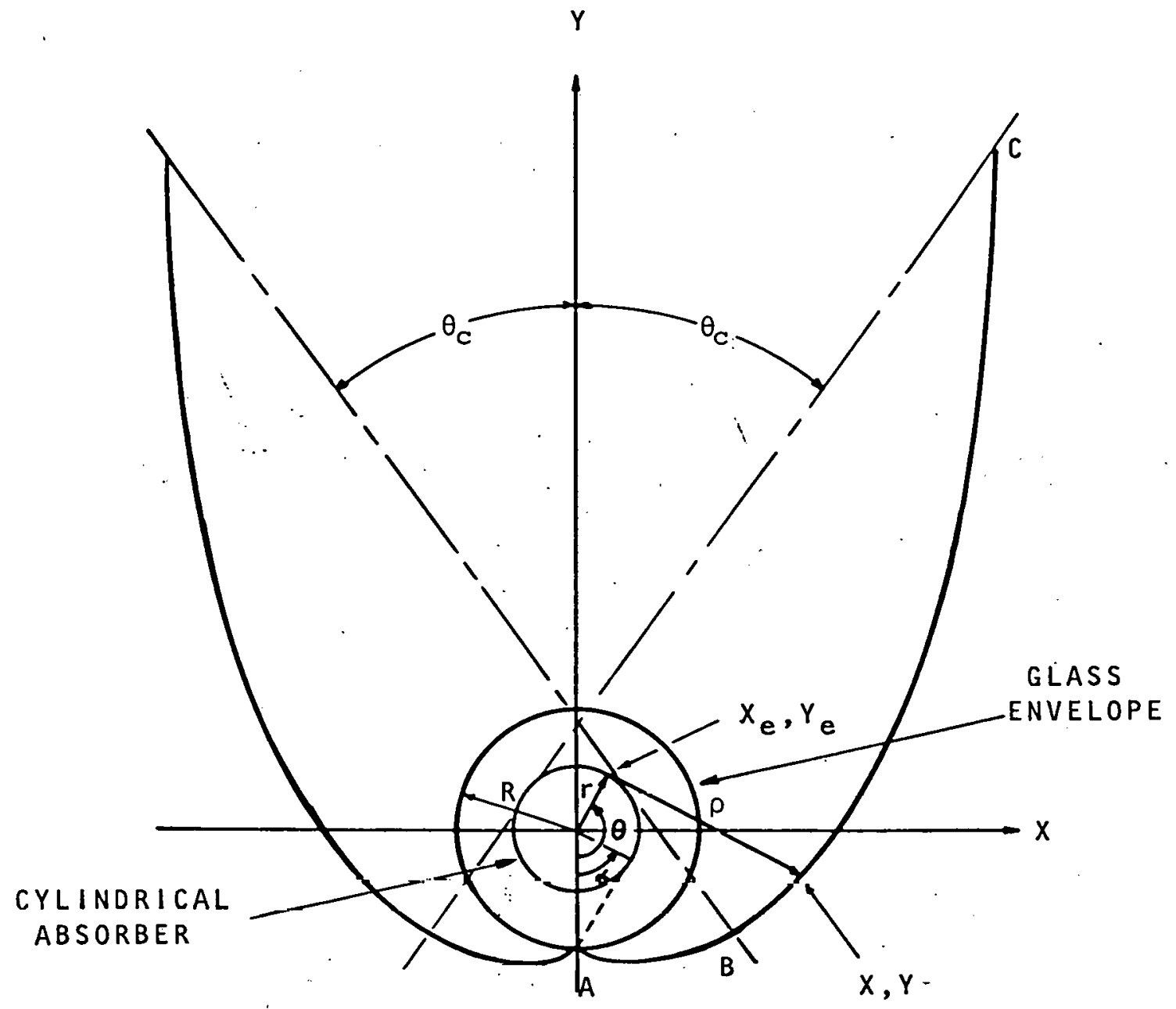

Figure $B, 1$

CPC WITH EVACUATED CYLINDRICAL ABSORBER 
reflections. The curve $A C$ of Figure $B-1$ is split into: two sections, $A B$ and $B C$, each described by a separate set of equations .

Let $\theta_{c}$ be called the critical angle and a ray at critical angle be called a critical ray. The dividing point between the two curves occurs at point $B$, where a critical ray tangent to the cylindrical absorber intersects the mirrors curve. The lower curve $A B$ is defined such that any normal to this curve is tangent to the cylindrical absorber. The upper curve $\mathrm{BC}$ is defined such that a critical ray striking the mirror surface at any point in this section will be reflected tangent to the cylindrical absorber. In this configuration, any ray striking the surface of the mirror within an angle $\theta_{c}$ of the plane of symmetry will eventually be reflected to the cylindrical absorber by means of single or multiple retlections.

The origin of the coordinate system is taken at the center of the cylindrical absorber. At $x=0$, i.e. at point $A$, the mirror is in contact with the glass envelope. By means of simple geometry, it can be shown that the coordinates $X$ and $Y$ of the cusp mirror can be expressed in the following parameteric form:

$$
\begin{aligned}
& X(\rho, \theta)=r \sin \theta-\rho(\theta) \cos \theta \\
& Y(\rho, \theta)=-r \cos \theta-\rho(\theta) \sin \theta
\end{aligned}
$$


The derivatives of $X$ and $Y$ with respect to $\theta$ are then given by:

$$
\begin{aligned}
& \frac{d X}{d \theta}=r \cos \theta+\rho \sin \theta-\frac{\partial \rho}{\partial \theta} \cos \theta \\
& \frac{d Y}{d \theta}=r \sin \theta-\rho \cos \theta-\frac{\partial \rho}{\partial \theta} \sin \theta
\end{aligned}
$$

Solution for $A B$ section:

In vector representation, the orientation of the tangent at a given point $(X, Y)$ on the cusp mirror is given by:

$$
\vec{t}=\vec{i} \frac{d X}{d \theta}+\vec{j} \frac{d Y}{d \theta}
$$

It can also be shown that the vector from the point $(X, Y)$ on the cusp mirror to a tangent point $(X C, Y C)$ on the cylindrical abeorber is given hy:

$$
\vec{\rho}=\vec{i} \cos \theta+\vec{j} \sin \dot{\theta}
$$

It is required that, along the $A B$ section of the cusp mirror, $\vec{\rho}$ be normal to $\vec{t}$, $i . e$. the dot product must vanish:

$$
(\vec{p} \cdot \vec{t})=\frac{d X}{d \theta} \cos \theta+\frac{d Y}{d \theta} \sin \theta=0
$$

By multiplying equations 3 and 4 by $\cos \theta$ and sin $\theta$, respectively, and adding them one obtains: 
$\frac{d X}{d \theta} \cos \theta+\frac{d Y}{d \theta} \sin \theta=r-\frac{\partial \rho}{\partial \theta}$

From equations 7 and 8 , one finds

$$
r-\frac{\partial \rho}{\partial \theta}=0
$$

$$
\text { or, by integration, }
$$

$$
\rho=r \theta+C
$$

where $C$ is a constant of integration that can be evaluated using the boundary condition, when $X=0, Y=-R$ (see Figure B.1).

Thus, for a specific angle, $\alpha$, equations 1 and become:

$$
\begin{aligned}
& r \sin \alpha-(r \alpha+C) \cos \alpha=0 \\
& -r \cos \alpha-(r \alpha+C) \sin \alpha=-R
\end{aligned}
$$

Solving the simultaneous system one finds:

$$
\begin{aligned}
& \alpha=\cos -1(r / R) \\
& C=r \tan \alpha-r \alpha
\end{aligned}
$$

The equations describing the section $A B$ of the cusp mirror then have the following explicit form:

$$
x=r \sin \theta-(r \theta+r \tan \alpha-r \alpha) \cos \theta
$$


$Y=-r \cos \theta-(r \theta+r \tan \alpha-r \alpha) \sin \theta$

Where $\theta$ covers a range from $\theta=\alpha$ to $\theta=\frac{\pi}{2}+\theta m$

Solution for the BC Section

In vector notation, a critical ray striking the $B C$ section of the cups mirror is given by:

$$
\vec{c}=\vec{i} \sin \theta_{c}-\vec{j} \cos \theta_{c}
$$

The critical ray will be reflected tangentially to the cylindrical absorber, the reflected vector being $\overrightarrow{\mathrm{r}}$. Since $c$ and $\vec{r}$ are unit vector, their dot product with $\vec{t}$, i.e., the tanget to the cusp mirror must be equal.

$$
\overrightarrow{(t} \cdot \vec{c})=(\vec{t} \cdot \vec{r})
$$

From equations $5,6,8$, one obtains the following expressions :

$$
\begin{aligned}
& \overrightarrow{(t \cdot \vec{c})}=\frac{d X}{d \theta} \sin \theta_{c}-\frac{d Y}{d \theta} \cos \theta_{c} \\
& (\vec{t} \cdot \vec{r})=r-\frac{\partial \rho}{\partial \theta} .
\end{aligned}
$$

Consequent1y,

$$
\frac{d X}{d \theta} \sin \theta_{c}-\frac{d Y}{d \theta} \cos \theta_{c}=r-\frac{\partial \rho}{\partial \theta}
$$




$$
\begin{aligned}
& \text { or, by integration, } \\
& X \sin \theta_{C}-Y \cos \theta_{C}+b=r \theta-\rho
\end{aligned}
$$

where $b$ is the constant of integration. Upon substituting $X$ and $Y$ from equations 1 and 2, respectively, one gets:

$$
r \cos \left(\theta-\theta_{c}\right)+\rho \cdot \sin \left(\theta-\theta_{c}\right)+b=r \theta-\rho
$$

The value of $b$ can be obtained from the boundary. condition at point $B$, where the critical ray is reflected into itself and $\rho$ is equal to $\rho\left(\theta_{b}\right)$. The relation between $\theta_{c}$ and $\theta$ is given by:

$$
\Psi=\theta-\left(\pi / 2+\theta_{c}\right),
$$

where $\Psi$ is the angle between the critical ray and the normal to the tangent at the point of reflection on the cusp mirror. At the point $B, \Psi=0$ so that

$$
\begin{aligned}
& \theta_{b}=\pi / 2+\theta_{c} \\
& \rho\left(\theta_{b}\right)=r \theta_{b}+c
\end{aligned}
$$

from equation 10, where $\mathrm{C}$ can be found from equation 14, sinee point $B$ is common for both $A B$ and $B C$ sections. Thus, upon substituting equation 25 and 26 into 
eg. 23, and solving the equation for $b$ one gets

$$
b=-r\left(\pi / 2+\theta_{C}\right)-2 C
$$

Using equation 27 in equation $23, \rho$ is found as

$$
\rho=\frac{r\left\{\pi / 2+\theta_{c}+\theta-\cos \left(\theta-\theta_{C}\right)\right\}+2 C}{1+\sin \left(\theta-\theta_{C}\right)}
$$

The explicit parametric equations describing the $B C$ section of the mirror curve are then given by

$$
\begin{aligned}
& X=r \sin \theta-\frac{r\left\{\pi / 2+\theta_{c}+\theta-\cos \left(\theta-\theta_{c}\right)\right\}+2 C}{1+\sin \left(\theta-\theta_{c}\right)} \cos \theta \\
& Y=r \cos \theta-\frac{r\left\{\pi / 2+\theta_{c}+\theta-\cos \left(\theta-\theta_{c}\right)\right\}+2 C}{1+\sin \left(\theta-\theta_{c}\right)} \sin \theta
\end{aligned}
$$

$$
\text { where } \theta \text { covers a range from } \theta_{b} \text { to } \frac{3 \pi}{2}-\theta_{c}
$$




\section{APPENIDIX C}

\section{CALCULATIONS FOR SEASONAL SOLAR ELEVATION VARIATIONS}

To determine the relation between concentration ratio and cutoff time (in hours after noon) of a nontracking collector, it is convenient to calculate the projected angle of solar incidence in the $X, Y, Z$ coordinate system of Figure C.1.

Let $n_{s}$ be the unit vector from the earth to the sun and $\mathrm{n}_{\mathrm{c}}$ the unit vector normal to the collector aperture, and $\mathrm{n}_{\mathrm{e}}$ the unit vector normal to the earth surface. Collector tilt $\beta_{0}$ is measured from the equatorial plane.

The coordinate system (X, Y, Z) of Figure C.1 is fixed in the earth, with the $Z$-axis as the axis of rotation and the $\mathrm{X}$-axis pointing towards the sun at noon. With these coordinates the unit vectors $n_{c}$ and $n_{s}$ take the following form:

$$
\begin{gathered}
\mathrm{n}_{\mathrm{c}}=\left(\cos \beta_{0}, 0, \sin \beta_{0}\right) \\
\mathrm{n}_{\mathrm{s}}=(\cos \delta \cos \omega,-\cos \delta \sin \omega, \sin \delta) \\
\text {. where } \beta=L-\beta \text { and the hour angle } \omega=2 \pi \mathrm{t} / 24 \\
(\mathrm{t} .=\text { time in hours from solar noon }) . \\
\text { This yields the angle of incidence } \theta \text { as }
\end{gathered}
$$



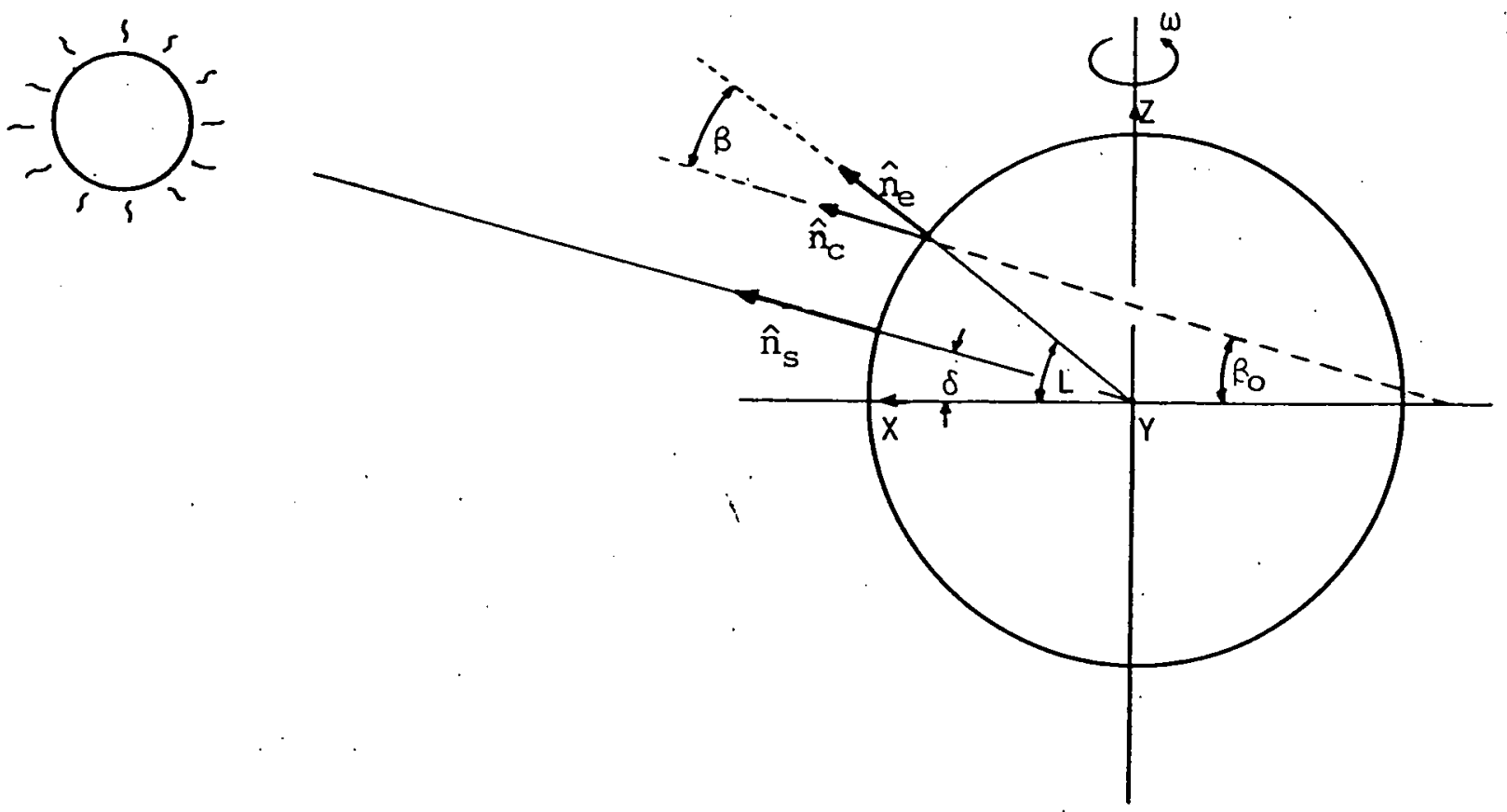

Figure C.1

SOLAR GEOMETRY

$x$ - axis points towards solar noon

$Y$ - axis points éast

$Z$ - axis of rotation (north is + )

$\delta$ - solar declination

$L$ - latitude (north is + )

$B_{0}=$ collector tilt from equatorial plane $=L-B$

$\hat{n}_{c}$ - unit vector normal to collector (assume east-west symmetric)

$\hat{n}_{e}$ - unit vector normal to earth's surface

$A_{S}$ - unit vector in direction of sun 
$\cos \theta=\hat{n}_{S} \cdot \hat{n}_{C}=\cos \beta_{O} \cos \delta \cos \omega+\sin \beta_{O} \sin \delta(3)$

In order to find the projection $\theta_{x z}$ of $\theta$ on the $x z$ plane, consider the projection of

$$
\hat{n}_{S, x z}=(\cos \delta \cos \omega, 0, \sin \delta)
$$

of $\mathrm{n}_{\mathrm{s}}$ on the $\mathrm{Y}=0$ plane, i.e. the plane defined by the sun at noon and by the axis of rotation.

The projected angle of incidence $\theta_{x z}$ is found by taking the dot product of the unit vector $n_{S}$ and $n_{e}$ using $B=0$ and $\beta_{O}=L$.

$$
\mathrm{n}_{\mathrm{s}}, \mathrm{xz}=(\cos \delta \cos \omega, 0, \sin \delta)\left(1-\cos ^{2} \delta \sin ^{2} \omega\right)=1 / 2
$$

and vector $\mathrm{n}_{\mathrm{e}}=(\cos \mathrm{J}, 0, \sin \phi)$. The result,

$$
\cos \theta_{x z}=\left(1-\cos ^{2} \delta \sin ^{2} \omega\right)^{-\frac{1}{2}}(\cos \cos \cos L+\sin \cos L)
$$

cān be written in a simplified form as

$$
\tan \left(\theta_{x z}+L\right)=\tan \delta / \cos \omega
$$

Equation 7 can be represented in graphical form for different latitudes. Figure C. 2 and C. 3 show the results 


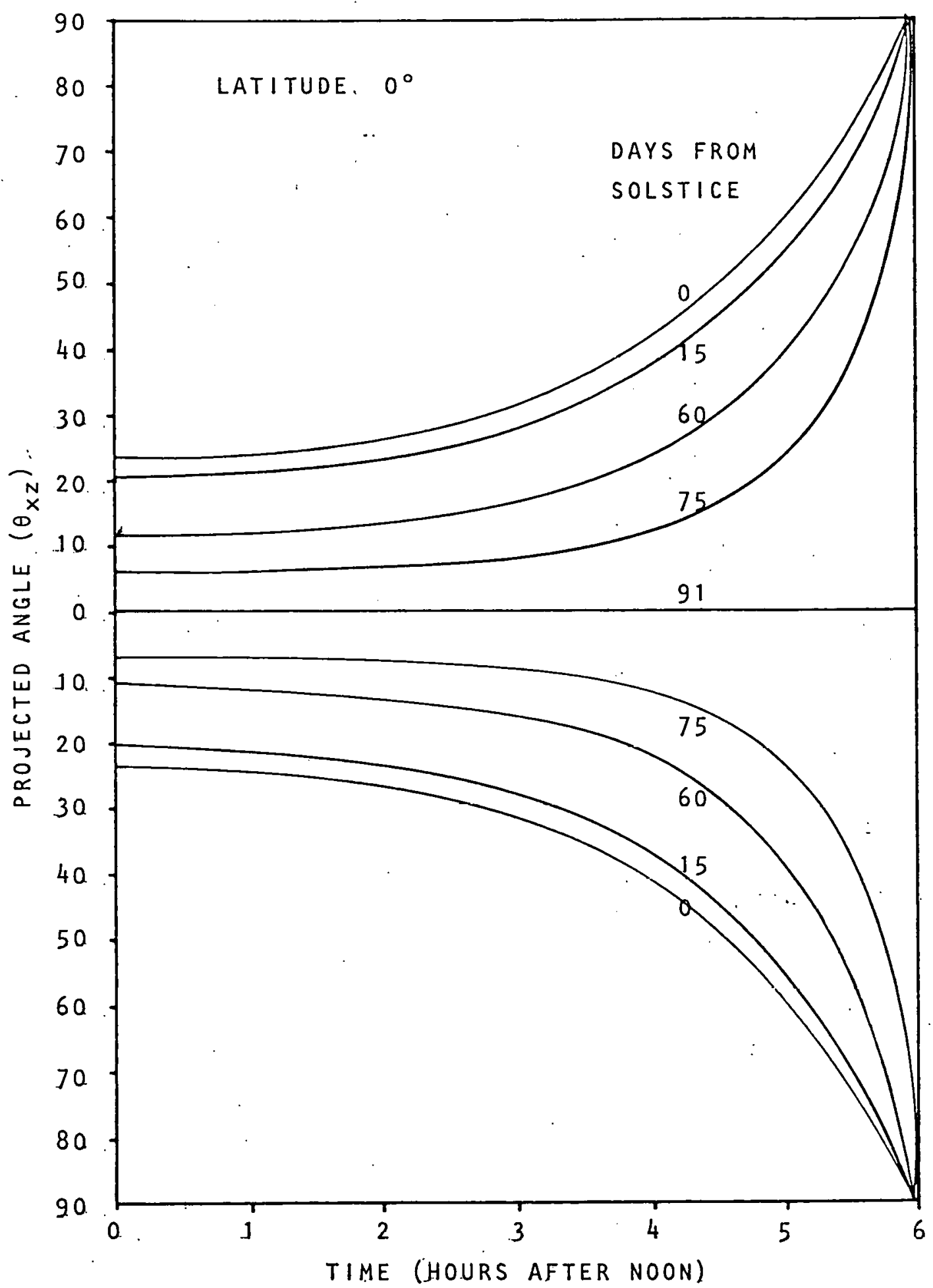

Figure C.2 


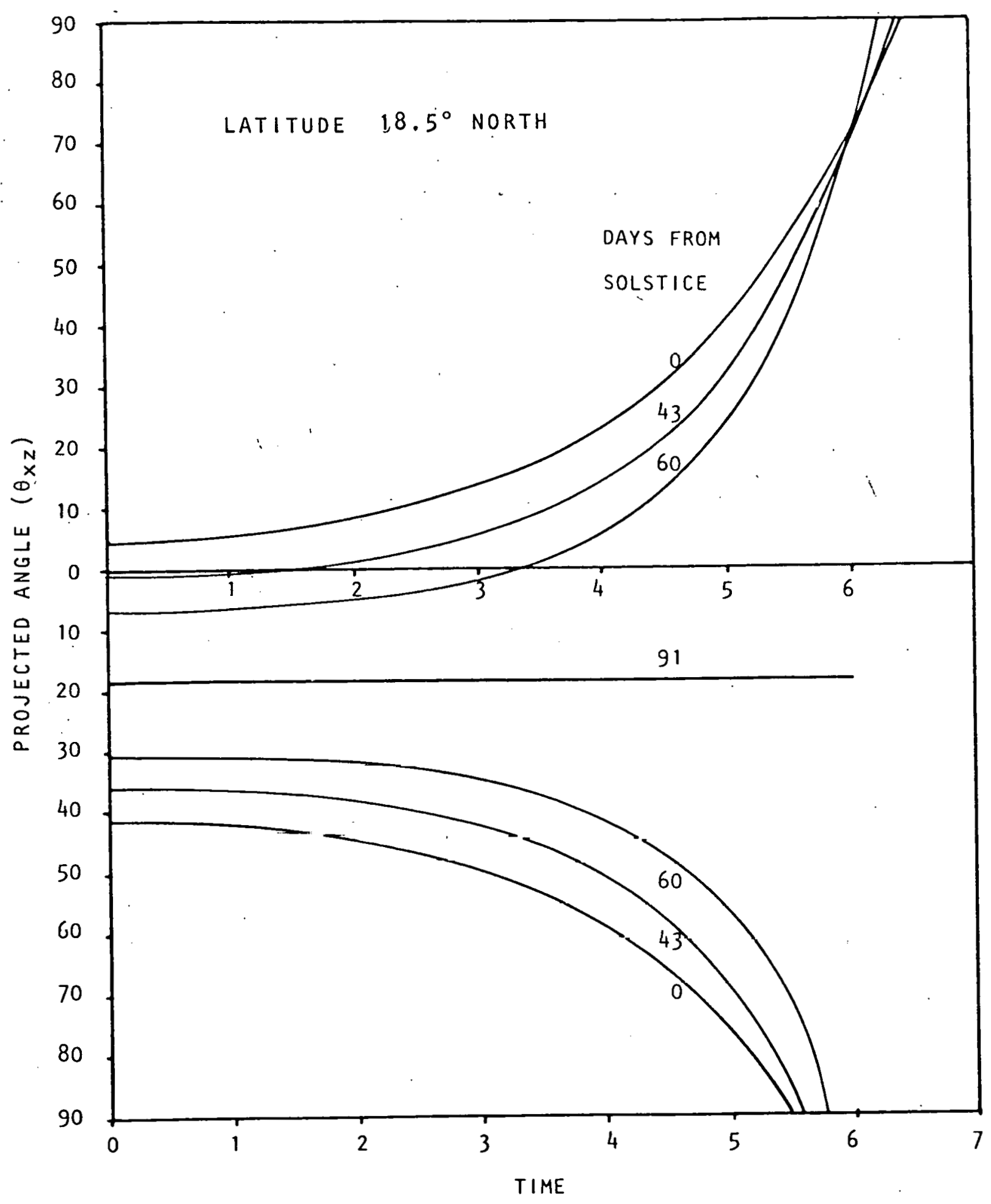

(HOURS AFTER NOON)

Figure C. 3 
for latitude $0^{\circ}$ and $18.5^{\circ}$ respectively.

Tables C.1, C.2 and C.3 were generated based on the procedure explained in chapter IV section $E$ and showing the orientation information for three different acceptance angles. 
TABLE C.I

TILT ADJUSTMENT DURING THE YEAR

$$
\theta_{C}=9^{\circ}
$$

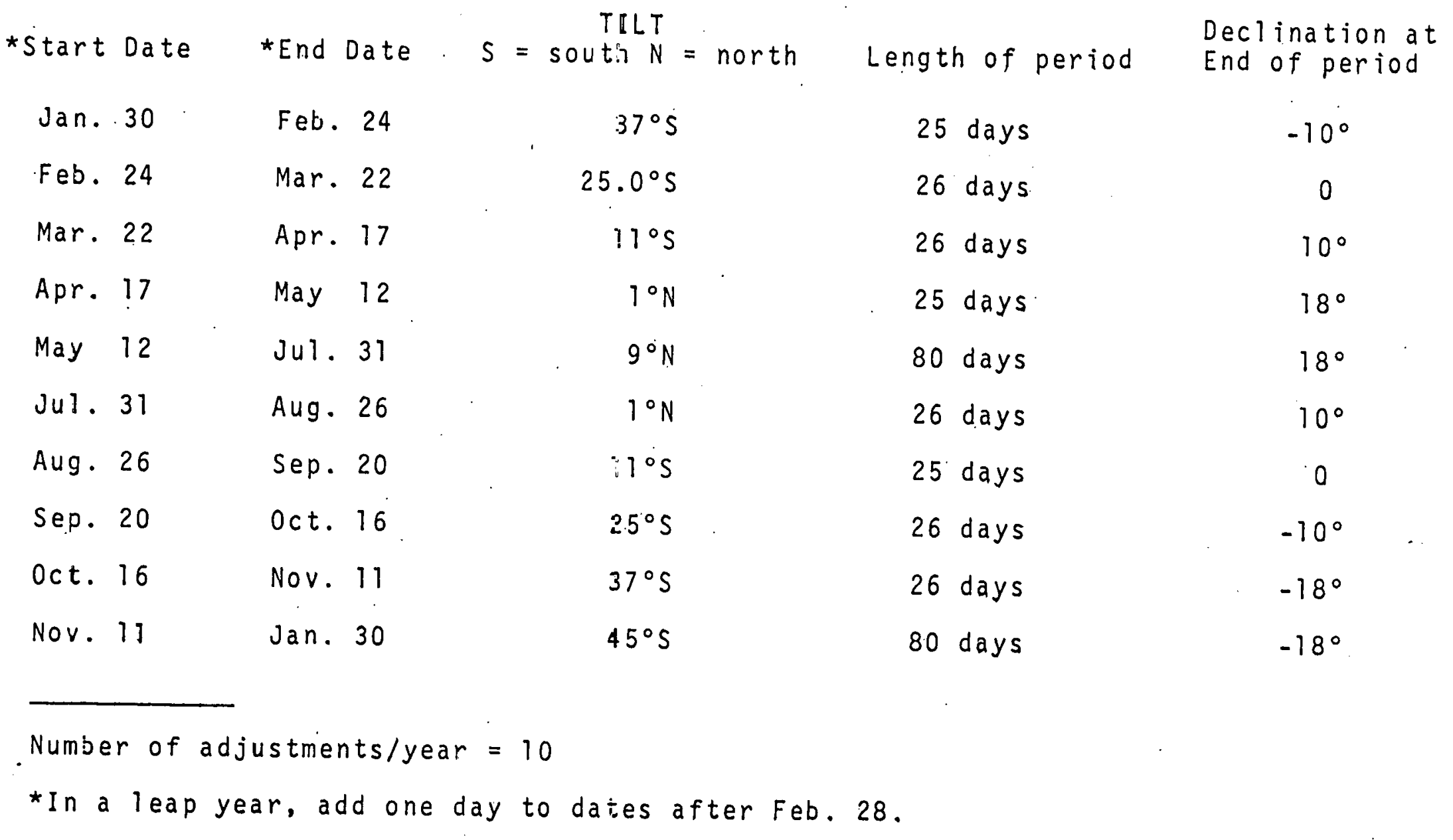


TABLE C.2

TILT ADJUSTMENTS DURING THE YEAR

$$
\theta_{C}=8^{\circ}
$$

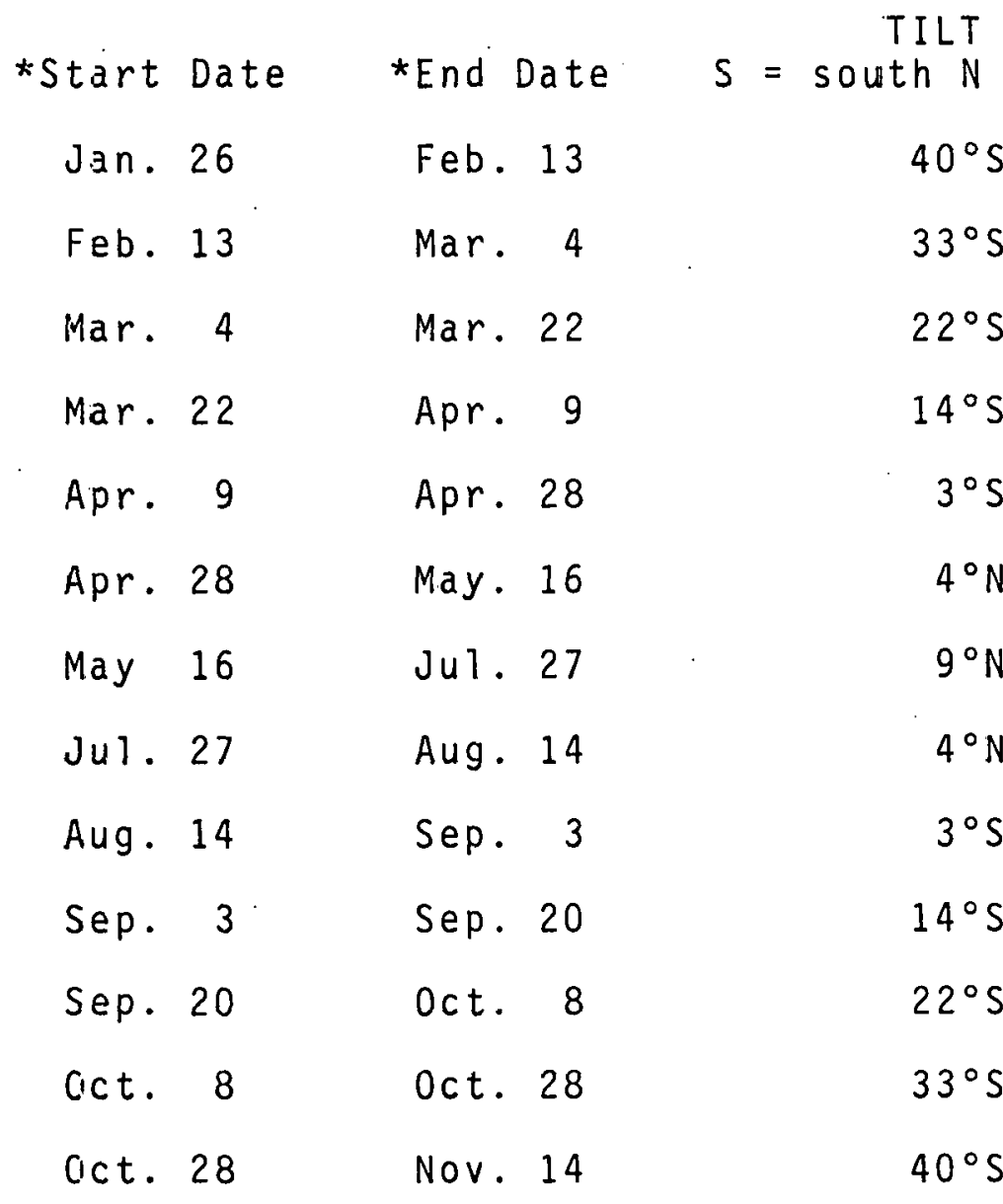

$\begin{array}{cc}\text { Lenth of period } & \begin{array}{c}\text { Declination at } \\ \text { End of period }\end{array} \\ 18 \text { days } & -14^{\circ} \\ 19 \text { days } & 7^{\circ} \\ 18 \text { days } & 0^{\circ} \\ 18 \text { days } & 7^{\circ} \\ 19 \text { days } & 14^{\circ} \\ 18 \text { days } & 19^{\circ} \\ 72 \text { days } & 19^{\circ} \\ 18 \text { days } & 14^{\circ} \\ 20 \text { days } & 7^{\circ} \\ 17 \text { days } & 0^{\circ} \\ 18 \text { days } & -7^{\circ} \\ 20 \text { days } & -14^{\circ} \\ 17 \text { days } & -19^{\circ}\end{array}$


TABLE C.2

TILT ADJUSTMENTS DURING THE YEAR

$$
\dot{\theta}_{c}=8^{\circ}
$$

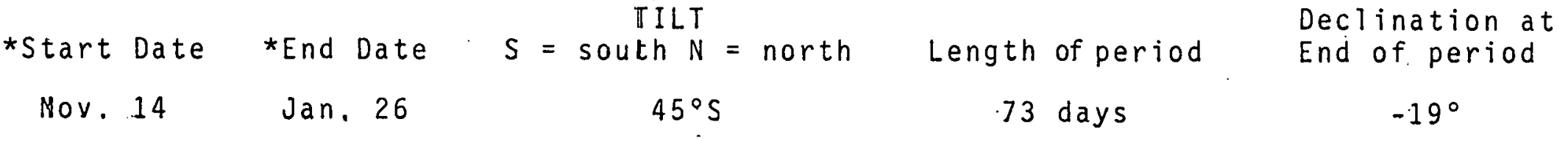

Number of adjustments/year $=14$

* In a leap year, add one day to dates after Feb. 28. continuation Table C.2 
TABLE C. 3

TILT ADJUSTMENTS DURING THE YEÁR

$\theta_{c}=7^{\circ}$

$\begin{array}{ccccc}\text { *Start Date } & \text { *End. Date } & S^{\prime}=\text { south } \mathrm{N}=\text { north } & \text { Length of period } & \begin{array}{c}\text { Declination at } \\ \text { End of period }\end{array} \\ \text { Jan. } 16 & \text { Jan. } 30 & 43^{\circ} \mathrm{S} & 14 \text { days } & -18^{\circ} \\ \text { Jan. } 30 & \text { Feb. } 13 & 39^{\circ} \mathrm{S} & 14 \text { days } & -14^{\circ} \\ \text { Feb. } 13 & \text { Nar. } 2 & 33^{\circ} \mathrm{S} & 17 \text { days } & -8^{\circ} \\ \text { Mar. } 2 & \text { Mar. } 24 & 24^{\circ} \mathrm{S} & 22 \text { days } & 10^{\circ} \\ \text { Mar. } 24 & \text { Apr. } 11 & 6^{\circ} \mathrm{S} & 18 \text { days } & 8^{\circ} \\ \text { Apr. } 11 & \text { Apr. } 28 & 3^{\circ} \mathrm{S} & 17 \text { days } & 14^{\circ} \\ \text { Apr. } 28 & \text { May. } 12 & 3^{\circ} \mathrm{N} & 14 \text { days } \\ \text { Nay. } 12 & \text { May. } 26 & 7^{\circ} \mathrm{N} & 14 \text { days } & 18^{\circ} \\ \text { May. } 26 & \text { Jur. } 18 & 10^{\circ} \mathrm{N} & 53 \text { days } & 21^{\circ} \\ \text { Jut. } 18 & \text { Aug. } 1 & 7^{\circ} \mathrm{N} & 14 \text { days } & 21^{\circ} \\ \text { Aug. } 1 & \text { Aug. } 14 & 3^{\circ} \mathrm{N} & 13 \text { days } & 18^{\circ} \\ \text { Aug. } 14 & \text { Aug. } 31 & 3^{\circ} \mathrm{S} & 17 \text { days } & 14^{\circ} \\ \text { Aug. } 31 & \text { Sep. } 23 & 6^{\circ} \mathrm{S} & 23 \text { days } & 8^{\circ}\end{array}$


TABLE C.3

TILT ADIUSTMENTS DURING THE YEAR

$$
\theta_{c}=7^{\circ}
$$

$\begin{array}{ccccc}\text { *Start Date } & \text { *End Date } & S=\text { south } N=\text { north } & \text { Length of period } & \begin{array}{c}\text { Declination at } \\ \text { End of period }\end{array} \\ \text { Sep. } 23 & \text { Oct. } 11 & 24^{\circ} \mathrm{S} & 18 \text { days } & -8^{\circ} \\ \text { Oct. } 11 & \text { Oct. } 28 & 33^{\circ} \mathrm{S} & 17 \text { days } & -14^{\circ} \\ \text { Oct. } 28 & \text { Nov. } 10 & 39^{\circ} \mathrm{S} & 13 \text { days } & -18^{\circ} \\ \text { Nov. } 10 & \text { Nov. } 24 & 43^{\circ} \mathrm{S} & 14 \text { days } & -21^{\circ} \\ \text { Nov. } 24 & \text { Nov. } 16 & 46^{\circ} \mathrm{S} & 53 \text { days } & -21^{\circ}\end{array}$

Number of adjustments/year - 18

* In a leap year, add one day to dates after Feb, 28. continuation Table C.3 


\section{APPENDIX D}

COMPUTER PROGRAM FOR CPC SHAPE 


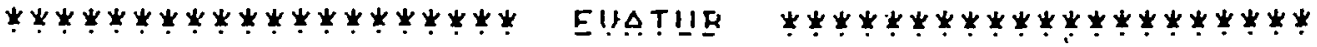

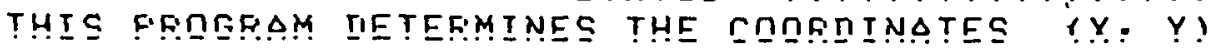

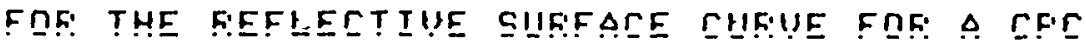

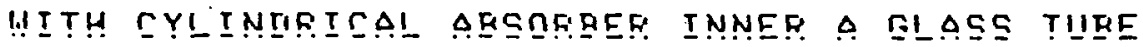

EN!UELOEFE:

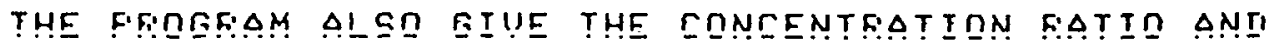

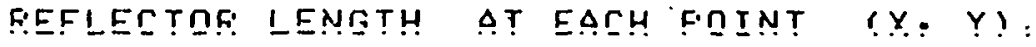

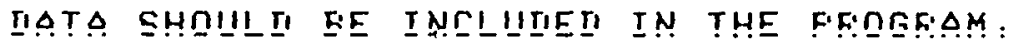

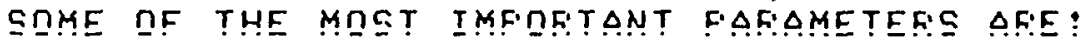

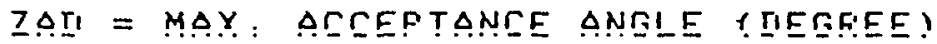

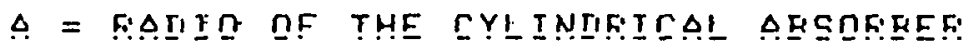

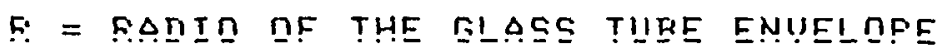

RE: = CONGENTESTIRN FATIO

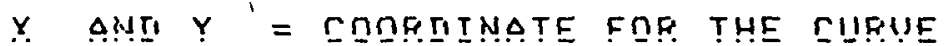

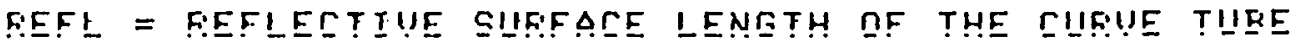

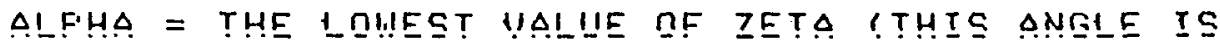

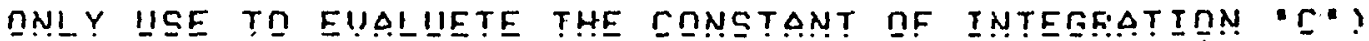

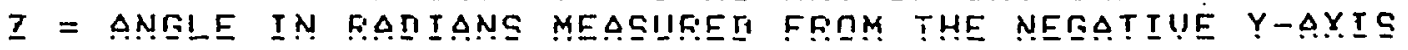

IISTS!

$Z \Delta \underline{\Delta}=9: n$

$\Delta=0.8125$

$F:=1: \underline{Q} \underline{Q}$

$\frac{5}{r}$

F:E $\triangle \underline{Y}$ LIMIT?

$Y \Delta=\underline{Y}$

$Y \Delta=-E$

$F I=\Delta: \Psi \Delta T \Delta M ! 1:$ ? -

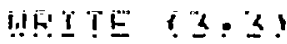

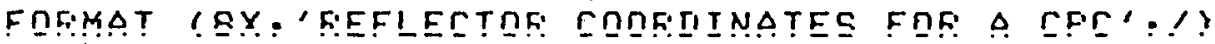

UIEITE (Z: 4 )

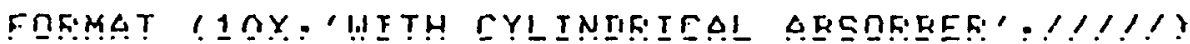

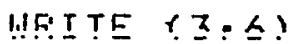

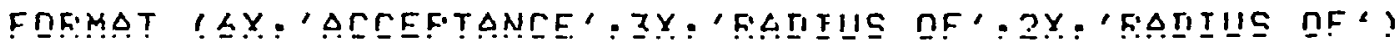
U!E.ITE \{ $3: ?\}$

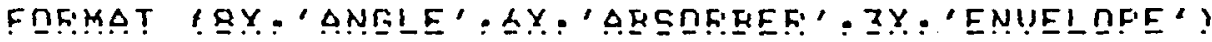

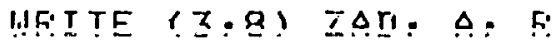

FOEMAST IXY: ZFI2:4:!!!

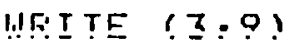

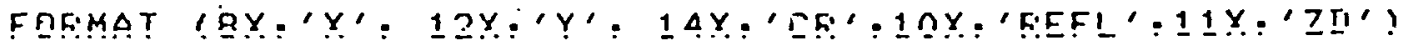

$\Delta I F H \Delta=\Delta C Q S$ (UIR!

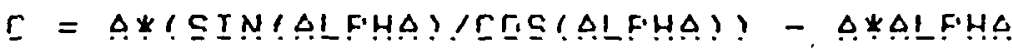

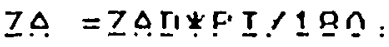

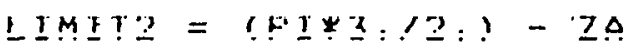

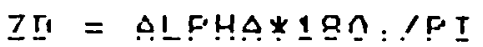




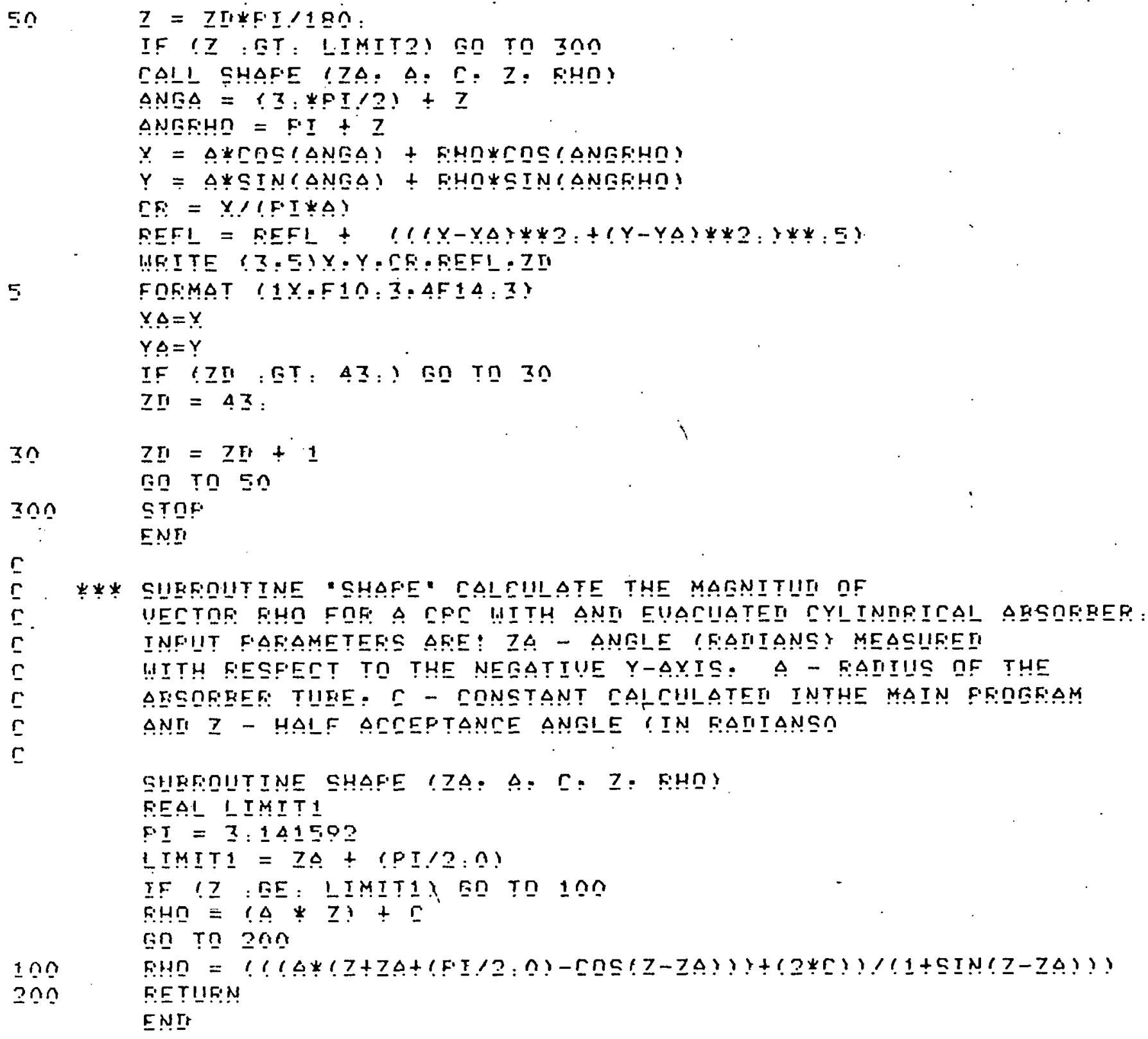




\title{
APPENDIX E
}

\author{
TEST DATA OBTAINED \\ BY \\ TRANSIENT $U_{L}$ - METHOD
}


T I ME

(MIN)

$n: 0$
$1: 0$
$3: 0$
$3: 0$
$4: 0$
$5: 0$
$6: 0$
$7: 0$
$0: 0$
$9: 0$

1. : :

11:?

$12: 2$

1즈:

14:?

15: :

$1 \leq$ : 0

1?:?

1ㅇ:

19: $:$

30: $: 0$

21:?

2그:음

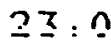

24:?

25: :

호: 0

2?:?

2으:음

29: :

즈: 0

포: 0

즌 $=0$

즈: ?

34:0

포: $:$

즈느으

주:음

3으:

3: :

$40: 0$

$41: ?$

$42: ?$

4 I : ?

$44: ?$
TUBE 1

25조 :

$240: 1$

244:?

민?

그즈:눈

즈즈:우

르스:

22? : 3

$224: 1$

2는 $:$ ?

21으:?

215: 4

ㄴ1는

20ํ:?

2ำ? 4

204:

$202: 4$

20ก: 1

19? :?

$195: 5$

1으르

191 : 4

1 으. 4

1은 즌

1오: 3

1즈:4

1 요 :

$179: 5$

1วก: ก

1근?

$174: 5$

172:웅

171: 4

1 수: 9

$1 \leq 2$ : 2

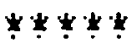

1논.

女ᄈ4*女

1스: 5

*ะ* $* *$

159:?

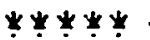

15?:2

*4ษ

$154: \leqslant$
TEMFERTATUFE $!^{\circ}()$ TUEE 2

TUBE $\$ 3$
노도: 웅

$2 \leq 5 ?: ?$

2ร?:?

그르:

240:

$245: \therefore$

$241: ?$

그으: 4

르도:

2즈는

$228=5$

$224:$ ?

2그:4

고웅

$21 \leq$ : 9

$214: 2$

211:?

2ก०.?

$2 n \leq \leqslant$

2에 : 1

201:?

$199=5$

197:4

$105: 2$

$10 x \cdot 1$

1ำ:?

1 RR : 9

1 ㄷำ

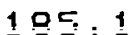

1 즈: ?

1 으: 4

$179:$ 소

1ㄱ? : ?

1그느:?

$174: 5$

$17 ?=?$

$171=2$

느의:?

스스: 1

느느느:소

1소돈 ?

1: :

$1 \leq 2$ : 2

1으:?

1.59: 5 
TIME

(!) (ب!)

$45:-$

4. : 은

$4 ?: ?$

4.ㄹ:

$49: ?$

5n:

51:

5은

$53: 0$

5. $4: 0$

$55: 0$

도: 은

5?:

도:으

59:0

으: 음

느: 웅

스:웅

노: ?

수: 음

도: : ?

노응

ㄴ? ?: 은

요: 0

수:웅

ำ: :

?1: :

구:은

$73: 0$

$74: 0$

$75: 0$

고요

ㄱำ:

?으:?

$79: ?$

ำ: 은

노 : 무

Q2: :

주: 0

Q4: : ?

ㄷ: :

Qㄴ. :

구:은

요 : ?

우: 은

ำ: ㅇ
TUBE $\$ 1$

$\underline{*} \boldsymbol{*} * \boldsymbol{*} \boldsymbol{*}$

152:?

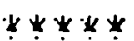

$149: 9$

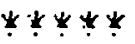

1 4? :4

*⿻*𠃋女

$145: 4$

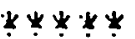

1 4 Z: 3

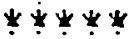

141:

$\underline{*} \div \pm \underline{*}$

1ㄱ:즈

*ะ*ะ*

1 3?: 4

******

$13 ㄷ ㅗ$

*⿻*𠃋女

1즈능

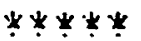

1 지:?

******

1 즈: 1

******

128:4

$4 * \pm *$

1는ㅇㅇㅇ

*ะ****

125: 4

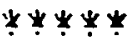

$124: 5$

******

$122: 5$

*⿻*𠃋?

121:1

*⿻*𠃋十

119:?

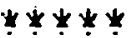

118:?

******

1느:?

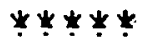

$115: \leq$

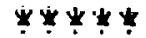

114,4
TEMFESATURE (OE)

TUEE $¥ 2$

TUEE $\$ 3$

120.

$170: 2$

․․…

125

4.k.k

123:

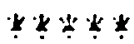

1 1?:?

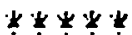

11스:?

눈

1 1 4:2

*****

111:음

*.?

1오:4

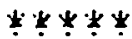

1으:

*****

10. 0

***女*

$102: 3$

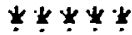

1므:

*⿻一𠃋十

?Q:

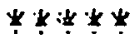

오응

눈

$94: ?$

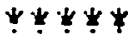

으: 2

$\underline{*} \pm \underline{*} *$

$91: ?$

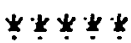

으: 1

*****

오르: 소

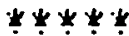

Q? : 2

*****

옹 : ?

**k*

Q4:

世制娄

Q3 : 4

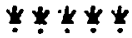

$15 \leqslant$ :

$155: 6$

$154: 2$

1드: ?

1돈?

1드:오

14 : :

149 : ?

147:1

$14 \leqslant: 0$

144:?

1 4 Z :?

142:?

$141:$ ?

$140: ?$

1주:?

1주: 1

조으:?

1즈? : 1

느노:은

1즈:2 2

1느: ?

1조:

프느:응

1조:?

1즈:?

1ำ: 1

12ㅇ:?

1?9: 5

1그:?

12ㄱ: 오

12느: 3

는도 노

124:?

$124: 1$

19:는

12르:?

1르:1

121:4

12n: 9

12ก: 2

119:4

*⿻****

11: ?

女? 


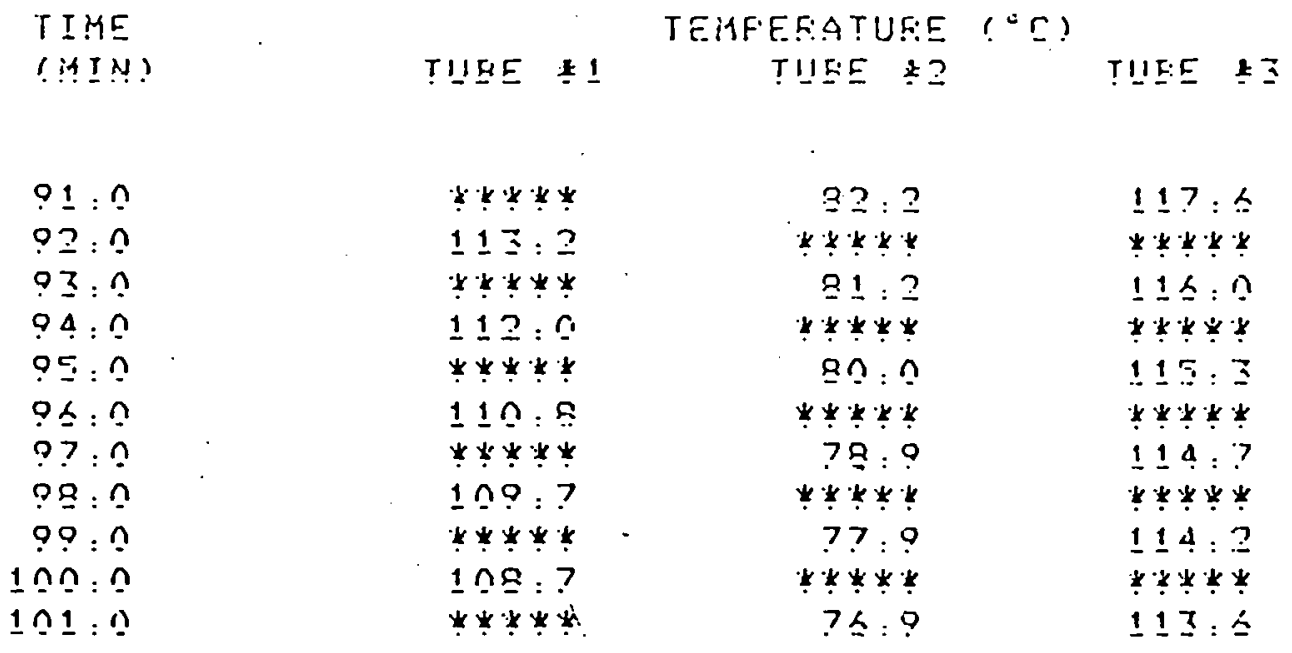




\section{APPENDIX F}

\section{CALCULATIONS FOR EFFICIENCY CURVE}

The following equation was used to calculate efficiency as a function of $\left(T_{f}-T_{a}\right) / I_{b}$.

$$
\eta=(\tau \alpha)-\mathrm{U}_{\mathrm{L}\left(\mathrm{T}_{\mathrm{f}}\right)} \frac{\mathrm{T}_{f}-\mathrm{T}_{\mathrm{a}}}{\mathrm{I}_{\mathrm{b}}}
$$

where: $\quad n=$ optical efficiency (measured, i.e. $26 \%$ )

$$
\begin{aligned}
\mathrm{U}_{\mathrm{L}\left(\mathrm{T}_{\mathrm{f}}\right)} & \begin{array}{l}
\text { overall heat transfer coefficient at fluid } \\
\text { temperature (obtained from figure } 7.4 \text {, tube:\#1) }
\end{array} \\
\mathrm{T}_{\mathrm{f}} & =\text { fluid temperature }\left({ }^{\circ} \mathrm{C}\right) \\
\mathrm{T}_{\mathrm{a}} & =\text { ambient temperature, i.e. } 30^{\circ} \mathrm{C} \\
\mathrm{I}_{\mathrm{b}} & =\text { beam or direct insolation }\left(\mathrm{W} / \mathrm{m}^{2}\right)
\end{aligned}
$$

Table F.1

CALCULATED RESULTS FOR THE EFFICIENCY CURVE

\begin{tabular}{rcccc}
$\mathrm{T}_{\mathrm{f}}$ & $\mathrm{U}_{\mathrm{L}\left(\mathrm{T}_{\mathrm{f}}\right)}$ & $\Delta \mathrm{T}$ & $\Delta \mathrm{T} / \mathrm{I}_{\mathrm{b}}{ }^{-}$ & $\eta$ \\
\hline 30 & 0 & 0 & 0 & .26 \\
120 & $0.70 / 5.25$ & 90 & .10 & .25 \\
165 & $1.05 / 5.25$ & 135 & .15 & .23 \\
210 & $1.40 / 5.25$ & 180 & .20 & .21 \\
255 & $1.90 / 5.25$ & 225 & .25 & .17 \\
300 & $3.00 / 5.25$ & 270 & .30 & .09
\end{tabular}




\section{APPEINDIX $G$}

\section{NOMENCLATURE}

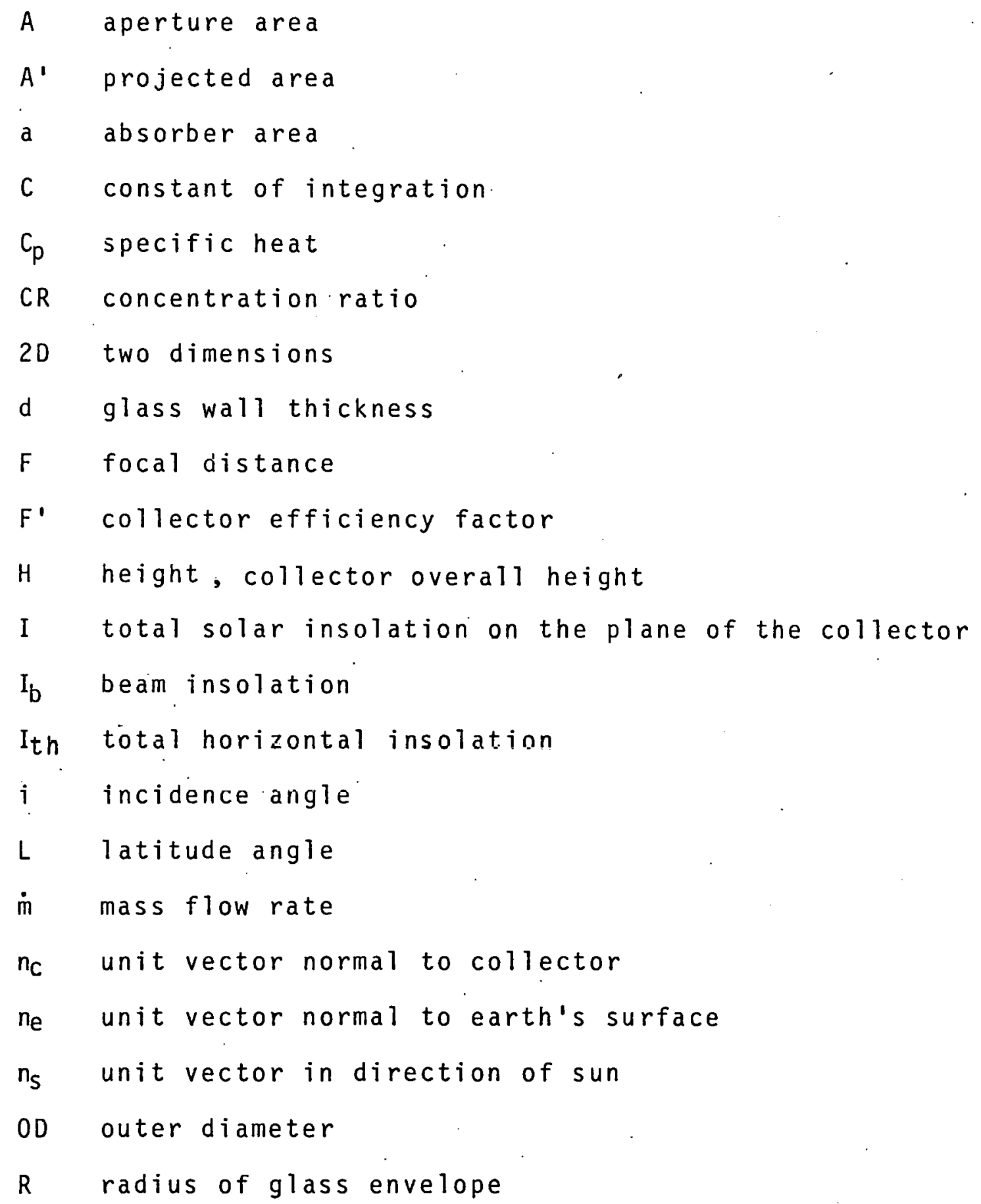




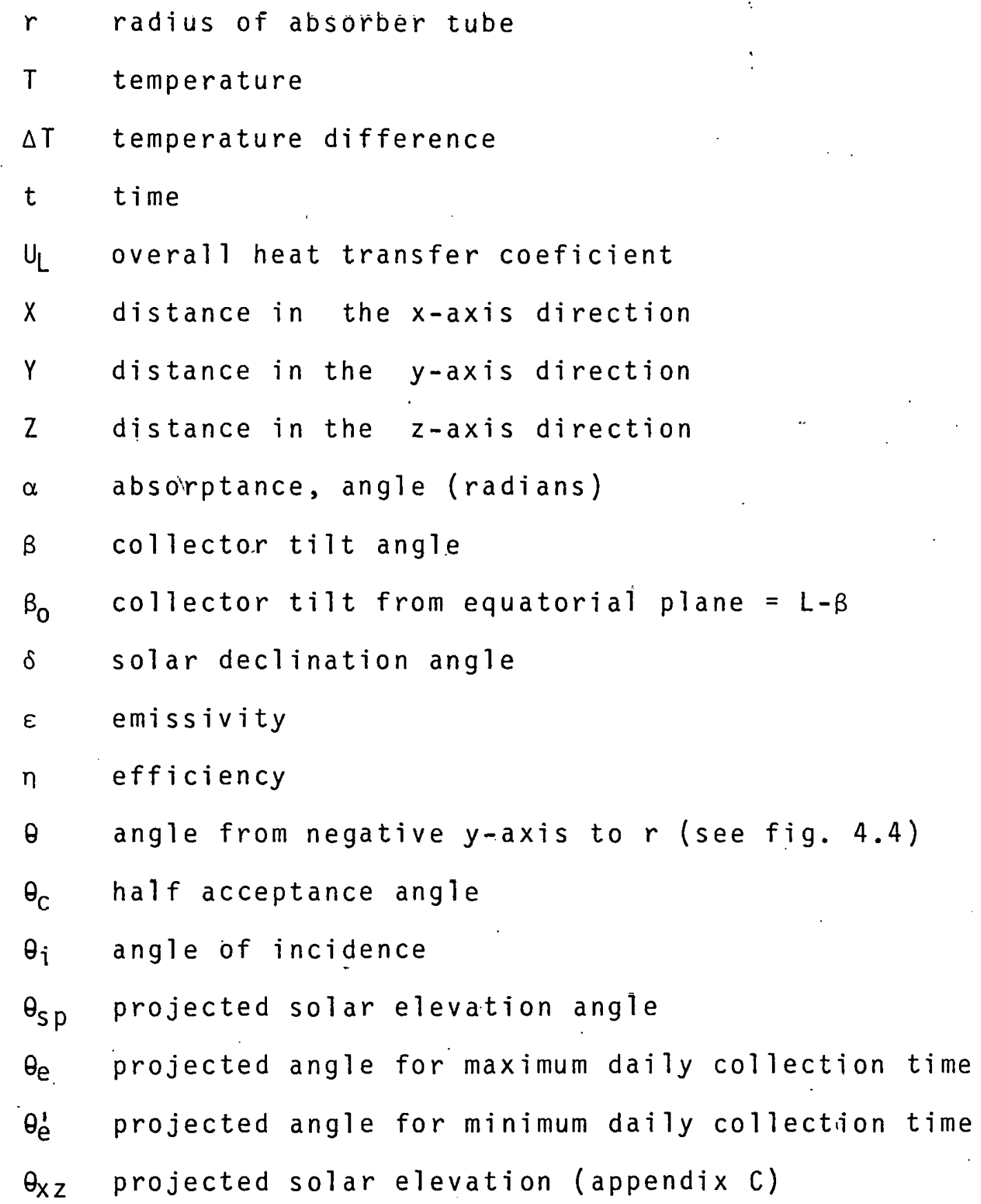

Subscript:

a ambient

e envelope 


$\begin{array}{ll}f & \text { fluid } \\ \text { h } & \text { horizontal } \\ 0 & \text { optical } \\ \text { p } & \text { plate } \\ \text { sky } & \text { sky } \\ \text { t } & \text { tube }\end{array}$

